\title{
Ambiente interativo para visualização de dados de neurônios
}

\author{
Danielle Bentivoglio Colturato
}

Orientadora: Profa. Dra. Maria Cristina Ferreira de Oliveira

Dissertação apresentada ao Instituto de Ciências Matemáticas e de Computação - ICMC-USP, como parte dos requisitos para obtenção do título de Mestre em Ciências de Computação e Matemática Computacional.

USP - São Carlos

Outubro/2001 
A Comissão Julgadora:

Profa. Dra. Maria Cristina Ferreira de Oliveira

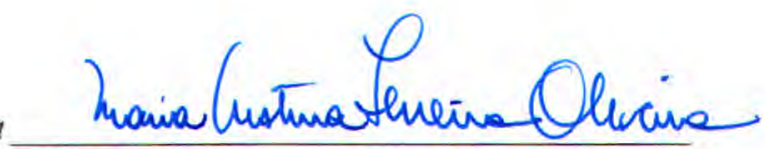

Prof. Dr. Luciano da Fontoura Costa

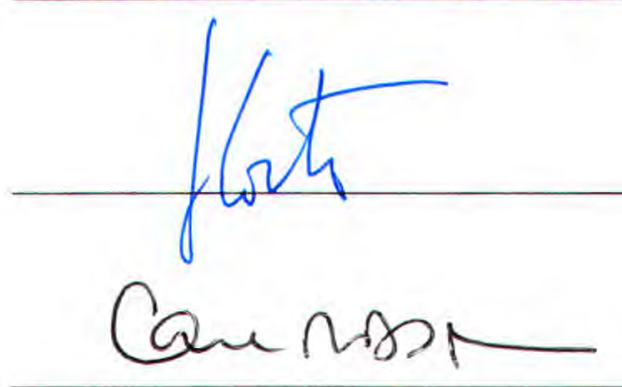


Aos meus pais Ademar e Soeli por tudo o que sou. 


\section{Agradecimentos}

Agradeço principalmente a Deus, por ter me dado forças para atingir o meu objetivo; Aos meus pais, pelo incentivo, apoio e carinho;

À professora, orientadora Maria Cristina Ferreira de Oliveira pelas suas valorosas críticas e incentivos;

Aos professores Prof ${ }^{a}$. $D r^{a}$. Rosane Minghim e Prof. Dr. João Batista que participaram da banca do meu Exame de Qualificação e colaboraram para o aperfeiçoamento desta dissertação;

Aos meus amigos(as) e colegas Ludimila, Luís Fernando, Bruno, Marcelo, Jorge, Valério, Tedy pela sua ajuda, apoio e amizade;

A todos os professores e funcionários do ICMC;

À FAPESP, a qual é a principal financiadora deste trabalho, por propiciar-me a oportunidade de estudar e crescer intelectualmente ao longo destes dois anos.

Por fim a todos que indiretamente contribuíram de uma forma ou de outra para a realização deste trabalho. 


\section{Sumário}

Resumo vii

$\begin{array}{ll}\text { Abstract } & \text { ix }\end{array}$

1 Introdução 1

2 Revisão Bibliográfica $\quad \mathbf{5}$

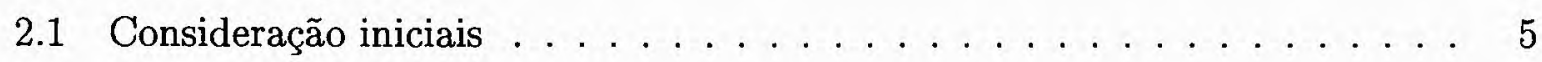

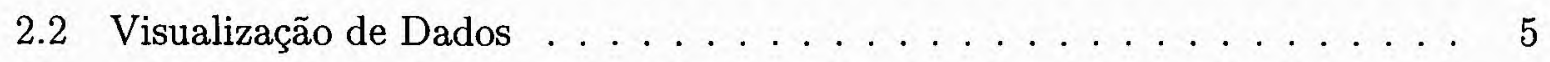

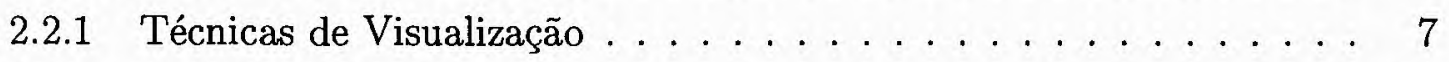

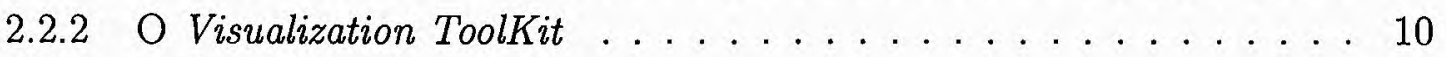

2.3 Uso de som em Sistemas Computacionais . . . . . . . . . . . . . . . . 14

2.4 Interação em Visualização $\ldots \ldots \ldots \ldots \ldots \ldots \ldots \ldots$

2.4.1 Técnicas de mapeamento do espaço de entrada para o espaço 3D . . 16

2.4.2 Técnicas de mapeamento do espaço 3D para o espaço de saída . . . 22

2.4.3 Soluções por hardware . . . . . . . . . . . . . 23

2.4 .4 Técnicas de interação em visualização . . . . . . . . . . 25

2.5 Interação em Realidade Virtual . . . . . . . . . . . . . . . . . 29

2.5.1 Características da Realidade Virtual . . . . . . . . . . 30

2.5.2 Dispositivos de interação com ambientes virtuais . . . . . . . . . 31

2.5.3 Interação em ambientes virtuais . . . . . . . . . . . 36

2.6 Considerações Finais $\ldots \ldots \ldots \ldots \ldots$

3 Ambiente de Visualização $\quad 41$

3.1 Considerações Iniciais . . . . . . . . . . . . . . . . . . . . . . 41

3.2 Plataforma de Desenvolvimento . . . . . . . . . . . . . . . . 42

3.3 Módulo de Extração de Superfícies . . . . . . . . . . . . . . . . 44

3.4 Módulo de Rendering Volumétrico Direto . . . . . . . . . . . . . 50

3.5 Módulo de Visualização Vetorial . . . . . . . . . . . . . . . 52

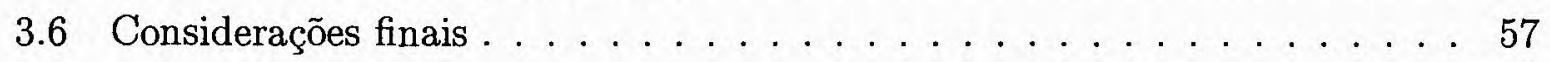


4 Utilização do ambiente $\quad 59$

4.1 Considerações Iniciais . . . . . . . . . . . . . . . . . . . . 59

4.2 Extração de Superfícies . . . . . . . . . . . . . . . . . . . 59

4.2 .1 Recorte de Superfícies . . . . . . . . . . . . . . . 60

4.2 .2 Sonda Sonora . . . . . . . . . . . . . . . . 6 64

4.2 .3 VRML e Animação . . . . . . . . . . . . . . . . 65

4.3 Rendering Volumétrico Direto . . . . . . . . . . . . . . . 67

4.4 Visualização Vetorial . . . . . . . . . . . . . . . . . . 69

4.4 .1 Glyphs......................... 69

4.4 Streamlines ....................... 69

4.5 Considerações Finais . . . . . . . . . . . . . . . . 70

$\begin{array}{lll}5 \text { Conclusão } & 71\end{array}$

$\begin{array}{ll}\text { Referências Bibliográficas } & 73\end{array}$ 


\section{Lista de Figuras}

1 Organização dos dados em malhas . . . . . . . . . . . . 6

2 Visualização dos ossos de um crânio por meio de transparências . . . . . 8

3 Visualização por meio de glyphs do campo vetorial de um neurônio . . . . 9

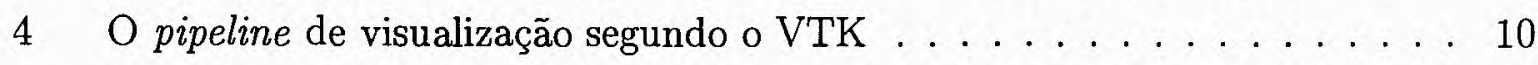

5 Estrutura do vtkCellArray para representar a topologia da célula . . . . . . 12

6 Estrutura do vtkUnstructuredGrid . . . . . . . . . . . . . 13

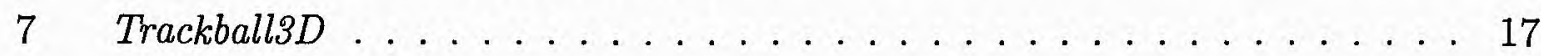

8 Correspondência entre movimentos do dispositivo e as coordenadas do es-

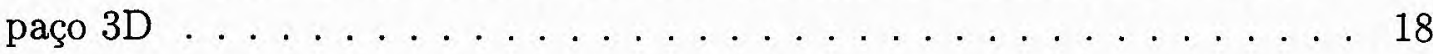

9 Representações gráficas do cursor 3D: (a) tríade (triad); (b) espaço cheio (full space); (c) cúbico $($ cubic $) \ldots \ldots \ldots \ldots \ldots$

10 Cursores Skitter (à esquerda) e Jack (à direita) . . . . . . . . . . . . . . 19

11 Deslizadores Gráficos(Sliders $) \ldots \ldots \ldots$. . . . . . . . . 21

11 Sobreposição de Deslizadores . . . . . . . . . . . . . . . . . . . . . . . 21

11 Contínuo em XY e exato em Z . . . . . . . . . . . . . . . . 21

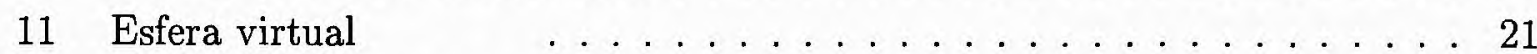

12 Manipulação direta baseado no sistema de coordenadas do objeto . . . . . 21

13 Cursores 2D como realimentadores visuais . . . . . . . . . . . 24

14 Roller mouse . . . . . . . . . . . . . . . . . . . . . . 24

15 Rockin'mouse ....................... . . 25

16 (a) Definição da área de brushing; (b) Dados após a aplicação da técnica de brushing . . . . . . . . . . . . . . . . . 26

17 Brushing planar: Axial, Sagital, Coronal. . . . . . . . . . . . . . 27

18 Modelos de BOOMs vendidos comercialmente . . . . . . . . . . . . 33

19 (a) Esquematização do CAVE . . . . . . . . . . . . . . . . . . . 34

19 (b) Immersive Work Wall. Tipo de WALL vendido comercialmente . . . . . 34

20 Composição do VW . . . . . . . . . . . . . . . . . . . . . . 35

21 Interface Principal $\ldots \ldots \ldots \ldots \ldots \ldots \ldots \ldots \ldots \ldots$

22 Hierarquia de classes . . . . . . . . . . . . . . . . . . . . . 44 
Interface do módulo de Extração de Superfícies . . . . . . . . . . 45

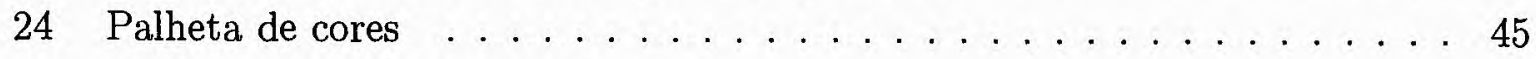

25 Interface da animação em VRML . . . . . . . . . . . . . . 46

26 Interface de Configurações do módulo de Extração de Superfícies . . . . . 49

27 Interface do Módulo de rendering Volumétrico Direto . . . . . . . . . . 51

28 Interface de Configurações do Módulo de rendering Volumétrico Direto . . 52

29 Interface do Módulo Vetorial por Glyphs . . . . . . . . . . . . 53

30 Visualização por Glyphs do campo vetorial de um neurônio . . . . . . . 54

31 Interface do Módulo Vetorial por Streamlines . . . . . . . . . . . 55

32 Interfaces de interação dos módulos de visualização vetorial . . . . . . 55

33 Visualização do arquivo VRML com streamlines . . . . . . . . . . . 56

34 Interface de animação do arquivo VRML com streamlines . . . . . . . . . 56

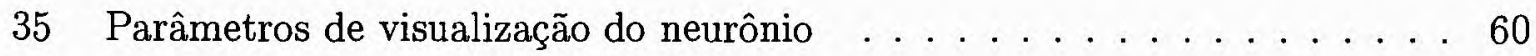

36 Parâmetros de visualização do dente . . . . . . . . . . . 60

37 Neurônio e dente gerados inicialmente . . . . . . . . . . . . 61

38 Isosuperfície selecionada em destaque . . . . . . . . . . . . . 61

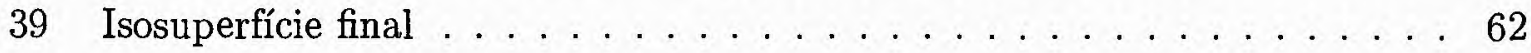

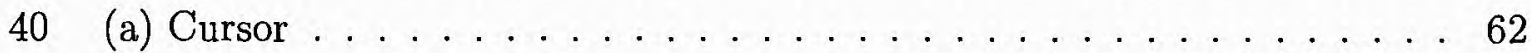

40 (b) Seleção de pontos . . . . . . . . . . . . . . . . . . 6 62

40 (c) Contorno do corte fechado . . . . . . . . . . . . . . . 62

41 (a) Seleção de pontos . . . . . . . . . . . . . . . . . . . 63

41 (b) Contorno fechado . . . . . . . . . . . . . . . 63

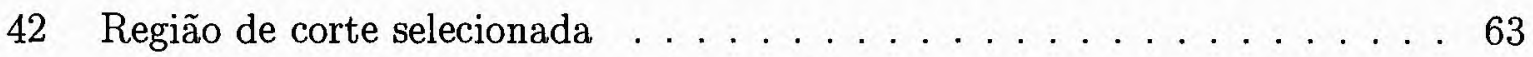

43 Translação e rotação da região recortada . . . . . . . . . . . . . 64

44 Sonda Sonora (canto inferior esquerdo) . . . . . . . . . . . . . 64

45 Teclas de movimento da sonda . . . . . . . . . . . . 65

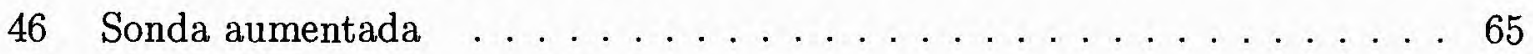

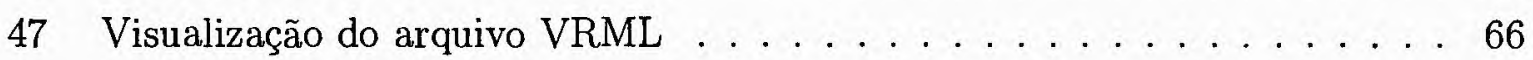

48 Tela de configuração e exibição da animação do modelo . . . . . . . . 66

49 Parâmetros de configuração e geração da visualização volumétrica . . . . . 67

50 Rendering volumétrico direto de um neurônio no modo normal e no modo

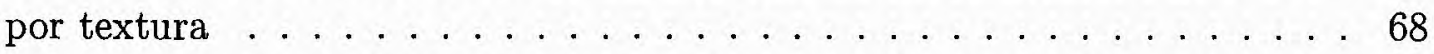

51 Rendering volumétrico direto com sonda sonora de um neurônio no modo

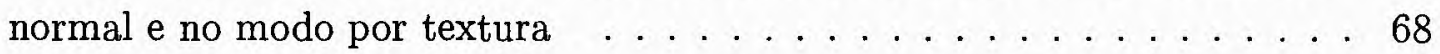

52 Interface e visualização do campo vetorial de um neurônio por meio de segmentos de reta $\ldots \ldots \ldots \ldots \ldots \ldots$ 
53 Interface e visualização do campo vetorial de um neurônio por meio de

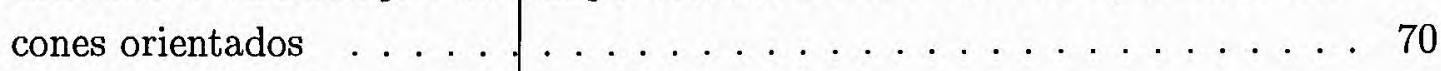

54 Interface e visualização do campo vetorial de um neurônio por meio de streamlines ........................ 70 


\section{Resumo}

Nesse trabalho é descrito um ambiente interativo para visualização de dados escalares e vetoriais definidos em malhas de dados estruturadas. $\mathrm{O}$ ambiente desenvolvido oferece uma interface de acesso para diversas classes de algoritmos de visualização implementadas na biblioteca VTK 3.1 (The Visualization Toolkit). O objetivo foi desenvolver um sistema voltado para um grupo particular de usuários, pesquisadores do Grupo de Visão Cibernética do IFSC, que geram dados relativos à forma e comportamento de neurônios artificiais. Esses usuários desejam manipular diretamente os modelos gerados a partir desses dados, necessitando de recursos adicionais aos oferecidos pela interface de manipulação do VTK. O ambiente permite a aplicação de técnicas de extração de superfícies e rendering volumétrico direto aos dados escalares, bem como de técnicas de visualização vetorial. Em nível de interface, foram implementadas diversas técnicas que visam facilitar a manipulação e a exploração dos modelos de visualização pelos usuários. Essas técnicas incluem: uma função para "recortar" regiōes de interesse em modelos de superfície e a utilização de uma sonda sonora pela qual um bloco de tamanho variável é inserido no modelo com o objetivo de colher informações e apresentá-las na forma de som. Também é possível gerar um arquivos VRML diretamente a partir dos modelos e criar animações dos mesmos. Apesar de ter sido concebido para atender a um grupo particular de usuários, o ambiente é genérico e pode ser utilizado por usuários em outros domínios de aplicação. 


\section{Abstract}

This work describes an interactive environment for visualization of scalar and vector data defined on structured grids. The environment offers an interface that allows the for indirect and direct manipulation of visualization models, being built on top of the VTK 3.1 (The Visualization Toolkit) visualization library. Our goal has been to develop an environment to meet the needs of the researchers of the Cybernetic Vision Research Group, whose work on the synthesis of artificial neural structures produces data on the shape and behavior of artificial neurons. Those users want to direct manipulate the visualization models created from such data, and need manipulation operations that extend those provided by the manipulation interface of VTK itself. The environment develop supports the application of surface extraction and direct volume rendering techniques, and also of some vector visualization techniques. At the user interface level, it provides several operations aimed at improving the manipulation and exploration of visualization models by end users. These include an operation to cut regions of interest from a given surface model, and a sound probe - visually represented by a block - which provides aural feedback on the information embedded in the model. It also allows the interaction with VRML worlds created from the visualization model under analysis, the the specification of animations of the VRML model. 


\section{Capítulo 1}

\section{Introdução}

A crescente disponibilidade de recursos computacionais para o cálculo, simulação e aquisição de dados permite que cientistas e engenheiros produzam enormes conjuntos de dados, bi ou tridimensionais (2D ou 3D), em geral multivariados. A aplicação de técnicas de Computação Gráfica a dados científicos com o objetivo de ganhar compreensão desses dados, testar hipóteses e esclarecer fenômenos e efeitos em geral, compreende o objeto de estudo da área denominada Visualização Científica (ViSC - Visualization in Scientific Computing) (MINGHIM \& OLIVEIRA, 1997).

O Grupo de Computação Gráfica e Processamento de Imagens (CG \& PI) do ICMC vem trabalhando no estudo, implementação e melhoria de técnicas de Visualização no contexto do projeto PowerVis (MINGHIM \& OLIVEIRA, 1997; OLIVEIRA, MINGHIM, TUTIDA \& SALVADOR, 1998; MINGHIM \& OLIVEIRA, 1998). Esse projeto visa a criação e implementação de técnicas multimodais de visualização para facilitar o uso das técnicas de mapeamento gráfico existentes diretamente por usuários em potencial. Nesse contexto, colaborações estão em andamento com diferentes grupos de pesquisa que são usuários de visualização e que fornecem os dados utilizados para as pesquisas em desenvolvimento.

O objetivo deste projeto de mestrado é disponibilizar um ambiente de visualização que atenda às necessidades dos pesquisadores do Grupo de Visão Cibernética do Instituto de Física de São Carlos (IFSC). Como decorrência dessa colaboração, foram identificadas várias técnicas que podem ser aplicadas à visualização dos dados gerados por esses usuários, apoiando o processo de análise dos mesmos. O grupo de Visão Cibernética tem 
trabalhado intensamente na análise da forma de neurônios e estruturas neurais (CESAR, COELHO \& COSTA, 1997; CESAR \& COSTA, 1997; COSTA, OLIVEIRA \& MINGHIM, 2000). Como parte desse trabalho, foram gerados modelos artificiais realísticos de estruturas neurais com os objetivos tanto de simular sistemas naturais como de investigar novas arquiteturas e paradigmas em redes neurais artificiais.

Várias visualizações desses modelos foram geradas utilizando a biblioteca de visualização VTK (Visualization Toolkit) (MINGHIM \& OLIVEIRA, 1998). Foram aplicadas técnicas de extração de superfícies e de rendering volumétrico, utilizando procedimentos do VTK que implementam as técnicas conhecidas como marching cubes (LORENSEN, 1987) e ray casting (ELVINS, 1992), respectivamente. Também foram aplicadas técnicas de visualização vetorial a dados gerados pela simulação de campos magnéticos ao redor dos neurônios artificiais. $\mathrm{O}$ processo de geração dessas visualizações foi conduzido pelos pesquisadores que atuam na área, em colaboração com os usuários finais, pesquisadores do grupo de Visão Cibernética.

Entretanto, uma das dificuldades encontradas é que os usuários, em geral, não dominam o processo de geração das visualizações, que é feito através de programação em $\mathrm{C}++$ utilizando as classes da biblioteca VTK. Isso implica na necessidade de apoio constante de alguém que domine o processo sempre que é preciso gerar visualizações de novos conjunto de dados, mesmo quando isso não envolve a identificação de técnicas e estratégias de visualização alternativas.

O ambiente desenvolvido é dedicado a atender as necessidades encontradas pelos pesquisadores de visualizarem/interagirem com os modelos tridimensionais dos neurônios. O sistema oferece uma interface adequada para o usuário executar as visualizações desejadas e alterar os parâmetros das mesmas, por exemplo: o tipo de técnica a ser usada, o número de isosuperfícies a serem geradas e o valor das mesmas; a tabela de cores a ser adotada; a taxa de amostragem dos dados vetoriais; etc. Adicionalmente, foram incorporadas algumas estratégias de interação, além dos recursos básicos oferecidos pelo VTK (rotação e escala via mouse). O ambiente é bastante genérico, e pode ser utilizado para visualização interativa de dados em outros domínios de aplicação. Por exemplo, os dados dentários utilizados no projeto "Visualização em Odontologia" (FASPESP, Proc. 98/12644-8), desenvolvido em colaboração entre o ICMC, a School of Information Systems - University of East Anglia - Inglaterra, e a Faculdade de Odontologia de Araraquara UNESP. A única restrição é que os dados (escalares ou vetoriais) estejam definidos sobre uma malha regular, segundo o tipo vtkStructuredPoints do VTK.

Esta dissertação apresenta a bibliografia estudada que fornece a base para o desenvolvimento deste projeto, bem como o sistema desenvolvido. No Capítulo 2 são apresentados 
os estudos relativos aos conceitos necessários para o desenvolvimento deste trabalho, incluindo uma breve introdução às técnicas clássicas de visualização científica, ao software Visualization Toolkit e ao uso de som em Sistemas Computacionais. São introduzidos aspectos sobre interação do usuário em visualização científica e interação no contexto de ambientes de Realidade Virtual. O Capítulo 3 descreve o trabalho desenvolvido, especificando cada módulo, suas funções, utilidades e classes utilizadas no desenvolvimento. $\mathrm{O}$ Capítulo 4 ilustra a utilização do sistema. 


\section{Capítulo 2}

\section{Revisão Bibliográfica}

\subsection{Consideração iniciais}

Neste capítulo são apresentados tópicos que abragem toda revisão bibliográfica necessária para o desenvolvimento do projeto. A seção 2.2 mostra como os dados devem estar organizados para poderem ser visualizados. A seção 2.2.1 apresenta noções básicas sobre as técnicas de visualização tradicionais, com enfâse nas técnicas utilizadas no desenvolvimento do projeto. A seção 2.2 .2 apresenta o software Visualization Toolkit, biblioteca gráfica utilizada como base para o desenvolvimento do ambiente. A seção 2.3 introduz o uso de som em sistemas computacionais e o software SVol, programa este utilizado em parte como base para o desenvolvimento de uma das funções de interação deste projeto de mestrado. Na seção 2.4 são exibidas técnicas de interação características de visualização e na seção 2.5 técnicas de interação em realidade virtual.

\subsection{Visualização de Dados}

Existem inúmeras técnicas para visualizar dados, mas para isto os dados devem estar organizados de alguma forma. Esta organização pode variar bastante: os dados podem surgir na forma de um conjunto de pontos esparsos, distribuídos sem qualquer organização pré-definida, ou na forma de uma malha (ou grade) de células que exibe alguma regularidade. Em uma malha volumétrica, se os dados encontram-se no interior de cada unidade 
da malha estes são chamados de voxels, e se estiverem nos vértices são chamados células. No caso dos voxels, exite um único valor correspondente à cada voxel, e esse é o valor do dado em toda a extensão do voxel, no caso das células, os dados estão posicionados nos vértices, e para conhecer o valor do dado em outro ponto da célula os valores nos vértices são interpolados. Dessa forma, a estrutura de um conjunto de dados está implicitamente definida por pontos e células.

De acordo com a organização definida pela estrutura, pode-se ter vários tipos de malhas: as malhas cartesianas, em que todos os elementos são quadrados (no caso 2D) ou cubos (no caso 3D) idênticos alinhados aos eixos principais; as malhas regulares, que possuem todos os seus elementos idênticos e alinhados aos eixos, mas estes são retângulos regulares, ao invés de quadrados ou cubos; as malhas retilíneas que apresentam-se na forma de hexaedros alinhados aos eixos, mas não necessariamente idênticos; as malhas estruturadas, em que os elementos são quadriláteros ou hexaedros não alinhados aos eixos principais; e as malhas desestruturadas, formadas por polígonos ou poliedros sem qualquer padrão explícito de conectividade.

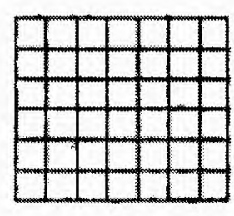

Malha Cartesina (20)

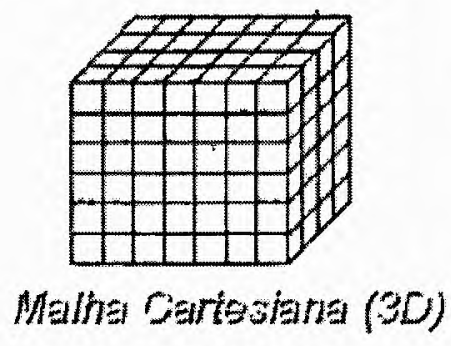

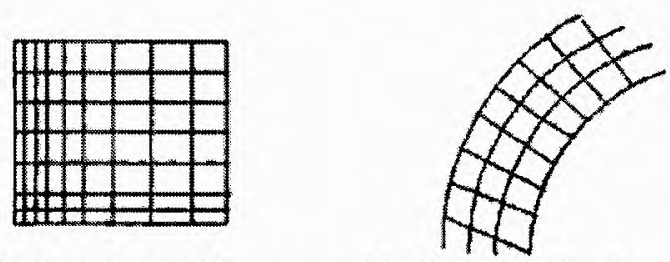

Melhas Fetilnes: Malhes: Estruturarda:

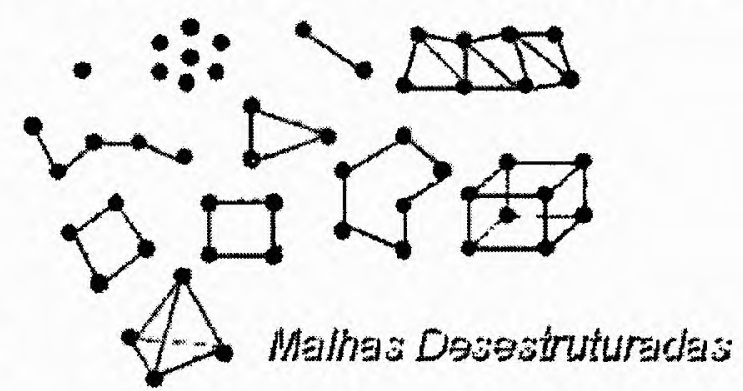

Figura 1: Organização dos dados em malhas

Os dados em si podem ser de natureza escalar (números que indicam temperatura, pressão, umidade, etc.), vetorial (vetores que indicam velocidade, campo elétrico, etc.) ou tensoriais (tensores que indicam fadiga de um material, etc.) No caso de dados escalares, existem dois tipos básicos de visualização: a visualização por extração de superfícies e rendering volumétrico direto (DVR). Para dados vetoriais existem diversas técnicas, como glyphs, streamlines, streaklines, streamrribons e mapeamento de texturas. Técnicas para dados tensoriais não serão discutidas neste texto. Na seção 2.2 .1 são discutidas algumas técnicas clássicas para visualiżação de dados escalares e vetoriais, e na seção 2.2 .2 
é apresentada uma introdução ao software Visualization Toolkit, biblioteca de visualização utilizada no desenvolvimento do projeto.

\subsubsection{Técnicas de Visualização}

A extração de superfícies é uma forma relativamente eficiente de obter uma representação visual de um conjunto de dados. Uma vantagem desta técnica é a possibilidade de identificação de estruturas em medições e simulações. Ela também permite a análise em tempo real pois, apesar do processo de extração das superfícies ser lento, o rendering das superfícies resultantes pode ser muito rápida, principalmente se feita por hardware. Algoritmos de extração de superfícies percorrem o volume de dados encontrando configurações de certos valores de interesse, ou então unem contornos identificados em diferentes fatias do volume. A extração de superfícies inclui duas classes de métodos: conexão de contornos, muito usada em aplicações médicas, e intersecção de voxels. Na primeira categoria, há a identificação dos contornos para um valor de interesse em cada fatia do volume de dados e, a seguir, as curvas em fatias adjacentes são conectadas em uma abordagem denominada tecelagem (patching), ou triangulação. Exemplos de algoritmos pertencentes à segunda categoria são o marching cubes e o dividing cubes (MINGHIM \& OLIVEIRA, 1997).

Já o rendering volumétrico direto (DVR - Direct Volume Rendering) não cria estruturas geométricas intermediárias, como superfícies. Essa solução permite ao usuário enxergar "dentro" (ou "através") do volume de dados, possibilitando a visualização de mais informações do que técnicas de rendering de superfícies, mas para que isto ocorra é necessário trabalhar com transparência. O rendering volumétrico direto é, tradicionalmente, realizado pela técnica de lançamento de raios (ray casting). Nessa técnica, os raios são lançados a partir do ponto de observação, passando pelos pixels da tela, e encontrando o volume de dados. Ao longo desse caminho são feitas amostragens, sendo que os valores amostrados contribuem de alguma forma para a cor final do pixel. Convencionalmente, a iteração principal do processamento opera na ordem do raio, isto é, um raio é lançado e são realizadas amostragens, separadas por distâncias fixas, até que este tenha atravessado todo o volume de dados. Apenas quando um raio é processado por inteiro o traçado do próximo é iniciado.

Os algoritmos dessa classe combinam cores e transparências associadas aos valores de dados que estão no caminho entre o observador e o fundo do volume. Essas cores e transparências são determinadas pelo usuário, que define faixas de valores nos dados como correspondentes a uma certa cor e nível de transparência, definindo assim uma escala de 
cores para mapear os valores de dados. Os diferentes níveis de transparência servem para que elementos internos possam ser vistos através dos elementos mais externos. Por exemplo, um determinado valor de dado pode ser associado a uma cor amarela com uma taxa de transparência de $50 \%$. Isso significa que os valores coloridos com esse amarelo serão transparentes na imagem final, deixando visíveis outros elementos que estariam encobertos por ele caso fosse totalmente opaco. Desta forma pode-se, por exemplo, gerar uma visualização de uma cabeça humana, apresentando pele e músculos com um certo grau de transparência, permitindo assim ver os ossos através deles (Figura 2).

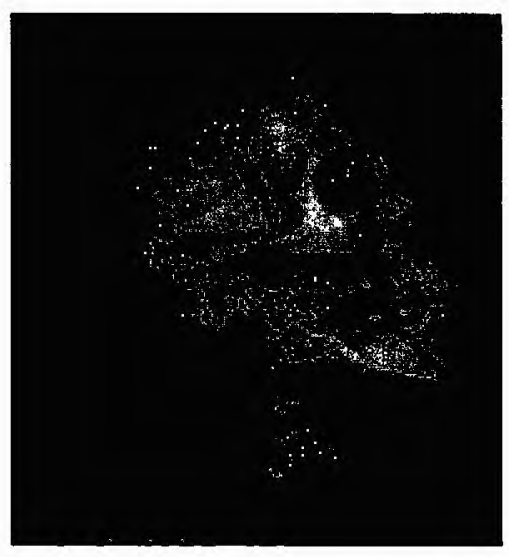

Figura 2: Visualização dos ossos de um crânio por meio de transparências

No caso de dados vetoriais, várias técnicas de visualização podem ser utilizadas. Uma técnica natural para a visualização de campos vetoriais é a utilização de setas, ou seja, segmentos de reta orientados que representam cada vetor, sendo que o segmento começa no ponto ao qual o vetor está associado. Sua orientação é dada pelos componentes $\left(u_{x}, u_{y}\right.$, $u_{z}$ ) do vetor, e o comprimento é proporcional à magnitude do mesmo. Genericamente, a técnica computácional 'envolve a escolha de uma quantidade de pontos representativos do domínio e a atribuição, a cada um deles, de um ícone orientado (ou glyph), que indique a direção do campo vetorial no ponto. Um problema encontrado neste tipo de representação é o congestionamento visual ("visual clutter"), que ocorre quando os glyphs se sobrepõem desorganizadamente devido à projeção na imagem $2 \mathrm{D}$ final, dificultando o conhecimento da posição e da orientação dos vetores. Outro problema encontrado refere-se à ambigüidade da projeção final dos glyphs pois, em geral, um segmento de reta projetado num plano pode corresponder a várias posições do mesmo no espaço, gerando problemas de orientação. Entretanto, a representação por glyphs é simples e rápida, principalmente no caso $2 \mathrm{D}$.

Outra técnica para visualização de dados vetoriais são as streamlines. Uma streamline é uma curva tangente ao campo vetorial em todos os pontos que pode ser construída a partir de um ponto inicial e segmentos de reta calculados da média dos vetores mais 


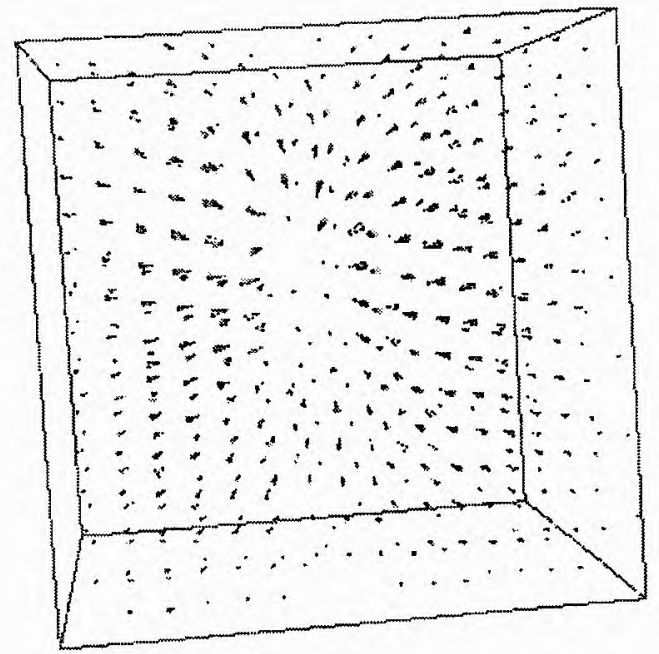

Figura 3: Visualização por meio de glyphs do campo vetorial de um neurônio

próximos. Pode-se, também, usar cores para indicar magnitude da velocidade a cada ponto da streamline. Uma dificuldade comum aos glyphs e streamlines é a densidade de informação apresentada ao observador.

Uma outra técnica são as streaklines, que são os conjuntos das trajetórias das partículas que passaram previamente por um determinado ponto $x_{i}$, em um determinado instante de tempo $t_{i}$. Uma streakline é formada ligando-se as posições dessas partículas, num instante de tempo $t=t_{0}+t$. A animação de streaklines ao longo do intervalo t permite visualizar a evolução do escoamento local ao longo do tempo. Exemplos de utilização desta técnica são descritos em Lane e Bryson \& Levit (LANE, 1996; BRYSON \& LEVIT, 1991).

Uma extensão natural da técnica de streamlines consiste em "alargar"a linha, criando uma fita. A fita pode ser construída gerando duas streamlines adjacentes e conectando-as a uma malha poligonal. Essa técnica, denominada streamribbons, funciona bem desde que as streamlines originais permaneçam relativamente próximas entre si. Se elas divergem, a fita resultante não é uma boa representação do fluxo, pois a superfície da fita deve ser tangente ao campo vetorial a cada ponto (pela própria definição de streamline) sendo que, em geral, uma malha poligonal conectando duas streamlines muito separadas entre si não satisfaz esse requisito.

Um outro recurso seria a utilização de mapeamento de texturas. Existem várias aplicações úteis para o mapeamento de texturas em visualização (SCHROEDER, MARTIN \& LORENSEN, 1998). Padrões de textura podem ser gerados procedimentalmente como uma função dos dados. Um exemplo seria mudar a aparência de uma superfície com base no valor do dado local. Mapeamentos de textura podem ser animados em função do tempo. Escolhendo um mapeamento cuja intensidade varia monotonicamente de escuro 
para claro, e "movendo" a textura ao longo do objeto, o objeto parece "movimentar-se" na direção do movimento do mapa de textura. Essa técnica pode ser usada para simular o movimento de um campo vetorial ilustrando, por exemplo, a magnitude dos vetores.

\subsubsection{O Visualization ToolKit}

O VTK (Visualization Toolkit) é um software multi-plataforma de baixo custo (SCHROEDER et al., 1998) que consiste de uma biblioteca de algoritmos e estruturas de dados para visualização compatível com plataformas UNIX e Windows. O software foi desenvolvido em $\mathrm{C}++$ segundo o paradigma de orientação a objetos e é extensível, permitindo o desenvolvimento de novas aplicações com uma interface gráfica própria, a alteração das técnicas já implementadas e a inclusão de novas técnicas de visualização, pois o código fonte está disponível. A geração de visualizações é feita com a criação de pipelines de visualização, que descrevem uma seqüência de transformações sobre os dados de entrada até o rendering final na tela, como mostra a Figura 4.

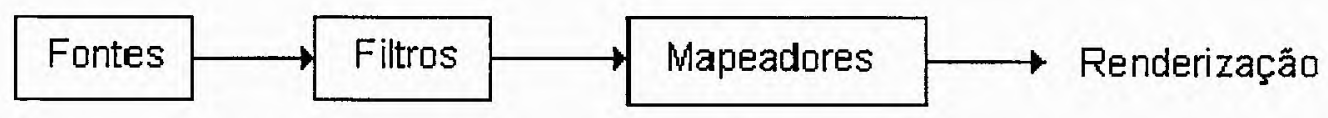

Figura 4: O pipeline de visualização segundo o VTK

O VTK possui um conjunto de classes com funcionalidades específicas, que podem ser dos tipos Fonte, Filtro, Mapeador e Gráfico. Objetos da classe Fonte iniciam o pipeline de visualização, fazendo a leitura de arquivos de dados externos ou criando dados a partir de variáveis de instância, e gerando um ou mais conjuntos de dados de saída. Objetos da classe Filtro recebem pelo menos um conjunto de dados de entrada e geram um ou mais conjuntos (em geral, transformados) de dados de saída. Os Mapeadores finalizam o pipeline de visualização, recebendo um ou mais objetos de entrada, e fazem o mapeamento desses dados para um determinado dispositivo ou para uma biblioteca gráfica. Os Escritores (writers) são mapeadores que escrevem dados em um arquivo. Os objetos do tipo Gráficos implementam a funcionalidade do núcleo de renderização. Esses objetos permitem a manipulação de fontes de luz, câmeras e atores, das propriedades dos atores e dos atributos de renderização (como a cor de fundo do renderizador).

A classe denominada vtkRenderWindow faz a comunicação entre o processo de rendering e o dispositivo de apresentação. Esse objeto gerencia as janelas no dispositivo de apresentação nos PCs (no ambiente Windows 95/98 ou Windows NT) e no UNIX (no ambiente $\mathrm{X}$ Window). As instâncias desse objeto armazenam características comuns como o tamanho, a posição e o nome da janela; e características específicas, como a profundidade 
da janela (número de bits alocados para cada pixel) e double buffering. Objetos da classe vtkRenderWindowInteractor capturam eventos ocorridos em uma janela de renderização e disparam operações associadas, como rotação e escalonamento de atores.

Uma dificuldade associada ao uso do VTK (do ponto de vista do usuário final) é que é necessário um bom domínio da linguagem $\mathrm{C}++$ (e dos conceitos de orientação a objetos) para escrever os programas de visualização. Alternativamente, os programas poderiam ser escritos em TCL/TK, Java ou Python, mas isso também requer bons conhecimentos de programação. Não existe uma interface gráfica a partir da qual pode-se descrever pipelines de visualização em um nível mais alto de abstração. Entretanto, nada impede que sejam implementados "ambientes" de visualização que ofereçam ao usuário uma interface gráfica interativa. Outro aspecto diz respeito à interação com os objetos de visualização. $O$ interactor do VTK permite algumas interações simples com o mouse, como seleção de objetos e elementos de visualização, operações com a câmera para prover diferentes visões da cena como dolly, pan, zoom-in, zoom-out, resetting e rotação. Outros eventos incluem apresentar os atores no modo fio-de-arame (wireframe) ou na forma de superfícies, habilitar ou desabilitar estéreo 3D para sistemas que suportam este tipo de recurso, reinicializar a câmera e encerrar a aplicação.

Os conjuntos de dados em um pipeline de visualização são formas abstratas. Eles consistem de uma estrutura e de atributos associados a estrutura. A estrutura é dividida em duas partes: topologia e geometria. A topologia é o conjunto de propriedades invariantes sobre certas transformações geométricas (por exemplo: rotação, translação e escalonamento não uniforme) e geometria é a instanciação da topologia, a especificação do posicionamento no espaço 3D. Os atributos são informações suplementares associadas a geometria e/ou a topologia. Existem cinco tipos de dados que podem ser representados no VTK: vtkPolyData, vtkStructuredPoints, vtkStructuredGrid, vtkRectilinearGrid e vtkUnstructuredGrid.

A existência de diferentes tipos de representação deve-se ao esforço de tentar minimizar a quantidade de memória requerida e também para implementar métodos eficientes de acesso a memória. O tipo de representação mais simples e mais compacto é o vtkStructuredPoints. Tanto os pontos como as células são representadas implicitamente pela especificação da dimensão do conjunto de dados, do espaçamento entre os dados e as coordenadas do ponto que estabelece a origem. As dimensões definem a topologia do conjunto de dados, enquanto a origem e o espaçamento definem a geometria. No caso do $v t k R e c t i l i n e a r G r i d$ a topologia é regular, mas a geometria é dita semi-regular. A topologia é implicitamente representada pela especificação das dimensões dos dados ao longo dos eixos $\mathrm{x}, \mathrm{y}$ e $\mathrm{z}$. A geometria é definida utilizando-se três vetores dos valores das coorde- 
nadas ao longo desses eixos. Estes três vetores de coordenadas podem ser combinados para determinar as coordenadas de qualquer ponto no conjunto de dados. No VTK, os vetores são representados como três instâncias de vtkScalars. Assim como no vtkStructuredPoints, a topologia do vtkStructuredGrid é regular e é definida pela especificação das dimensões no sistema de coordenadas topológico i-j-k. Entretanto, a geometria do vtkStructuredGrid é representada pela especificação de pontos de coordenadas no sistema de coordenadas global $\mathrm{x}, \mathrm{y}, \mathrm{z}$. A classe abstrata vtkPoints e uma de suas subclasses concretas (por exemplo, vtkFloatPoints) são usadas para representar os pontos de coordenadas.

Ao contrário do vtkStructuredPoints e do vtkStructuredGrid, a topologia do vtkPolyData não é regular. Tanto a geometria como a topologia precisam ser especificadas. $\mathrm{O}$ dado, no vtkPolyData, é representado por instâncias da classe vtkPoints (e subclasses), assim como no vtkStructuredGrid. O vtkCellArray representa explicitamente a topologia das células. Esta classe define uma lista de conectividade entre cada célula, e a estrutura da lista é uma seqüência de números inteiros (Figura 5). O tipo da informação não é representada diretamente na estrutura, no lugar disto o vtkPolyData possui quatro listas separadas para os vértices, linhas, polígonos e malhas de triângulos. $O$ tipo de dado vtkUnstructuredGrid é o mais geral em termos da sua habilidade em representar a estrutura, topológica e geometricamente. Tanto os pontos como as células são representados explicitamente usando classes derivadas do vtkPoints e vtkCellArray.

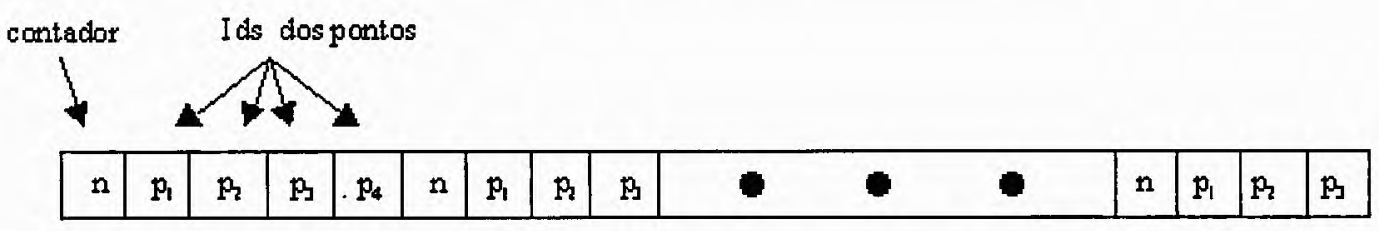

Figura 5: Estrutura do vtkCellArray para representar a topologia da célula

A classe vtkUnstructuredGrid é similar à vtkPolyData, com a diferença de que o vtkUnstructuredGrid é capaz de representar todos os tipos de células, o que não é o caso do $v t k P o l y D a t a$. Outra diferença é que o vtkUnstructuredGrid representa o tipo de informação de maneira diferente. No vtkPolyData as células são categorizadas em quatro listas separadas, representando as células indiretamente. No vtkUnstructuredGrid as células são representadas explicitamente pela classe vtkCellTypes. A classe vtkCellTypes é representada por um vetor de informações suplementares. Para cada célula há uma flag do tipo inteiro que define o tipo da célula, e uma outra variável que registra a localização da definição da célula no vtkCellArray correspondente (Figura 6). 


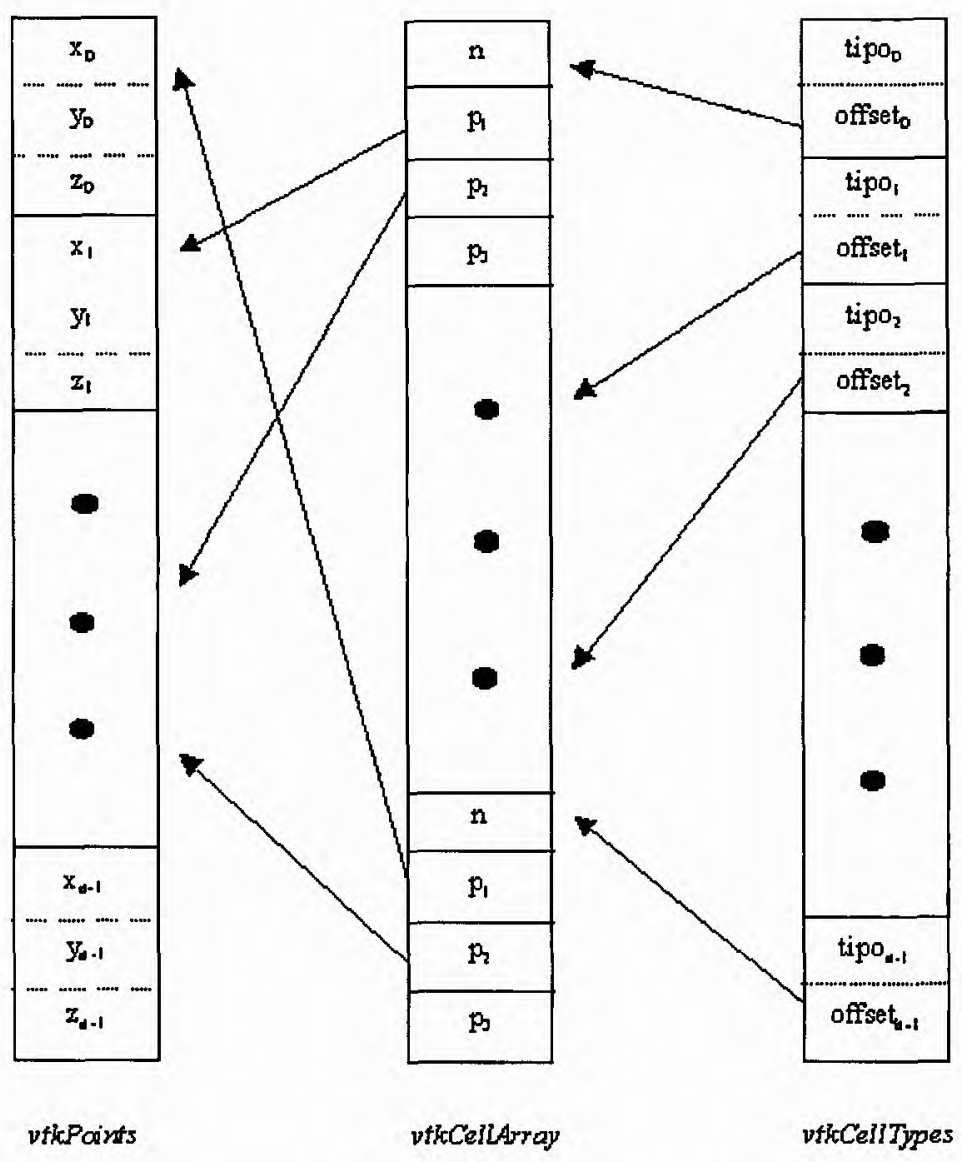

Figura 6: Estrutura do vtkUnstructuredGrid 


\subsection{Uso de som em Sistemas Computacionais}

O som e a habilidade auditiva humana, quando usados em apresentações gráficas, podem resolver, ou pelo menos melhorar, o entendimento da representação de dados problemáticos. A palavra sonificação (sonification) tem sido usada para indicar o mapeamento sonoro de dados numéricos com a intenção de fornecer informações. O som pode servir como um auxílio em sistemas de visualização, ou seja, pode reforçar as imagens produzidas pelas técnicas visuais. Adicionalmente, pode ser um meio de representar dados que não puderam ser representados visualmente no caso de sobrecarga do canal visual e também em casos de dados difíceis de serem representados em duas dimensões.

Algumas das contribuições do uso de som em sistemas de visualização são a representação de dados, validação de dados gráficos e a adição da dimensão do tempo. A representação de dados diz respeito ao poder que o som tem de complementar ou suplementar apresentações visuais. Na validação dos dados gráficos, o mapeamento sonoro de dados que estão sendo representados visualmente pode confirmar ou questionar o resultado obtido na representação gráfica. Os resultados perceptivos contribuem pelo fato da audição ter propriedades diferentes da visão, assim, o uso do som pode identificar padrồes e estruturas não observados na imagem. O tempo pode ser naturalmente representado por mapeamentos sonoros. Assim a adição do tempo é uma contribuição importante que o som traz para as apresentações visuais.

Existem, portanto, várias possibilidades do uso do som em sistemas computacionais, tanto quando usado como um elemento aditivo ao sistema ou como um elemento auxiliar à visão. Algumas das vantagens mais importantes são a rapidez no processamento do som pelos seres humanos, a capacidade de orientação de sinais sonoros, a boa resolução temporal, a possibilidade de oferecer um canal adicional de informação, a liberdade de visão, a possibilidade de apresentação de múltiplas linhas de dados simultaneamente, o papel de alarme, a grande afetividade do ser humano com o som, a habilidade do ser humano de escutar paralelamente, grande habilidade de detecção e memória, e o auxílio ao canal visual, dentre outras. A seguir descrevemos brevemente o Sistema SVol (Sonificação Volumétrica), que serviu de base para a implementação de uma função sonora no sistema desenvolvido neste projeto de mestrado.

O SVol é um sistema de sonificação desenvolvido por Salvador (SALVADOR, 1998) que visa a utilização do som para acrescentar recursos de sonificação em ambientes de visualização. O SVol é um protótipo de um sistema de sonificação para o uso em conjunto com técnicas de visualização volumétricano VTK que oferece ferramentas sonoras para ajudar no entendimento de apresentações visuais de dados. 
A contrução dos sons foi implementada por uma biblioteca que realiza a comunicação MIDI ${ }^{1}$, constrói comandos e pacotes sonoros, e mapeia valores dos dados em parâmentros sonoros (SALVADOR, 1998). A biblioteca sonora gera estímulos sonoros usando a placa de som local ou um sintetizador externo. O SVol opera associado a três processos gráficos associados a visualizações volumétricas denominados: Display Progressivo, Sonda Sonora e Display da Malha.

O Display Progressivo realiza as sonificações que dependem de sincronização com a formação do gráfico na tela. O processo gráfico é implementado para que o volume seja apresentado fatia a fatia, em uma direção escolhida pelo usuário. O Display da Malha é um processo gráfico que leva em consideração que valores ou características importantes podem ser perdidos durante o mapeamento gráfico. No Display da malha, valores escalares contidos na malha são mapeados de várias maneiras para som, permitindo ao usuário a identificação de valores especiais, padrões e estruturas através do som. Outro processo gráfico implementado em SVol é a sonda sonora. Neste processo uma "caixa"de tamanho variável, que representa a sonda, é apresentada dentro do volume de dados. As informações coletadas por essa sonda são apresentadas através de som. As sonificações implementadas para a sonda sonora são densidade e população da sonda sonora.

A densidade local representa a ocupação da sonda sonora, isto é, quanta informação (ou informação de interesse) está contida na sonda. Esse valor é calculado identificando qual o conteúdo existente na sonda em relação ao conteúdo total que a sonda pode suportar. O valor obtido é, então, sonificado. A cada movimento da sonda, sua densidade é calculada, mapeada para o atributo freqüência do som e apresentada. Altas densidades são mapeadas para baixas freqüências, a baixas densidades são mapeadas para altas freqüências. Essa relação inversa é baseada na indicação de que o ser humano tende a associar a idéia de "cheio"e "pesado" com baixas frequiências e com timbres complexos, e o oposto, "leveza"e "liberdade" com sons suaves e com altas frequiências.

A população da sonda está relacionada com a idéia de conteúdo dentro da sonda. Nesse caso, a quantidade relaciona o conteúdo da sonda sonora e o conteúdo do volume total sob análise. A proporção entre esses valores é sonificada. O som resultante indica, para altas frequiências, que a sonda contêm uma pequena parte do volume, e para baixas freqüências, uma grande parte do volume. O mapeamento é realizado da mesma maneira que o da sonificação da densidade local. O usuário pode interagir com a visualização $\mathrm{e}$ mover a sonda pelo volume de dados, mudar o tamanho da sonda, e escolher a sonificação desejada.

\footnotetext{
${ }^{1}$ MIDI (Musical Instrument Digital Interface) é um padrão de comunicação criado nos anos 80 para instrumentos musicais eletrônicos e computadores (FERREIRA, 1995).
} 


\subsection{Interação em Visualização}

Uma característica de muitos sistemas de visualização tradicionais é o fato de possuírem recursos limitados para que o usuário interaja adequadamente com os dados. Os sistemas de interação precisam atuar em sintonia com o pensamento do usuário, para que o mesmo se sinta a vontade com o sistema. Para isto, são necessárias técnicas de interação adequadas, sendo que algumas técnicas de interação tipicamente usadas em sistemas de visualização são discutidas ao longo dessa seção.

A complexidade de certos sistemas de visualização pode resultar em interfaces complexas, de uso difícil e/ou com tempo de resposta inviável. Uma das principais preocupações na construção de interfaces gráficas para aplicações 3D consiste na obtenção de uma interação eficiente entre o usuário e o ambiente 3D. Um grande problema encontrado na construção de interfaces gráficas para aplicações 3D é a dificuldade de mapear ações sobre uma cena 3D usando dispositivos 2D tradicionais. Duas abordagens são discutidas neste texto: uma considera o desenvolvimento de técnicas de interação em software que permitam o mapeamento entre os dispositivos de entrada 2D e o espaço 3D, e a outra abordagem considera o desenvolvimento de novos dispositivos 3D capazes de estabelecer uma correspondência natural entre as ações dos usuários sobre os dispositivos e os movimentos ou ações obtidos no espaço 3D. A justificativa para a utilização da primeira abordagem consiste no fato de que os dispositivos de entrada 2D, aliados à evolução das técnicas de mapeamento, têm permitido interações razoavelmente amigáveis (ALEGRE, 1997) e a justificativa para a construção de novos dispositivos vem da necessidade de se obter uma correspondência natural entre as ações dos usuários sobre os dispositivos e o movimento correspondente no espaço 3D. Porém, muitos destes novos dispositivos são bastante específicos, relativamente caros, e não portáteis.

Nas sessões 2.4.1, 2.4.2 e 2.4.3 são apresentadas algumas dessas soluções por software e por hardware, com ênfase nas soluções por software. Na seção 2.4.4 são discutidas técnicas de interação tipicamente usadas em ambientes de visualização.

\subsubsection{Técnicas de mapeamento do espaço de entrada para o es- paço 3D}

$\mathrm{Na}$ literatura são encontradas diversas técnicas de mapeamento por software para estabelecer interação com o espaço 3D a partir de dispositivos de entrada e saída 2D. No caso de comandos de entrada essas técnicas procuram estabelecer uma correspondência entre as coordenadas $\left(\mathrm{x}^{\prime}, \mathrm{y}^{\prime}\right)$ captadas pelos dispositivos $2 \mathrm{D}$ convencionais e os pontos $(\mathrm{x}, \mathrm{y}, \mathrm{z})$ 
do espaço 3D.

\subsubsection{Movimentos circulares}

Um dos primeiros estudos que utilizou um dispositivo de posicionamento bidimensional foi a mesa digitalizadora de Evans (EVANS, TANNER \& WEIN, 1981), que incorpora um dispositivo lógico denominado trackball $3 D$. O trackball $3 D$ procura simular o movimento de um dispositivo trackball em três dimensões utilizando um dispositivo 2D. Para isto, os movimentos horizontais $2 \mathrm{D}\left(\mathrm{x}^{\prime}\right)$ são mapeados para movimentos em $\mathrm{x}$ no espaço $3 \mathrm{D}$; movimentos verticais $2 \mathrm{D}\left(\mathrm{y}^{\prime}\right)$ para movimentos em y no espaço $3 \mathrm{D}$; e os movimentos circulares (no sentido horário e anti-horário) são interpretados como movimentos em z.

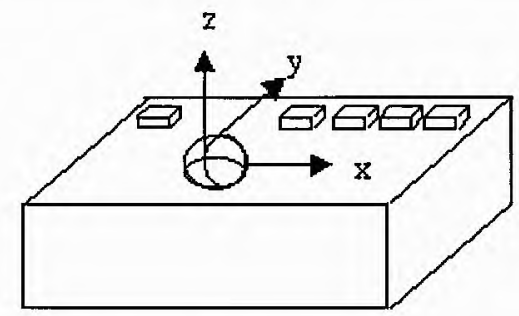

Figura 7: Trackball3D

O trackball 3D provê vários modos de utilização do dispositivo pelo acionamento de um dos seis botões acoplados ao dispositivo. Os modos de alternância são:

- XYZ (controle simultâneo dos três eixos ortogonais)

- XY (controle dos eixos X e Y)

- Z (controle do eixo Z)

- X (controle do eixo X)

- Y (controle do eixo Y)

- VELOCIDADE/DESLOCAMENTO

Os botões X e Y simulam o trackball desabilitando os sensores em Z e Y ou X. No modo DESLOCAMENTO, as saídas são utilizadas para controlar a magnitude dos parâmetros manipulados (ângulo, escala, posição). No modo VELOCIDADE, as saídas são utilizadas para controlar a taxa com que a imagem se move, de maneira análoga ao joystick.

A inconveniência deste método de mapeamento é que, independentemente do movimento do usuário, linear (em x e y) ou circular (em z), normalmente existirá uma variação (positiva ou negativa) no eixo $\mathrm{z}$, o que nem sempre é desejável; principalmente quando se requer somente movimentos lineares em $\mathrm{x}$ ou $\mathrm{y}$. 


\subsubsection{Particionamento do espaço de entrada}

Uma técnica mais intuitiva para o posicionamento e manipulação de objetos no espaço 3D foi proposta por Nielson e Olsen (NIELSON \& OLSEN, 1986). Nesta técnica, o espaço bidimensional de entrada é particionado em regiões correspondentes entre os movimentos planares do dispositivo de posicionamento $2 \mathrm{D}$ e as componentes $\mathrm{x}, \mathrm{y}, \mathrm{z}$ do espaço tridimensional, como mostrado na Figura 8. Esta técnica adota como base de raciocínio a imagem projetada de um cursor tridimensional composta de três eixos ortogonais. Um deslocamento do mouse sobre o plano (espaço de entrada - x'y') determina um vetor de deslocamento do mouse entre a sua posição anterior e a nova (movimentos relativos do mouse). Como o cursor nada mais é do que uma realimentação visual dos movimentos do usuário no espaço de entrada, a nova posição do cursor tridimensional projetado na tela deve corresponder à nova posição do mouse no espaço de entrada. Esta associação entre as projeções dos eixos do cursor 3D e o vetor de deslocamento do mouse permite estimar o deslocamento efetivo do cursor no espaço 3D.

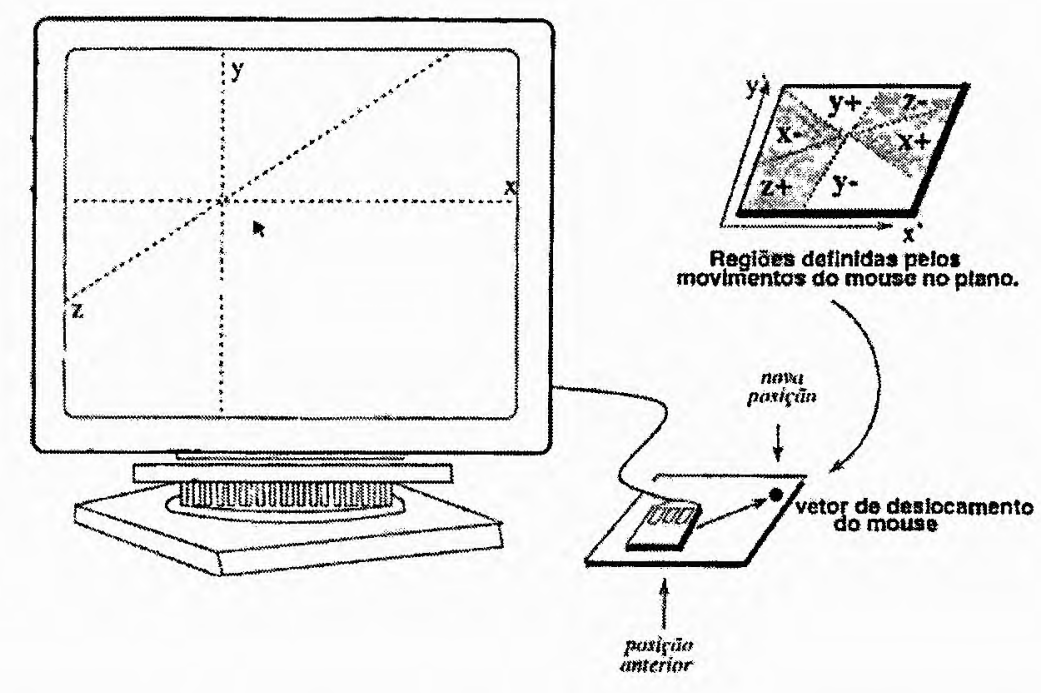

Figura 8: Correspondência entre movimentos do dispositivo e as coordenadas do espaço $3 \mathrm{D}$

O algoritmo que implementa esta técnica é baseado na projeção do cursor 3D sobre o plano da tela de visualização. Como parte da informação é perdida na projeção, o método é impreciso na obtenção de posições 3D a partir do mouse. Apesar desta inconveniência, o método é bastante intuitivo e flexível, e permite que sejam adotadas diferentes representações do cursor 3D (Figura 9). 


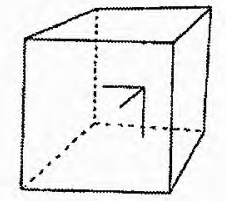

(a)

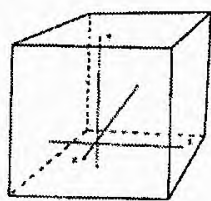

(b)

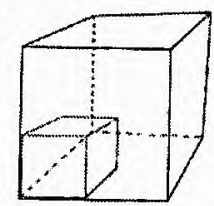

(c)

Figura 9: Representações gráficas do cursor 3D: (a) tríade (triad); (b) espaço cheio (full space); (c) cúbico (cubic)

\subsubsection{Uso de movimentos em diferentes planos da cena}

Nesta técnica, desenvolvida por Bier (BIER, 1990; ALEGRE, 1997; HAND, 1997), a manipulação de objetos 3D é baseada em elementos da própria cena, tais como as arestas de um objeto. Bier propõe o uso de dois tipos de cursores, os Skitters e os Jacks. Os Jacks servem como elementos base para a aplicação de transformações 3D e como referência para especificar parâmetros dessas transformações. Por exemplo, a rotação de um objeto pode ser especificada pela rotação do Jack. O posicionamento interativo dos Jacks na cena é feito por meio de um cursor tridimensional chamado skitter (Figura 10).

O skitter pode ser posicionado sobre uma aresta, um vértice ou uma face, na superfícies dos objetos, no centro dos objetos ou em qualquer plano do espaço 3D. A realimentação visual do skitter é um cursor com três eixos ortogonais, ou seja, é representado por vetores $\mathrm{x}, \mathrm{y}$ e z positivos e unitários, tipicamente com os eixos x e y correspondendo à superfície de um objeto e o eixo z correspondendo à normal a superfície. O Jack é representado com os eixos na direção positiva e negativa, e é usado para marcar pontos e fazer alinhamentos com outros Jacks. Os cursores não são manipulados simultaneamente. Um problema encontrado no uso do skitter é que os seus movimentos só ocorrem na direção dos eixos que definem os três planos ortogonais, ou seja, na direção dos seus próprios eixos.
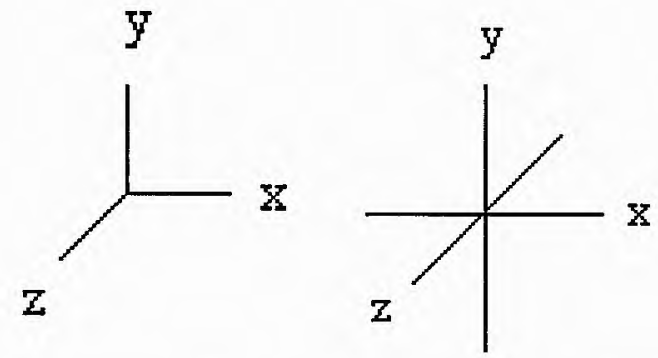

Figura 10: Cursores Skitter (à esquerda) e Jack (à direita) 


\subsubsection{Uso de controladores virtuais}

O trabalho de Chen (CHEN \& MOUNTFORD, 1988) é especialmente orientado ao problema de movimentos rotacionais no espaço 3D. A estratégia usada nesta técnica de mapeamento foi a introdução de controladores virtuais manipulados por um dispositivo bidimensional. Esta técnica introduz novas formas de rotação de objetos 3D pelo uso de quatro controladores virtuais:

- Deslizadores gráficos (sliders) (Figura 11a): para realizar rotações em torno dos eixos $\mathrm{x}, \mathrm{y}, \mathrm{z}$. O uso de deslizadores na tela dá ao usuário um melhor controle do ângulo de rotação em torno do eixo $\mathrm{x}, \mathrm{y}$ ou $\mathrm{z}$ aplicado sobre o objeto;

- Sobreposição de deslizadores (Figura 11b): variação na qual os deslizadores são sobrepostos à imagem do objeto (overlapping sliders). Os movimentos x, y e z são representados por movimentos verticais, horizontais e circulares do mouse;

- Contínuo em xy e exato em z (Figura 11c): contínuo em x e y porque um movimento de arrasto ( $d r a g$ ) dentro do círculo deslocando o mouse da esquerda para a direita e de cima para baixo permitirá a rotação do objeto em torno dos eixos x e y, respectivamente. Os movimentos de arrasto na diagonal permitirão uma rotação proporcional sobre os eixos $\mathrm{x}$ e $\mathrm{y}$. É dito exato em $\mathrm{z}$ porque um movimento de arrasto fora do círculo rodará o objeto todo no sentido horário ou anti-horário, dependendo do sentido do movimento, fazendo o objeto girar em torno do eixo z;

- Esfera virtual (Figura 11d): utiliza-se uma "esfera virtual" como controlador para simular os movimentos de um trackball 3D. O usuário pode imaginar o objeto imerso em uma casca de vidro, sendo que movimentos verticais do mouse dentro do círculo provocam rotações do objeto em torno do eixo $\mathrm{x}$, movimentos horizontais do mouse provocam rotações em torno do eixo $y$, e movimentos circulares ao longo da esfera ou fora dela provocam movimentos em $\mathrm{z}$.

\subsubsection{Sistema de referência do objeto}

O mecanismo de interação com objetos 3D através de um mouse apresentado por Emmerik (EMMERIK, 1990) permite a definição de parâmetros de três tipos de transformação 3D: rotação, escalonamento e translação. A manipulação de movimentos é baseada no sistema de coordenadas de referência do objeto. São definidos sete pontos de controle virtuais (Figura 12) no sistema de coordenadas local do objeto, sendo que um dos pontos está posicionado na origem do sistema e os outros nos seis eixos (um em cada semi-eixo). 


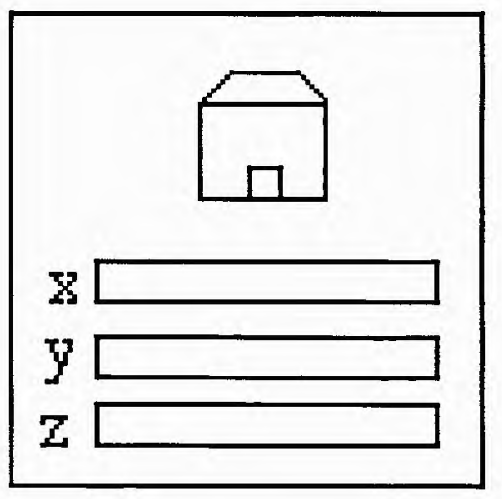

Figura 11: Deslizadores Gráficos(Sliders)

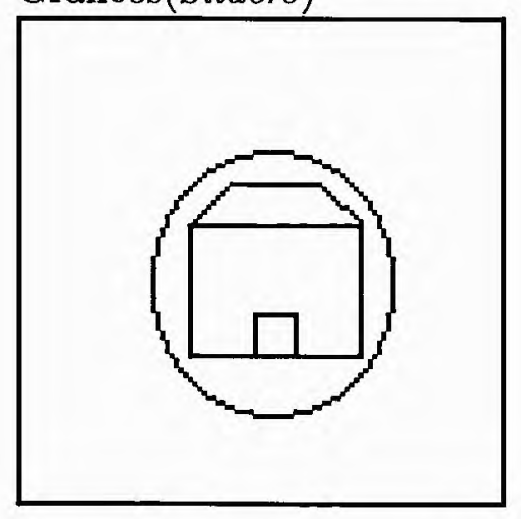

Figura 11: Contínuo em XY e exato em Z

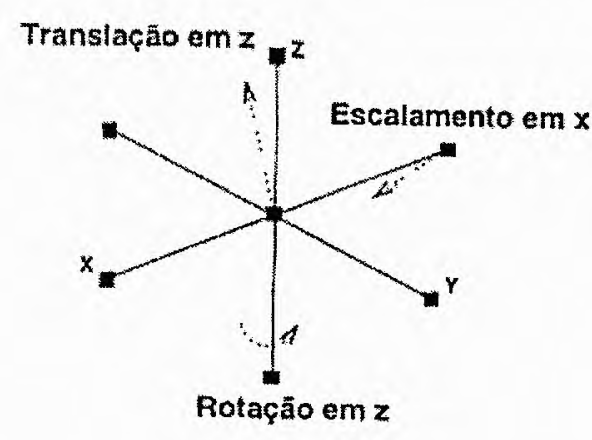

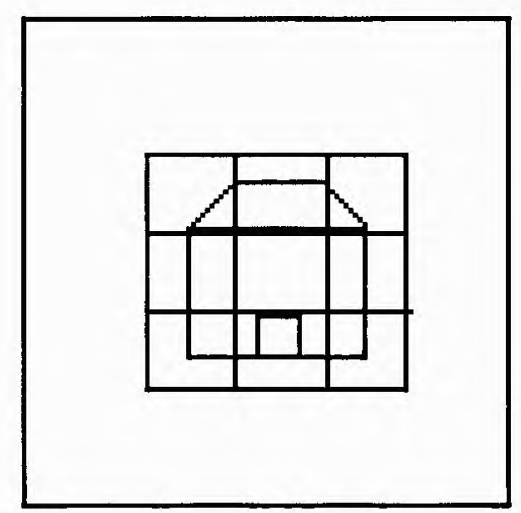

Figura 11: Sobreposição de Deslizadores

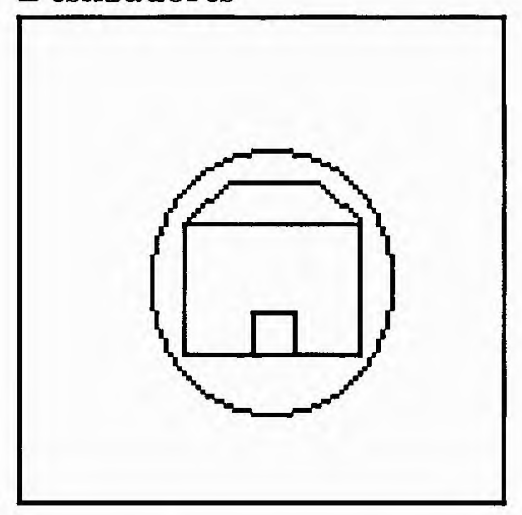

Figura 11: Esfera virtual

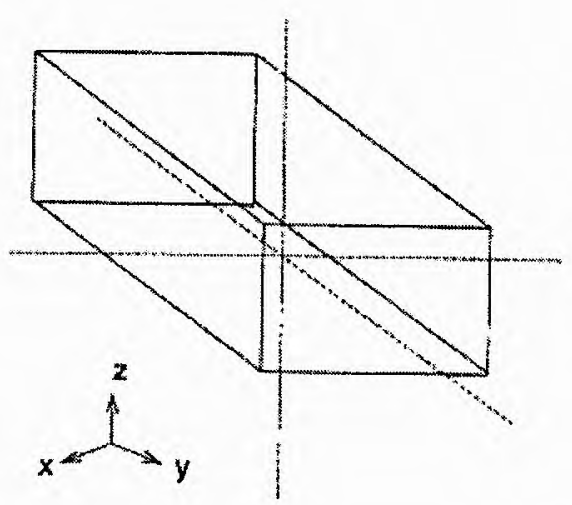

Figura 12: Manipulação direta baseado no sistema de coordenadas do objeto

O usuário deve selecionar o ponto de controle e arrastá-lo (drag). O ponto de controle escolhido, a direção e a origem do movimento do mouse determinam os parâmetros da transformação. Por exemplo, para especificar um movimento de translação, o ponto de controle na origem do sistema é arrastado paralelamente a este eixo, ou seja, se o usuário 
selecionar o ponto de controle central e arrastá-lo paralelamente ao eixo $\mathrm{z}$, o sistema de coordenadas será transladado na direção z. Para a rotação do objeto em torno de um eixo, o ponto de controle é escolhido em um dos dois eixos e arrastado em direção paralela ao terceiro, por exemplo, uma rotação em z é especificada arrastando o ponto de controle do eixo $\mathrm{x}$ paralelo ao eixo y ou vice-versa.

\subsubsection{Técnicas de mapeamento do espaço $3 \mathrm{D}$ para o espaço de saída}

Embora as técnicas de interação 3D vistas anteriormente (como por exemplo as técnicas de Evans (EVANS et al., 1981), Nielson (NIELSON \& OLSEN, 1986) e Bier (BIER, 1990)) implementem as suas próprias estratégias para exibição de objetos $3 \mathrm{D}$, elas não exploram recursos para manipulação da câmera e realce do espaço tridimensional. A adição destas técnicas de exibição às técnicas de mapeamento descritas pode tornar mais real o ambiente de interações 3D. Nas șeções 2.4.2.1 e 2.4.2.2 são apresentadas duas técnicas de exibição: técnicas para realce visual do ambiente $3 \mathrm{D}$ e técnicas para representações gráficas do cursor $3 \mathrm{D}$, respectivamente.

\subsubsection{Técnicas para realce visual}

Philliphs et al. (PHILLIPS, BADLER \& GRANIERI, 1992) descrevem uma técnica para melhorar o processo de manipulação direta tridimensional pelo deslocamento automático e adequado da câmera virtual. Muitas das melhores técnicas para manipulação direta são sensíveis ao ângulo de visão ${ }^{2}$ e podem requerer que o usuário coordene a localização do ponto de observação durante o processo de manipulação. Em alguns casos esse processo é automatizado, o que significa que o sistema pode, por si só, evitar situações de degeneração nas quais translações e rotações são difíceis de realizar devido à inconveniência do ângulo de visualização da câmera.

O sistema pode ainda selecionar pontos e ângulos de visão, tornando visível o objeto a ser manipulado, exceto nos casos onde o objeto é obstruído por outro objeto. Inclui um mecanismo que automaticamente coloca a câmera no ponto de observação e que evita os problemas de degeneração dos eixos sofrida pela maioria dos métodos de manipulação direta. A idéia básica é rotacionar a câmera em pequenos ângulos com a finalidade de alcançar uma visão melhor da cena.

\footnotetext{
${ }^{2}$ Por exemplo, as descritas por: Evans (EVANS et al., 1981), Nielson (NIELSON \& OLSEN, 1986) e Chen (CHEN \& MOUNTFORD, 1988).
} 
Esta técnica usa uma metáfora visual ${ }^{3}$ chamada de "câmera na mão", que manipula a câmera virtual sobre a cena 3D. Esta metáfora consiste em imaginar a cena posicionada sobre a mão do observador. A cena é movida enquanto o botão do mouse estiver pressionado. Num outro trabalho realizado por Staples (STAPLES, 1993) propõe-se um estudo para enriquecimento do vocabulário visual das interfaces tridimencionais e das formas de representação da profundidade espacial nestas interfaces. $O$ estudo sugere que a escolha de recursos como perspectiva, cores, luzes, variação do claro-escuro, opacidade, transparência e sombras não devem ser aleatórios. É o caso, por exemplo, do estudo de Hagen (HAGEN, 1991), que propõe a criação de imagens realistas baseado nas regras convencionais da perspectiva.

\subsubsection{Uso de realimentadores visuais}

Osborn (OSBORN \& AGOGINO, 1992) realizou um trabalho para visualização e construção de objetos 3D a partir de vistas 2D do objeto. No trabalho, manipulam-se objetos 3D de modo a oferecer ao usuário diferentes ângulos de observação e definem-se vistas aéreas, frontais e laterais do objetos. O trabalho de Osborn é uma aplicação prática e melhorada das técnicas de mapeamento usadas por Chen. Em seu trabalho, Osborn utiliza dois dos quatro controladores virtuais descritos por Chen: "contínuo em XY e exato em Z"e a esfera virtual. Diz-se que a técnica foi melhorada porque, ao invés de ser usado um círculo para o uso da primeira e da segunda técnicas, o usuário usa as fronteiras do próprio objeto a ser manipulado. As bordas do objeto atuam como controladores do movimento rotacional. Uma outra característica importante a ser destacada nesta técnica é o uso de diferentes formatos bidimensionais para representação do cursor 2D de acordo com o comportamento do software. A Figura 13 mostra alguns cursores 2D como realimentadores visuais. Sendo (a) cursor do tipo arrow usado para seleção; (b) cursor do tipo hand usado para indicar a possibilidade de manipulação direta; (c) cursor do tipo crossing arrows para quando a manipulação direta é inicializada; (d) cursor tipo spining arrows para quando se está manipulando o objeto em torno de $\mathrm{x}$ e $\mathrm{y}$; (e) cursor no formato grabbing hand usado quando o objeto é rotacionado em torno de $\mathrm{z}$.

\subsubsection{Soluções por hardware}

Nas soluções por hardware defende-se a utilização de dispositivos de posicionamento 3D, como o Flyer mouse, o Rockin' mouse e o Roller mouse, descritos nessa seção, assim como

\footnotetext{
${ }^{3}$ Desenvolvida por Ware e Osborne em 1990 (WARE \& OSBORN, 1990) para usá-la com o dispositivo bat descrito na seção 2.4.3
} 


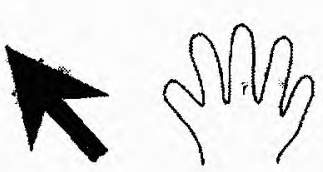

(a)

(b)

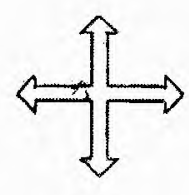

(c)

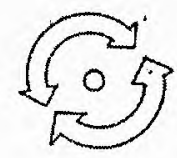

(d)

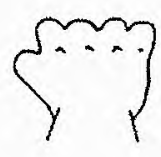

(e)

Figura 13: Cursores 2D como realimentadores visuais

a utilização de dispositivos de Realidade Virtual, apresentados na seção 2.5.2.

Para Colin (WARE \& JESSOME, 1988), posicionar um objeto no espaço tridimensional é uma operação que requer seis variáveis de entrada: três para especificar posicionamento e três para especificar orientação. Um objeto pode ser transladado na direção dos eixos x, y e z e pode ser rotacionado em torno dos três eixos para mudar sua orientação. O posicionamento de um objeto no espaço tridimensional com uma única interação exige um dispositivo que permita a entrada de seis variáveis. O flyer mouse ou bat, uma extensão lógica do mouse convencional, codifica posições relativas e capta entrada de seis variáveis para a manipulação do objeto. Sendo assim, a manipulação do objeto requer uma interface sensora que necessita de um protocolo de interação que funciona como uma espécie de "comunicador de interação". Este dispositivo possui baixa resolução, o que o torna inapropriado para movimentos precisos. Mas, para casos em que a precisão é indispensável, pode-se mudar o mapeamento de movimentos da mão para movimentos do objeto ou ajustar a sensibilidade do cursor.

O Roller mouse, também chamado mouse 3D (Figura 14), possui um mecanismo de manipulação direta e é baseado em um esquema de construção similar ao mouse convencional (VENOLIA, 1993). O hardware consiste de uma esfera para codificação dos dados de entrada, um botão para interação e duas rodas laterais. A realimentação visual é representada por um cursor tridimensional representado por um cone sólido. Possui dois tipos de movimentos: o movimento do corpo do mouse, que controla o cursor tridimensional nas direções vertical e horizontal, e o movimento das rodas que permite a aproximação e o afastamento do cursor na direção de profundidade.

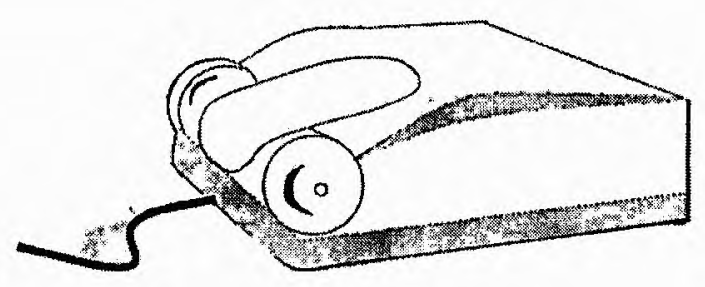

Figura 14: Roller mouse 
Um mecanismo de interação snap-to pode ser associado ao cursor, que funciona de forma análoga a um atrator magnético: a força de atração é inversamente proporcional à distância entre o objeto e o cursor. O snap-to é um modelo intuitivo de atração magnética que tem como objetivo ajudar o usuário a alinhar os objetos tanto em orientação como em posição.

O Rockin' mouse (BALAKRISHNAN, BAUDEL, KURTENBACH \& FITZMAURICE, 1997) é um dispositivo que permite ao usuário 4 DOF (graus de liberdade). Assim como o mouse regular, o Rockin'mouse (Figura 15) pode detectar posições planares e realizar todas as funções usuais. Possui a mesma forma do mouse regular, com a exceção da sua base, que possui um formato curvilíneo para que ele possa ser inclinado. A implementação do protótipo deste dispositivo operava em uma mesa digitalizadora capaz de detectar a posição da coordenada do sensor nos planos x-z da mesa e também o grau de inclinação do sensor em relação aos eixos x e z.

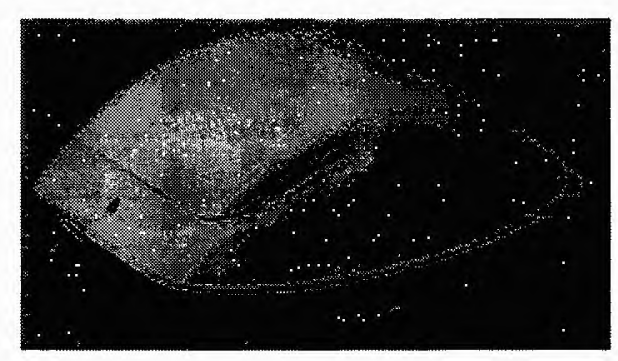

Figura 15: Rockin'mouse

\subsubsection{Técnicas de interação em visualização}

Em interfaces exploratórias é importante que o mapeamento entre os dados e a sua representação visual seja contínua e dinâmica. Certos tipos de técnicas interativas permitem manter um contato direto com os dados, ou seja, o usuário tem a ilusão de estar interagindo diretamente com os dados, o que não ocorre realmente, visto que não há nada de fisicamente direto em usar o mouse para mover um objeto na tela. No entanto, se a resposta do sistema for rápida o usuário pode ter a ilusão de controle direto (WARE, 1999). Normalmente, os dados são transformados antes de serem apresentados na tela. $O$ mapeamento interativo de dados é o processo de ajustar a função que mapeia atributos dos dados em atributos visuais. Um mapeamento não linear entre os dados e a sua representação visual pode posicionar os dados em um intervalo onde o padrão seja mais facilmente visível. Por exemplo, quando o atributo visual é a cor, a técnica de mapeamento interativo de cores pode ser usada. 
Para conjuntos de dados complexos pode ser útil limitar um intervalo de valores de dados visíveis e mapeá-los em atributos visuais. Isto pode ser feito com o uso de sliders. Este tipo de interface é denominada query dinâmica (SHNEIDERMAN, 1994). Ajustando-se os intervalos dos dados dos sliders, subconjuntos de dados podem ser isolados e visualizados.

Uma outra técnica interativa é o brushing. Brushing é uma técnica de visualização de dados que identifica e realça subconjuntos do conjunto de dados. A técnica de brushing em scatterplots ${ }^{4}$ é implementada criando-se matrizes de $\mathrm{p}(\mathrm{p}-1) / 2$ scatterplots para cada par de variáveis $x_{i}, y_{i}$ no conjunto de dados que consiste de $\mathrm{p}$ variáveis. Usando-se um dispositivo apontador, uma pequena região é selecionada em um dos scatterplots. Essa região é realçada tanto no scatterplot ao qual ela pertence quanto nos demais scatterplots que compõem a matriz (EICK \& WILLS, 1994). Wong (WONG \& BERGERON, 1996) introduz uma forma de brushing na qual os dados a serem destacados são, geralmente, mostrados em uma resolução diferente dos dados originais. Esta técnica utiliza-se de aproximações de wavelets para suportar a visualização científica de grandes conjuntos de dados multivariados multidimensionais. Wavelets podem ser consideradas como sendo matrizes de filtros que aceitam dados com $n$ itens, e geram (n/2) itens de aproximação e (n/2) itens de detalhes (WONG \& BERGERON, 1996).

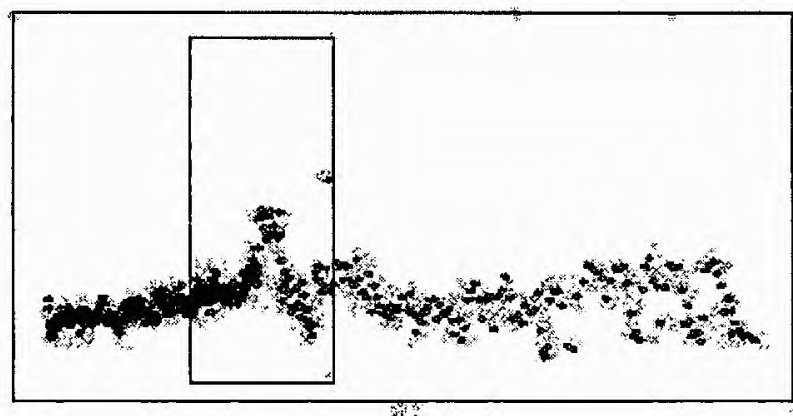

(4)

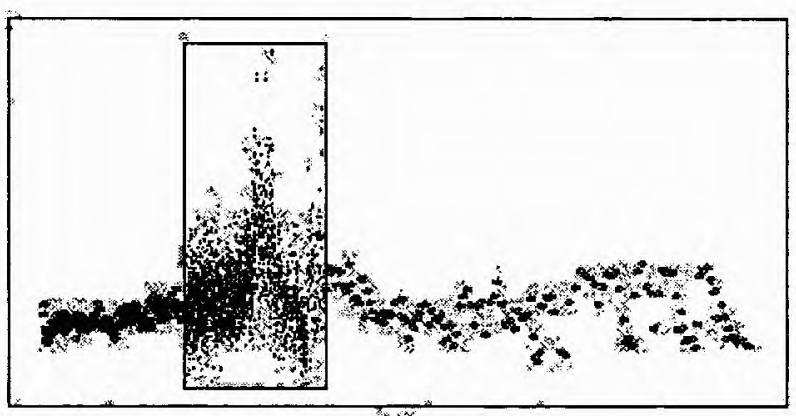

(b)

Figura 16: (a) Definição da área de brushing; (b) Dados após a aplicação da técnica de brushing

As Figuras 16a e 16b mostram um exemplo simplificado de brushing com. wavelet em um scatterplot. Os dados que estão fora da área de brushing permanecem inalterados, dando uma visão geral da estrutura, enquanto que os dados selecionados são apresentados de maneira realçada. Wong (WONG \& BERGERON, 1997) apresenta três técnicas de visualização baseadas em brushing de multi-resolução em conjuntos de dados volumétricos tridimensionais: brushing qualitativo, brushing planar e o brushing volumétrico.

O processo do brushing qualitativo destaca áreas de interesse de acordo com os valores

\footnotetext{
${ }^{4}$ Scatterplots são gráficos que visualizam a relação entre três variáveis (representando as coordenadas $\mathrm{X}, \mathrm{Y}$ e $\mathrm{Z}$ para cada ponto do espaço tridimensional) categorizadas por um grupo de variáveis
} 
dos dados. Por exemplo, se em uma imagem de uma cabeça a parte mais importante é o crânio, somente os valores dos dados correspondentes aos ossos e as juntas são utilizados para gerar as isosuperfícies. O resto dos dados, principalmente carne e pele, podem ser obtidos da versão original dos dados. O processo de brushing planar destaca seções do volume de dados. Existem três tipos de brushing planar: axial, sagital e coronal, sendo que cada um indica uma orientação diferente do plano que passa pelo volume de dados (Figuras 17). Já o brushing volumétrico apresenta um sub-volume de alta resolução dentro do volume de dados inicial. O objetivo é aplicar a técnica de brushing a pequenas regiões do volume de dados que não obtiveram sucesso somente com o uso do brushing planar ou quantitativo.
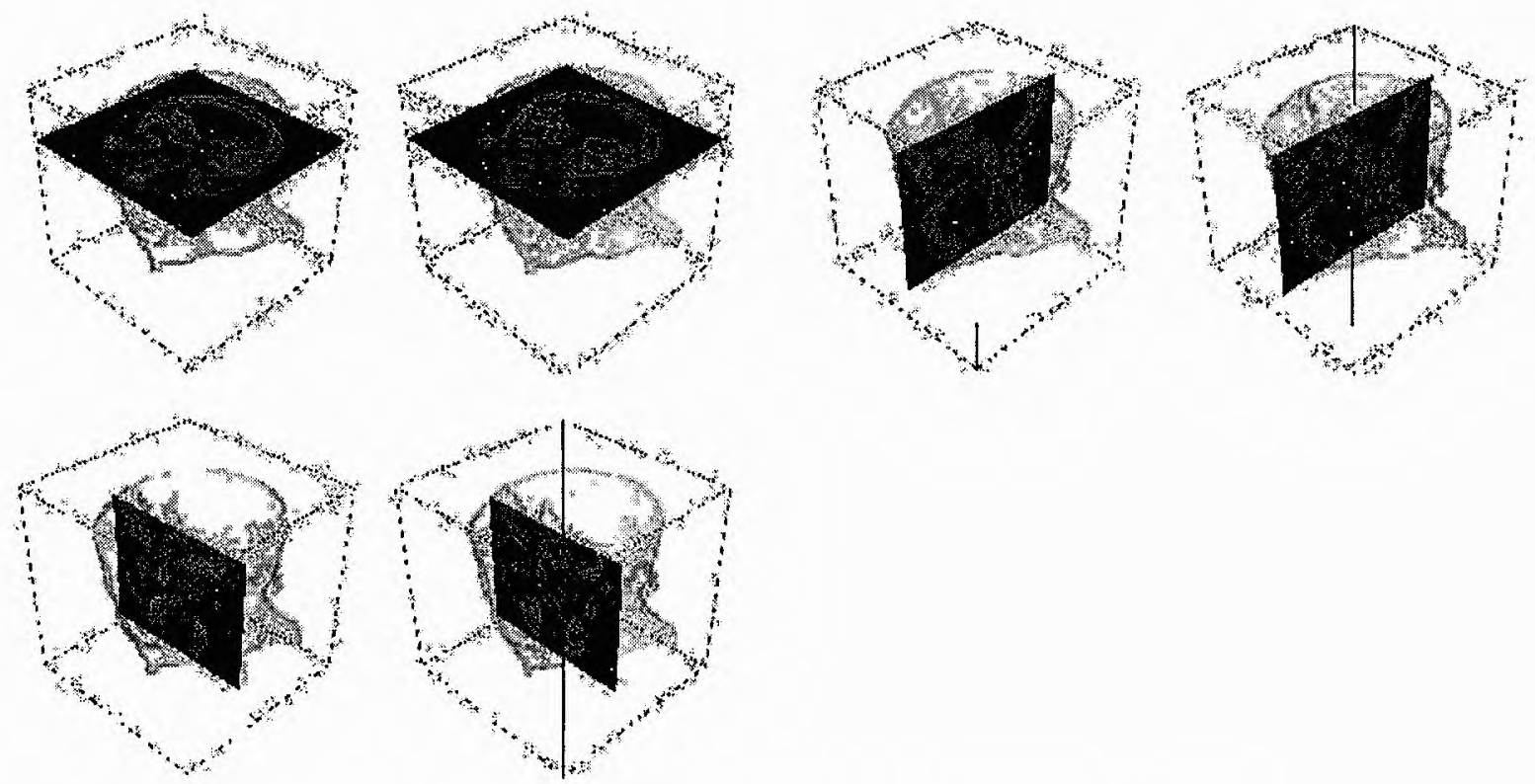

Figura 17: Brushing planar: Axial, Sagital, Coronal.

Duas técnicas interativas convencionais em sistemas gráficos tradicionais são o zoom e o pan. Elas permitem ao usuário visualizar a imagem, ou parte dela, com um nível maior de detalhes, ou controlar o que será mostrado na tela. Um dos problemas encontrados é que quando o usuário diminui o zoom (zoom out) para se orientar ele não possui detalhe suficiente para realizar qualquer trabalho real, e quando aumenta (zoom in) o contexto é perdido. Uma técnica de interação que utiliza zoom e pan integralmente através do rastreamento de movimentos relativos da cabeça é a pre-screen projection (HIX, 1995). Esta técnica rastreia a posição da cabeça do usuário em três dimensões e altera a cena do monitor dando um efeito perspectivo em resposta aos movimentos da cabeça do usuário. A projeção da cena virtual é calculada como se ela estivesse na frente da tela. Sendo assim, quando o usuário aproxima-se da tela os objetos são expandidos (zoom) e vice- 
versa. Com a técnica de pre-screen projection o usuário pode navegar (pan e zoom) sobre a cena integralmente, ou seja, de forma unificada, não precisando utilizar estas duas tarefas separadamente.

Outra técnica muito utilizada em visualização de informações é o fisheye view (FURNAS, 1981). A idéia é detalhar profundamente algumas regiões enquanto o restante da informação é exibido com um menor nível de detalhe. Isto pode ser feito por três métodos: distorcendo graficamente a visão, fazendo com que os itens diminuam a medida que se afastam do ponto focalizado, apresentar visões parciais filtrando quais itens devem ou não aparecer na tela usando funções de cálculo de distância, ou usar representações e abstrações para, por exemplo, representar um circuito através de retângulos ou ícones. Algumas variações desta técnica foram propostas e implementadas por diversos pesquisadores. Furnas (FURNAS, 1981) descreve uma função "de grau de interesse"generalizada onde o valor de interesse de um nó em um gráfico depende tanto da importância e do nível de detalhes de cada ponto da estrutura a ser visualizada quanto da distância entre o ponto a ser focalizado e qualquer outro ponto da estrutura. Ele criou sistemas para visualizar e filtrar códigos de programas estruturados e taxonomias biológicas e verificou que fisheye viéw é realmente superior a visões planares por meio de estudos de usabilidade.

Sarkar e Brown (SARKAR \& BROWN, 1992) apresentam uma versão mais gráfica desta técnica que inclui transformações polares e planares em gráficos conectados e usa distância Euclidiana para calcular o "grau de interesse". O sistema mostra todos os nós da rede, com exceção dos nós que possuem um valor inferior a um certo threshold, que no caso, são removidos do gráfico. Schaffer e Greenberg (SCHAFFER \& GREEBERG, 1993) promoveram a idéia do uso de filtros e de fisheye view da informação em hierarquias pelo uso de queries dinâmicas. Filtrando as informações, somente os elementos que satisfazem a um certo critério são mostrados e, através das queries dinâmicas, pode-se mudar os valores dos atributos do filtro interativamente. Outras pesquisas nesta área incluem métodos como Tree-Maps (SHNEIDERMAN, 1992), Cone Trees (ROBERTSON, MACKINLAY \& CARD, 1991), Variable Zoom (SCHAFFER, ZUO, BARTRAM, DILL, DUBS, GREENBERG \& ROSEMAN, 1993) e fisheye view para grupos de trabalhos (GUTWIN \& GREENBERG, 1997). Este último difere da técnica tradicional por dois motivos: o usuário pode criar, mover ou editar objetos na área de trabalho, e várias pessoas podem ver e manipular objetos ao mesmo tempo usando pontos focais diferentes. 


\subsection{Interação em Realidade Virtual}

Interfaces que envolvem controle tridimensional altamente interativo de processos computacionais podem ser desenvolvidas com o uso da Realidade Virtual (RV). Existem diversas definições de RV na literatura. Agrupando-se algumas delas (BURDEA \& COIFFET, 1994; JACOBSON, 1991; KRUEGER, 1991), pode-se dizer que RV é uma técnica avançada de interface pela qual o usuário pode realizar imersão, navegação e interação em um ambiente sintético tridimensional gerado por computador, utilizando canais multisensoriais. Com este tipo de interface o usuário entra no espaço virtual das aplicações e visualiza, manipula e explora os dados da aplicação em tempo real, usando seus sentidos e os movimentos naturais $3 \mathrm{D}$ do corpo (KIRNER, n.d.). A idéia de imersão está ligada ao sentimento de estar dentro do ambiente. A idéia de interação está ligada à capacidade do computador detectar as ações de entrada do usuário e modificar instantaneamente o mundo virtual e as ações sobre ele (capacidade reativa). As pessoas gostam de ser cativadas por uma boa simulação e de ver as cenas mudarem em resposta aos seus comandos. Esta é a característica mais marcante nos vídeo-games. A idéia de envolvimento, por sua vez, está ligada ao grau de motivação para o engajamento de uma pessoa em determinada atividade. O envolvimento pode ser passivo, como ler um livro ou assistir televisão, ou ativo, ao participar de um jogo com algum parceiro. A realidade virtual tem pótencial para os dois tipos de envolvimento ao permitir a exploração de um ambiente virtual e ao propiciar a interação do usuário com um mundo virtual dinâmico (KIRNER, n.d.).

Segundo Bryson (BRYSON, 1994), tradicionalmente a visualização científica é utilizada com duas finalidades: exploração e apresentação. No início da visualização científica, era bastante difícil para o pesquisador produzir visualizações além dos gráficos tradicionais. Era requerido familiaridade com programação em computação gráfica, uma necessidade que foi resolvida com a criação de "lojas de visualização", onde visualizações eram produzidas "sob encomenda". Um pesquisador provia dados para um programador de visualização que, então, produzia uma imagem ou animação de alta qualidade. Assim, existia um investimento significativo envolvido na produção de visualização. Isso serviu ao propósito da visualização como meio de apresentação, mas inibiu o uso da visualização como meio de exploração.

Atualmente, sistemas de visualização oferecem maiores facilidades para visualização exploratória. No entanto, existem dificuldades principalmente devido a três fatores: o tempo requerido para renderizar a visualização a partir de uma entrada do usuário, a falta de usabilidade da interface que controla a visualização, e a falta de intuitividade das próprias técnicas. A questão do tempo é devida, principalmente, à velocidade do hardware do sistema de visualização, à complexidade dos algoritmos usados para realizar 
a visualização, e ao tamanho e complexidade dos conjuntos de dados. Reduzir significativamente o tempo de renderização de uma visualização fortalece o-manuseio dos modelos de visualização como parte do processo.de exploração e descoberta. Ou seja, é necessário buscar a capacidade de interação em tempo real.

Em nível da interface, como mencionado na seção anterior, outro problema está principalmente na dificuldade de mapear os dispositivos tradicionais de interação, que são 2D, em ações sobre uma cena 3D. Nesse processo ocorre uma grande limitação na interação com a visualizàção. Assim, uma alternativa consiste em utilizar dispositivos de realidade virtual, que são de natureza 3D. Ou seja, a questão se resume em conseguir uma interface $3 \mathrm{D}$ que seja natural ao ser humano, aproveitando sua experiência de manipulação de objetos $3 \mathrm{D}$ no ambiente em que vive. Com a ajuda de dispositivos de interação apropriados, as atividades de interação em mundos virtuais $3 \mathrm{D}$ se tornam mais próximas do natural, o que é mais difícil quando se faz uso de dispositivos $2 \mathrm{D}$ para interação.

Outra alternativa, de menor custo, consiste na programação voltada para a WWW (World Wide Web) utilizando a linguagem VRML, ou seja, programação em VRML (Virtual Reality Modeling Language) (SMITH, 2001; NADEAU, MORELAND \& HECK, 1998). VRML é uma linguagem de descrição de cenas, que permitem construir ambientes tridimensionais (3D). Tal como o HTML (Hyper Text Markup Language), formato que define a aparência e conteúdo de um página bidimensional (2D) com links e diversa informação, o VRML é um formato que define a aparência e conteúdo de um mundo virtual 3D com links e diversa informação. Maiores informações sobre a linguagem serão apresentadas na seção 2.5.3.3.

Em vista da sua importância na discussão de interação em visualização, nesta seção são discutidos alguns aspectos da realidade virtual e seu uso nesse contexto.

\subsubsection{Características da Realidade Virtual}

O projeto de ambientes virtuais não é simples, em parte devido à demanda de alto desempenho de tais sistemas. Atualizações rápidas são requeridas para prover ao usuário uma sensação de reposta capaz de impedir a desorientação. Outra dificuldade é que o conhecimento.formal de fatores humanos envolvidos no uso desta tecnologia é, ainda, mínimo. Os ambientes virtuais são caracterizados por uma série de requisitos que contribuem para a sensação de "realidade"(BAKER \& WICKENS, 1995):

- A visão é em perspectiva 3D ou estereoscópica, ao invés da visão planar usada em ambientes desktop. A. percepção de profundidade está diretamente associada à visão 
estereoscópica, em que cada olho registra uma imagem diferente e o cérebro usa o pequeno deslocamento lateral destas imagens para medir a profundidade de objetos próximos. A percepção de profundidade pode ocorrer, entretanto, com dois olhos ou com apenas um. Quando apenas um olho é usado, a profundidade é percebida baseada em características inerentes à imagem, como perspectiva linear, sombras, oclusões (objetos mais distantes são bloqueados por objetos mais próximos), texturas e detalhes do objeto. Também importante na visão monocular é o "motion paralax": quando se move a cabeça, objetos mais próximos movem-se mais depressa do que objetos mais distantes [PIN99]. Além disto, são usadas informações sobre a rotação de cada olho, ou da chamada "convergência", para determinar a real posição de um objeto.

- O ponto de observação é, freqüentemente, egocêntrico, provendo ao usuário uma visão do espaço virtual segundo sua posição física e direção de visão dentro do espaço, o que permite a sua imersão no mundo virtual. Existem dois tipos de visões do usuário, no que tange à interação [BAK95]: a visão exocêntrica, típica das ferramentas desktop em que o usuário é mantido do lado de fora da cena; e a visão egocêntrica, típica de ambientes virtuais.

- A interação é centrada no usuário. O explorador tem controle sobre que partes do mundo são visitadas, e em que seqüência.

- O ambiente é dinâmico, ao invés de estático.

- Técnicas multi-sensoriais são empregadas para interação com o usuário. A entrada pode ser através de fala, movimento do corpo todo ou gestos. A experiência do usuário do mundo virtual ocorre através de respostas do sistema envolvendo canal de visão, resposta auditiva, resposta de força (force feedback) nas mãos ou até resposta tátil.

\subsubsection{Dispositivos de interação com ambientes virtuais}

Os dispositivos para Realidade Virtual têm como função básica proporcionar a sensação de imersão do usuário no ambiente. Para tanto, atuam de duas formas (PINHO \& KIRNER, 1999): lendo os movimentos feitos pelo usuário (e pelas várias partes de seu corpo) e despertando seus sentidos a fim de simular sensações. No que tange à entrada de dados, temos duas categorias: leitura da posição de um ponto no corpo do usuário (rastreamento) e a leitura do ângulo de flexão ou rotação de um membro ou parte do corpo do usuário. Os dispositivos de rastreamento têm por objetivo principal determinar a posição ou a 
orientação de uma parte do corpo do usuário. Existem seis tipos básicos de rastreadores: mecânicos, ultrassônicos, magnéticos, por extração de imagens, óticos e sem referencial (PINHO \& KIRNER, 1999). Alguns dispositivos são descritos a seguir.

\subsubsection{Luvas Eletrônicas e Stereo Glasses ou Shutter Glasses}

As luvas eletrônicas surgiram da necessidade de manipular objetos no ambiente virtual. Elas tentam capturar os movimentos das mãos (e dos dedos) e usá-los como forma de interação com o usuário. A mais famosa de todas as luvas de uso doméstico, a "Power Glove", criada pela empresa Mattel para a Nintendo, é uma luva que usa tinta condutiva para aferir o movimento dos dedos.

Já os Shutter Glasses são úteis em aplicações como visualização científica ou cirurgias nas quais várias pessoas precisam observar a mesma imagem estéreo. Estes dispositivos geram estas imagens estéreo a partir de uma tela de computador convencional. A idéia é colocar no usuário um par de óculos com lentes de cristal líquido capazes de bloquear sua visão quando necessário. Para o funcionamento do sistema, deve haver um controle que-atua da seguinte forma: exibe-se na tela a imagem correspondente a do olho esquerdo e bloqueia-se a visão do olho direito. A seguir, faz-se o contrário. Nestes sistemas, a dificuldade é a garantia do sincronismo no processo de exibição e bloqueio.

\subsubsection{Head Mounted Displays (HMD) e BOOM - Binocular Omni-Orientation Monitor}

$O$ capacete de visualização HMD cumpre a função de fornecer a imagem do ambiente virtual ao usuário. Quando o usuário veste o capacete, é como se ele se isolasse do mundo real e mergulhasse no ambiente virtual, ou seja, se o usuário olha para cima, por exemplo, espera ver o céu, se olha para baixo espera ver o chão, e assim por diante. Portanto, o capacete possui as funções de entrada, já que detecta o movimento da cabeça, e de saída (fornece a imagem).

A idéia dos HMDs ou VPC (Visores Presos a Cabeça) é exibir em duas pequenas telas (uma para cada olho) imagens de uma cena virtual. Os HMDs são construídos, normalmente, usando dois tipos de monitores: os CRTs, ou os monitores de cristal líquido, os LCDs. Os monitores CRT, em função da avançada tecnologia disponível nesta área, podem exibir imagens de alta resolução com uma qualidade de cor excelente, mesmo em pequenas dimensões. Entretanto, são relativamente pesados, volumosos e colocam altas voltagens muito próximas à cabeça do usuário. Os LCDs, por sua vez, são leves e podem ser usados com pequenas voltagens. Entretanto, a resolução ainda é baixa. Acoplados aos 
HMDs, em geral, existem sistemas de rastreamento da posição da cabeça para permitir que se atualize as imagens do mundo virtual de acordo com a direção de observação.

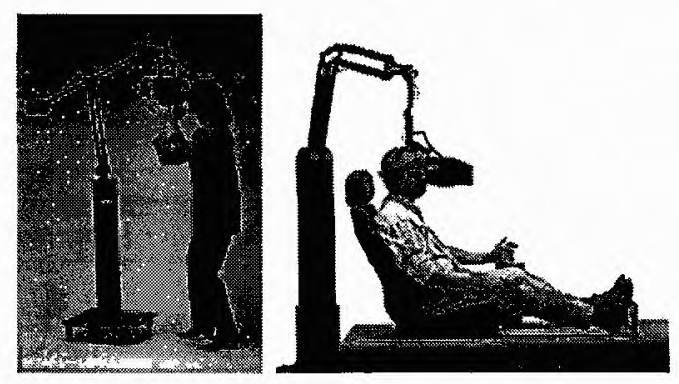

Figura 18: Modelos de BOOMs vendidos comercialmente

Em algumas aplicações de Realidade Virtual a qualidade da imagem é essencial. Nestas, torna-se essencial o uso de óculos baseados em CRTs. Para evitar, então, problemas com as altas voltagens necessárias e com o peso inerente a estes dispositivos, foram criados os BOOMs. O BOOM, assim como o HMD, oferece visão estereoscópica, mas possui uma estrutura de suporte para que o usuário não tenha que suportar o peso do dispositivo (Figura 18). Tratam-se de pequenos monitores colocados em uma caixa dentro da qual o usuário pode olhar. Esta caixa fica suspensa por um braço mecânico, que leva a corrente elétrica necessária até os monitores. O braço mecânico é, em geral, articulado, permitindo que o usuário, segurando a caixa, possa girá-lo em qualquer direção. Se for colocado nas juntas deste braço mecânico um conjunto de sensores, este pode servir também como rastreador da posição da cabeça. A empresa FakeSpace (FAKE SPACE Lab; 2000) fabrica um BOOM de alta resolução (1280x1024) capaz de exibir imagens de 16 milhões de cores e que permite ao usuário 6 DOF (graus de liberdade).

\subsubsection{Dispositivos Geradores de Som 3D}

A adição de som em qualquer processo de exibição de imagens que pretende ser, de alguma forma, interativo, torna a experiência muito mais realista. Quando uma bola quicando aparece no centro da tela, a agregação de um som mono ou estéreo, com a simples reprodução do som real, sincronizado com o movimento da bola, dá uma sensação de realismo muito grande para quem observa. Quando coloca-se um HMD em um usuário, os sons do mundo virtual, além de terem um timbre, devem ter um dado adicional: sua posição. Ou seja, deve ser possível identificar de onde vem o som no ambiente virtual.

O primeiro problema no caso do som $3 \mathrm{D}$ é que a geração do som para cada ouvido deve mudar a cada movimento do corpo ou da cabeça do usuário, bem como da fonte sonora. $\mathrm{Na}$ área de som $3 \mathrm{D}$ um dos trabalhos mais importantes já realizados está sendo 
conduzido pelo Ames Research Center da NASA, que está produzindo um equipamento chamado Convolvotron que opera em PCs, permitindo até 4 canais de entrada. Há, também, sistemas que trabalham com 2 canais. Nestes sistemas, algumas caixas de som são colocadas em uma sala e dispostas em forma de círculo. O usuário, colocado no centro do círculo, tem a ilusão de que o som anda dentro da sala (PINHO \& KIRNER, 1999).

\subsubsection{CAVE e WALL}

O CAVE, ou CAVE Automatic Virtual Environment, foi criado por cientistas do Laboratório de Visualização Eletrônica da Universidade de Illinois em 1992. Ele constitui-se de uma sala escura na qual as imagens são projetadas nas paredes e no chão em alta resolução, incluindo áudio e visão estereoscópica. As imagens parecem flutuar no espaço. É usado para pesquisa; exploração, prototipação rápida, engenharia, design e marketing.

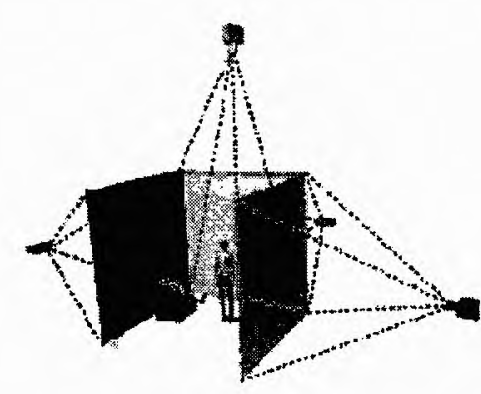

Figura 19: (a) Esquematização do CAVE

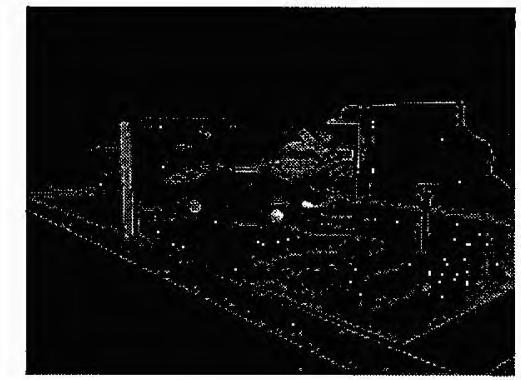

Figura 19: (b) Immersive WorkWall. Tipo de WALL vendido comercialmente

Vários centros de pesquisa e universidades desenvolvem trabalhos utilizando este tipo de interface, como é o caso da Escola Politécnica da USP em São Paulo (ZUFFO, SOARES, ZUFFO \& LOPES, 2001) e da Universidade de Michigan (MICHIGAN, 2000). O projeto desenvolvido na Universidade de Michingan tem como objetivo obter um ambiente para treinamento médico Virtual (Reality-Enhanced Medical Readiness Trainer - MRT(r)) que integre as mais avançadas tecnologias, como simuladores de pacientes humanos, sistemas de realidade virtual imersivos CAVE, tecnologia Internet, vídeo conferência e alguns outros aspectos relacionados a sistemas virtuais distribuídos e compartilhados para o treinamento de emergências médicas. O WALL é um ambiente virtual semelhante, utilizado para apresentações em grupos ou trabalhos colaborativos que possui dois ou mais projetores de alta resolução e visão estereoscópica por shutter glasses. 


\subsubsection{Virtual Workbench (VW)}

O Virtual Workbench (OBEYSEKARE, WILLIAMS, DURBIN, ROSENBLUM, ROSENBERG, GRINSTEIN, RAMAMURTI, LANDSBERG \& SANDBERG, 1996) é um ambiente virtual não imersivo que permite ao usuário ver e interagir com objetos virtuais 3D. É um ambiente ideal para trabalhos colaborativos em que várias pessoas podem se reunir ao redor de uma mesa e estudar objetos virtuais 3D. Este ambiente é composto, basicamente, de um projetor de alta resolução, sinais de sincronização, uma mesa na qual será exibida a imagem, óculos estéreo (stereo glasses), espelho, e um computador que gera a imagem (Figura 20).

A cena do ambiente virtual é criada em uma estação gráfica de alto desempenho utilizando uma biblioteca gráfica padrão. A visão dos olhos esquerdo e direito são geradas separadamente usando técnicas gráficas convencionais e enviandas ao projetor a uma taxa de $120 \mathrm{~Hz}$. Os usuários ficam em frente à mesa e usam óculos estéreo que podem habilitar ou desabilitar as lentes esquerda e direita em sincronismo com a projeção da imagem estereoscópica. Neste ambiente é possível simular o volume de dados no topo da mesa ou abaixo. Um exemplo de uma aplicação pode ser de uma mesa de operação virtual, onde o corpo virtual parece flutuar sobre ela. Já na visualização de dados oceânicos, por exemplo, seria mais apropriado posicionar o oceano embaixo da mesa.

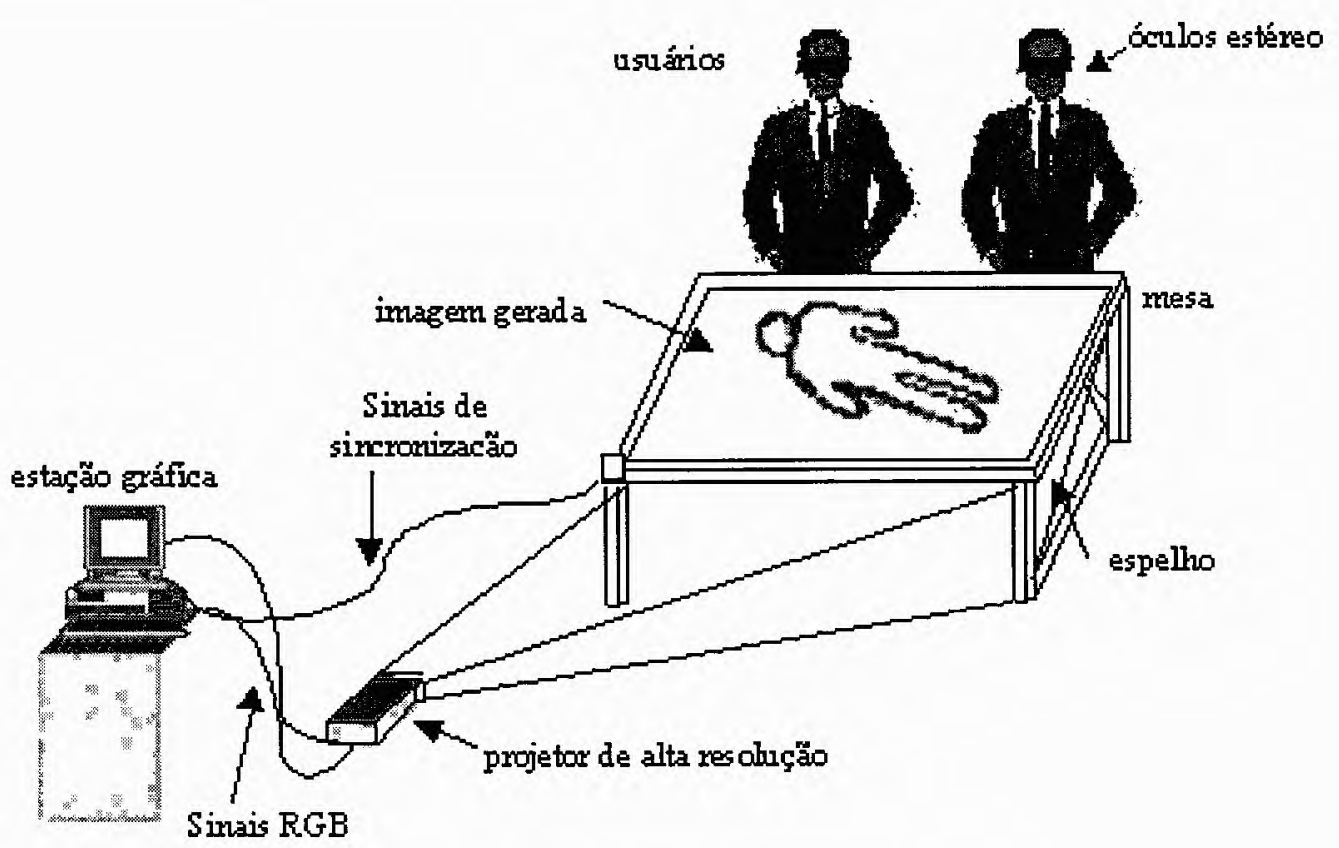

Figura 20: Composição do VW 


\subsubsection{Interação em ambientes virtuais}

Ainda que muitos sistemas de computação gráfica interativos possuam a capacidade de renderizar modelos $3 \mathrm{D}$ de alta qualidade e em tempo real, problemas de interação com o ambiente virtual de forma natural e precisa ainda permanecem. Os ambientes virtuais podem ser apresentados aos usuários por diferentes configurações de sistemas computacionais, variando desde um simples sistema desktop até um sistema de realidade virtual. Sistemas desktop são, normalmente, compostos por monitor e mouse tradicionais; no entanto, pode-se estender tal configuração com a adição de joystick $3 \mathrm{D}$ e, capacidade de exibição esteróscópica com o emprego de óculos especiais (shutter glasses), por exemplo.

Na metáfora desktop, o controle é realizado pela manipulação de ícones, menus, botões, scrollbars e outras widgets. Para exploração de dados virtuais, o princípio de manipulação direta (toque no objeto com uma mão virtual, por exemplo) sugere o suporte às atividades do usuário por meio de sondas (probes), que são ferramentas ou instrumentos de medição que o usuário pode embutir e manipular dentro do espaço de dados. Na exploração de um mundo virtual composto de dados científicos, o usuário deve realizar um número de tarefas, incluindo navegação, localização de objetos no espaço de dados, posicionamento e operação de ferramentas, e manipulação de objetos de aplicações (BAKER \& WICKENS, 1995). Nas próximas sessões são apresentadas algumas destas tarefas.

\subsubsection{Navegação}

A navegação possibilita ao usuário conhecer e explorar o ambiente virtual. O suporte efetivo à navegação tem o objetivo de ajudá-lo a responder a questões como: "Onde estou?", "Onde quero ir?"e "Como chego lá?". A seguir são apresentados alguns conceitos essenciais ao planejamento apropriado da navegação em ambientes virtuais.

A imersão complica a navegação porque o senso geral de localização pode ser perdido. A formação de uma idéia mental de todo o ambiente virtual, chamada de mapa cognitivo, pode ajudar o usuário a se localizar, e é uma ferramenta fundamental para o sucesso da navegação e da interação com o ambiente. Um bom mapa suporta todas as outras tarefas de navegação, tais como procura por um objeto alvo, ou viagem a um ponto alvo. Um mapa cognitivo geral pode ser mais facilmente desenvolvido em conjuntos de dados com pontos de referência (landmarks), que são características dentro da cena que ajudam o usuário a registrar sua caminhada e conhecer sua localização. O landmark deve ser renderizado em um estilo que o torne facilmente visivel, rapidamente reconhecido e facilmente distinguido dos outros landmarks e dos outros objetos do mundo virtual. Como os landmarks podem esconder parte dos dados, é desejável que o usuário tenha controle 
sobre a sua presença e o seu grau de opacidade. Os mapas cognitivos ajudam o usuário a estar ciente de sua posição no contexto geral.

A técnica de navegação denominada vôo (Flying) permite que o usuário eleve sua posição de modo a obter uma "visão de pássaro". Migalhas de pão (breadcrumb marks) são sinais que podem ser deixados na cena pelos usuários para, por exemplo, marcar o território já visitado ou a posição de início. Mapview é uma ferramenta que provê um pequeno mapa que dá uma visão geral do ambiente, com um símbolo de "onde estou"indicando a posição do usuário no espaço. Essa técnica oferece uma visão exocêntrica que complementa a egocêntrica.

Uma série de estudos relata que usuários contam com a visão do mapa geral durante a fase inicial de investigação e passam para uma visão egocêntrica depois que desenvolvem um mapa mental do mundo virtual. A orientação do mapa exocêntrico pode ser significativa. O mapa pode ser apresentado de duas formas: com uma referência canônica, com o norte para cima, ou em track-up, onde a orientação é dada pela posição e direção de observação do próprio usuário. Na navegação para busca de objetos, os usuários empregam seus mapas cognitivos quando procuram por um objeto alvo. O sucesso na busca por um objeto particular no espaço virtual é afetado pelo tipo de controle do usuário e também pelo ponto de observação.

\subsubsection{Manipulação de Objetos}

A seleção e manipulação de um objeto pode ser feita de forma indireta (escolha de uma lista, por exemplo) ou de forma direta (toque de um objeto com uma mão virtual, por exemplo). Dentre as diversas tarefas executadas dentro do ambiente virtual 3D para a manipulação de objetos, são exemplos a seleção, a escala, a translação, a rotação, a criação, a exclusão e a edição.

No projeto de ambientes virtuais para exploração de dados científicos, os objetos fundamentais são aqueles que constituem a representação visual dos dados. Esses dados podem ser complexos e multivariados. O ambiente virtual deve suportar controles do usuário que mapeiam as variáveis em características observáveis na visualização. Isso pode ser feito pelo mapeamento dos objetos de dados em objetos de visualização.

A seleção do objeto a ser segurado pode ser pelo "contato"da mão virtual com o objeto. Alguns mecanismos podem ser empregados para alternar entre fase de grasping (segurar com firmeza) e travel(viagem pelo mundo virtual). O contato direto com o objeto é uma boa alternativa quando este está perto. Em ambientes virtuais extensos, o objeto pode estar além do alcance do usuário. Existem algumas técnicas para facilitar a 
interação em tais cenários, como, por exemplo, fornecer ao usuário "braços extra longos", ou permitir que o dispositivo envie um raio na cena, capaz de apanhar os objetos atingidos ao pressionar de um botão ou com uso de um laser pointer (HAND, 1997).

Quando usuários fazem uso de sondas (probes) como ferramenta de manipulação 3D, eles freqüentemente desejam voltar e ver o que estavam fazendo a partir de um ponto de observação mais global. Em tarefas de travel é aceitável degenerar a imagem a fim de manter uma taxa de quadros adequada. O compromisso com a qualidade da imagem é o que é mais difícil em tarefas de manipulação, uma vez que essas tarefas dependem da apresentação precisa e da resolução espacial alta dos objetos.

\subsubsection{A importância do VRML}

Por meio da combinação de dispositivos de controle reais e virtuais, é possível criar algumas técnicas de interação com 3-DOF/6-DOF (graus de liberdade) de bom desempenho e que ainda podem ser usadas com um mouse ou outro dispositivo 2D. Estas técnicas podem ser úteis quando usadas em aplicações distribuídas (via Internet por exemplo).

VRML é a abreviação de Virtual Reality Modeling Language, ou Linguagem para Modelagem em Realidade Virtual. É uma linguagem independente de plataforma que permite a criação de cenários $3 \mathrm{D}$, por onde se pode passear, visualizar objetos por ângulos diferentes e interagir com eles. A linguagem foi concebida para descrever simulações interativas de múltiplos.participantes, em mundos virtuais disponibilizados na Internet e ligados com a WWW (World Wide Web), mas a sua primeira versão da linguagem não possibilitou muita interação do usuário com o mundo virtual. Nas versões futuras foram acrescentadas características como animação, movimentos de corpos, som e interação entre múltiplos usuários em tempo real.

Apresentada pela primeira vez em 1994 na Conferência Mundial sobre World Wide $W e b$, realizada em Genebra na Suiça, a linguagem tem como objetivo dar o suporte necessário para o desenvolvimento de mundos virtuais tridimensionais multi-usuários na Internet, sem precisar de redes de alta velocidade. O código VRML é um subconjunto do formato de arquivo ASCII do Open Inventor, da Silicon Graphics, com características adicionais para navegação na Web. Esta característica é equivalente às âncoras do HTML, ou seja, pode-se criar âncoras em um ambiente vịtual que levem a outros ambientes virtuais.

A linguagem, na sua versão 1.0 , trabalha com geometria $3 \mathrm{D}$, permitindo a elaboração de objetos baseados em polígonos, possui alguns objetos pré-definidos como cubo, cone, cilindro e esfera, suporta transformações como rotação, translação e escala, permite a apli- 
cação de texturas, luz, sombreamento, etc. Outra característica importante da linguagem é o Nível de Detalhe (LOD, level of detail), que permite o ajustamento da complexidade dos objetos, dependendo da distância do observador. Maiores informações sobre a linguagem podem ser encontradas em (SMITH, 2001; NADEAU et al., 1998).

\subsection{Considerações Finais}

Neste capítulo foram apresentadas as técnicas de visualização mais conhecidas: extração de superfícies e rendering volumétrico direto para dados escalares; glyphs, streamlines, streaklines, streamribbons e mapeamento de texturas para dados vetoriais. Algumas destas técnicas, como extração de superfícies, rendering volumétrico direto, glyphs, streamlines e mapeamento de textura, foram utilizadas no desenvolvimento do projeto. Também foi apresentada uma breve introdução ao VTK, software no qual o projeto foi desenvolvido. Foi apresentada uma breve definição sobre sonificação e o seu uso em sistemas de visualização, e foi descrito o software SVol, com ênfase no processo da sonda sonora, utilizado deste projeto.

Foram apresentados alguns tópicos sobre interação em visualização, discutindo-se duas abordagens para tratar o problema de manipulação no espaço 3D: por software e por hardware. Também foram abordadas algumas técnicas típicas de interação em visualização. Por alguns motivos (tais como popularidade e baixo custo do dispositivo mouse) esta seção enfatizou a solução por software, deixando a abordagem por hardware como complemento para a compreensão do problema.

Foi apresentada uma introdução à Realidade Virtual, mostrando as suas principais características, modos de interação em RV, os dispositivos mais utilizados e uma introdução a linguagem VRML. No contexto de interação, a RV é o que há de mais recente e inovador, porém existem restrições quanto à utilização dessa nova ferramenta devido ao seu custo inicial, que ainda é inviável para algumas instituições. Apesar disto, podemos aumentar o nível de interação com os dados utilizando programação em VRML. No Capítulo 3 é descrito o ambiente desenvolvido e, no Capítulo 4 são apresentados alguns exemplos de sua utilização. 


\section{Capítulo 3}

\section{Ambiente de Visualização}

\subsection{Considerações Iniciais}

O grupo de Visão Cibernética do IFSC-USP tem trabalhado na análise da forma de neurônios e estruturas neurais reais e artificiais. Particularmente, Coelho e Costa (COELHO \& COSTA, 1994) trabalharam na síntese de estruturas neurais por gramáticas estocásticas que operam sobre uma série de regras de produção bem definidas derivadas a partir de caracterizações estatísticas e fractais de cada tipo de neurônio. Como parte desse trabalho, foram gerados modelos artificiais realísticos de estruturas neurais com o objetivo de simular sistemas naturais, bem como investigar novas arquiteturas e paradigmas em redes neurais artificiais.

Uma das saídas geradas por tais gramáticas, com o objetivo específico de gerar uma representação gráfica para propósitos de visualização, consiste em uma descrição do neurônio na forma de uma poligonal bi ou tridimensional definida em um espaço discreto. Nesse espaço discreto, valores 0 ou 1 indicam a presença ou ausência do neurônio, respectivamente. Esses dados foram processados com a aplicação de uma Gaussiana, com o objetivo de estudar as interações entre os diferentes componentes dos neurônios. A função Gaussiana "expande"a fronteira do neurônio num conjunto de valores em uma faixa de variação específica. O resultado é um conjunto de valores escalares entre 0 e 1 posicionados no espaço discreto. O campo magnético na região neuronal também pode ser simulado, o que resulta em um conjunto de dados vetoriais, também posicionados em um espaço discreto. 
Técnicas de visualização científica foram aplicadas para gerar representações visuais desses dados capazes de apoiar o trabalho de análise dos resultados (COSTA et al., 2000). Inicialmente, os dados foram processados para gerar uma malha cartesiana estruturada (com geometria e topologia regular) de forma a permitir a aplicação de técnicas convencionais de extração de superfícies e de rendering volumétrico sobre os dados escalares. Para isso, foram inseridos vértices no volume de dados aos quais foi associado o atributo escalar 2.0. Assim, valores entre 0 e 1 presentes na malha representam informação de interesse, e o valor 2.0 corresponde ao "fundo". Várias visualizações foram geradas a partir desses dados, utilizando a biblioteca VTK. O objetivo das visualizações iniciais era exibir as formas dos neurônios depois da aplicação da Gaussiana, o que poderia fornecer subsídios para uma análise quantitativa dos resultados produzidos pela gramática de simulação. Foram utilizados procedimentos do VTK que implementam as técnicas conhecidas como marching cubes (LORENSEN, 1987) e ray casting (ELVINS, 1992), respectivamente, para extração de superfícies e rendering volumétrico.

Neste trabalho de mestrado foi desenvolvido um ambiente integrado para visualização dos dados relativos à simulação das estruturas de neurônios geradas por pesquisadores do Grupo de Visão Cibernética. O ambiente desenvolvido unifica módulos de visualização de dados escalares (por extração de superfícies e por rendering volumétrico direto) e de dados vetoriais (por glyphs e streamlines) com uma interface que permite ao usuário gerar modelos de visualização e interagir diretamente com os mesmos. O ambiente resultante é, na verdade, genérico, e pode ser utilizado para visualizar dados escalares e vetoriais gerados em qualquer outro domínio de aplicação, desde que descritos por malhas regulares.

Neste capítulo são descritas as características do sistema e os recursos implementados. O ambiente possui quatro módulos principais, descritos nas Seções 3.3 a 3.5. A Seção 3.2 apresenta a plataforma de desenvolvimento.

\subsection{Plataforma de Desenvolvimento}

O ambiente escolhido para implementar o sistema foi o $\mathrm{C}++$ Builder 4.0 da Borland, juntamente com a biblioteca VTK, descrita na Seção 2.2.2. O Builder foi escolhido devido a seus recursos para implementação das interfaces com o usuário. Utilizando-se somente programação em linguagem $\mathrm{C}++$ o programador fica responsável por grande parte da codificação da interface, e a construção de uma boa interface com o usuário poderia demandar bastante tempo. Outra facilidade desse ambiente é ser compatível com o Microsoft Visual C++ e suportar a maioria dos códigos e cabeçalhos desenvolvidos no Visual, facilitando a conversão de programas previamente desenvolvidos no Visual para' o 
Builder. Esta facilidade foi útil no início do projeto, pois foram utilizados como ponto de partida alguns programas desenvolvidos no Visual C++ $5.0^{\circ}$ e VTK 2.3, em um projeto em nível de iniciação científica (FAPESP, Proc. 99/06444-9), os quais foram convertidos para o C++ Builder 4 e VTK 3.1.

Com base no estudo bibliográfico efetuado e na interação com potenciais usuários, foram definidas as principais funcionalidades necessárias para atender às necessidades da aplicação. Optou-se pelo desenvolvimento de um protótipo evolutivo ao qual as funcionalidades seriam acrescentadas gradualmente. Os conjuntos de dados manipulados são do tipo vtkStructuredPoints, que define uma malha de dados com topologia e geometria regulares. Neste tipo de dado tanto os pontos como as células são representadas implicitamente pela especificação das dimensões do conjunto de dados (i.e., o número de pontos em cada direção), do espaçamento entre os pontos de dados e da origem. As dimensões definem a topologia do conjunto de dados, enquanto a origem e o espaçamento definem a geometria.

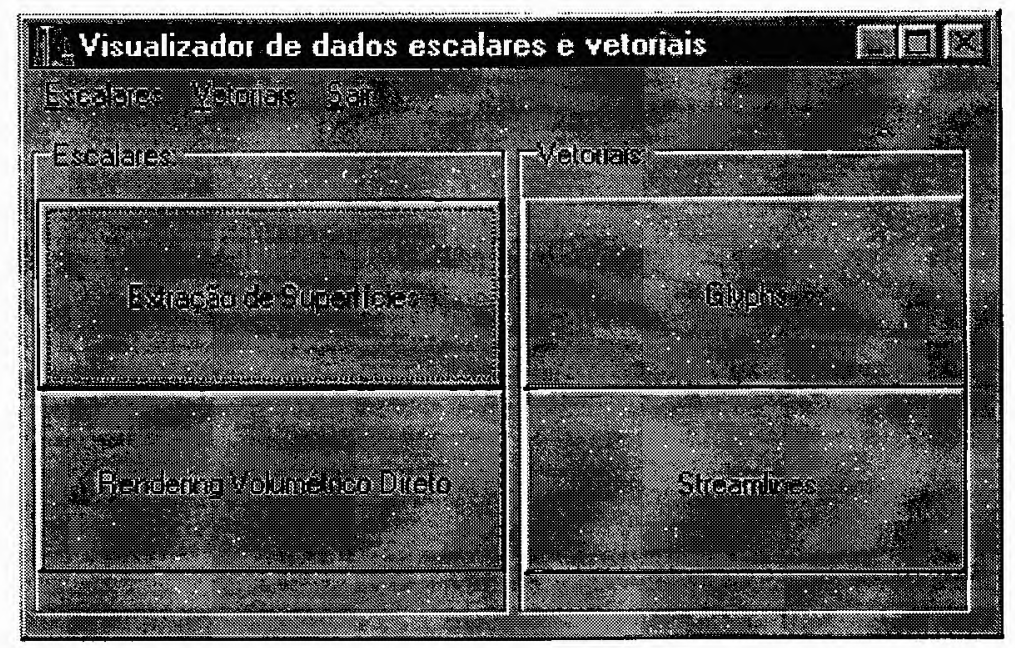

Figura 21: Interface Principal

Os quatro módulos principais do ambiente são acessados a partir da janela principal (Figura 21): Extração de Superfícies, Rendering Volumétrico Direto, Visualização Vetorial (por Glyphs e por Streamlines).

Em relação a implementação, foram criadas as sete classes: UInteração.cpp (1), URecorte.cpp (2), USound.cpp (3), UGlyphs.cpp (4), UStreamline.cpp (5), UIsoSound.cpp (6), UDVRSound.cpp (7) e incorporadas as classes SV_Sound.cpp, SV_SoundProbe.cpp, SV.Interactor.cpp, SVInteractor_Probe.cpp. As classes (2), (3), (4) e (5) herdam da classe (1) toda a parte de interação como rotação, zoom e visualização VRML. A classe (3), responsável pela parte sonora, passa por herança todas as funções sonoras para as classes (6) e (7). A Figura 22 ilustra esta hierarquia de classes. 


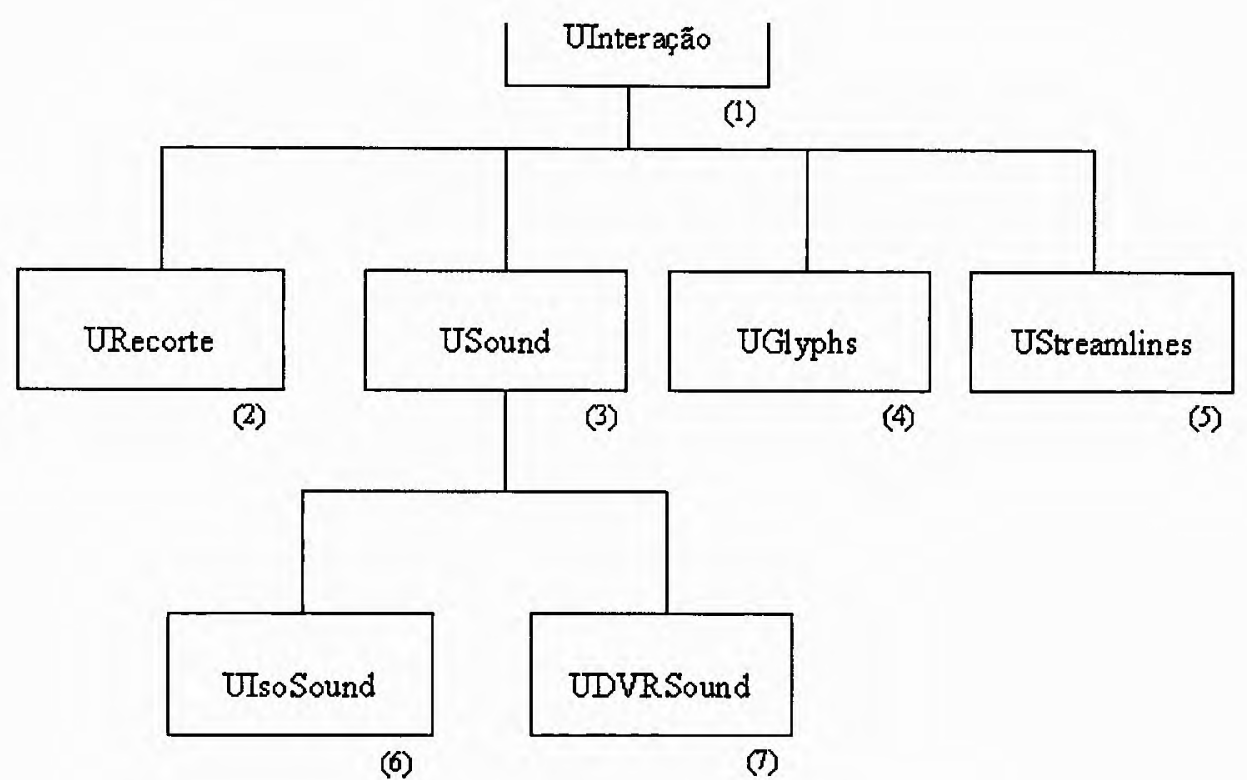

Figura 22: Hierarquia de classes

\subsection{Módulo de Extração de Superfícies}

A função básica do módulo de extração de superfícies consiste em gerar isosuperfícies de valor escalar constante a partir do volume de dados escalares. Nesse módulo utilizou-se a classe vtkContourFilter do VTK para implementar o processo de extração de isosuperfícies de interesse. vtkContourFilter é um filtro que recebe como entrada qualquer tipo de conjunto de dados e gera como saída isosuperfícies, ou isolinhas. A forma exata dos dados de saída depende da dimensão dos dados de entrada, por exemplo, dados que consistem de células $3 \mathrm{D}$ gerarão isosuperfícies, dados de células $2 \mathrm{D}$ gerarão isolinhas, e dados de células $1 \mathrm{D}$ ou $0 \mathrm{D}$, isopontos. Neste filtro, os contornos são especificados um a um pelo método SetValue.

O VTK oferece vários objetos especializados na geração de contornos para tipos particulares de conjuntos de dados, como vtkMarchingCubes, vtkMarchingSquares, vtkDividingCubes, e outros. Com a utilização do vtkContourFilter não há a necessidade da instanciação destes objetos diretamente, pois o filtro seleciona automaticamente a classe que implementa o melhor algoritmo para o conjunto de dados em uso.

A interface inicial do módulo (Figura 23) oferece recursos para a especificação das isosuperfícies a serem geradas e a alteração de parâmetros de visualização. O usuário deve especificar o nome do arquivo de dados utilizado para gerar a visualização (Figura 23 (1)), o qual deve estar no formato do vtkStructuredPoints (descrito na Seção 2.2.2), e em seguida os valores das isosuperfícies de interesse e os parâmetros RGBA para o 


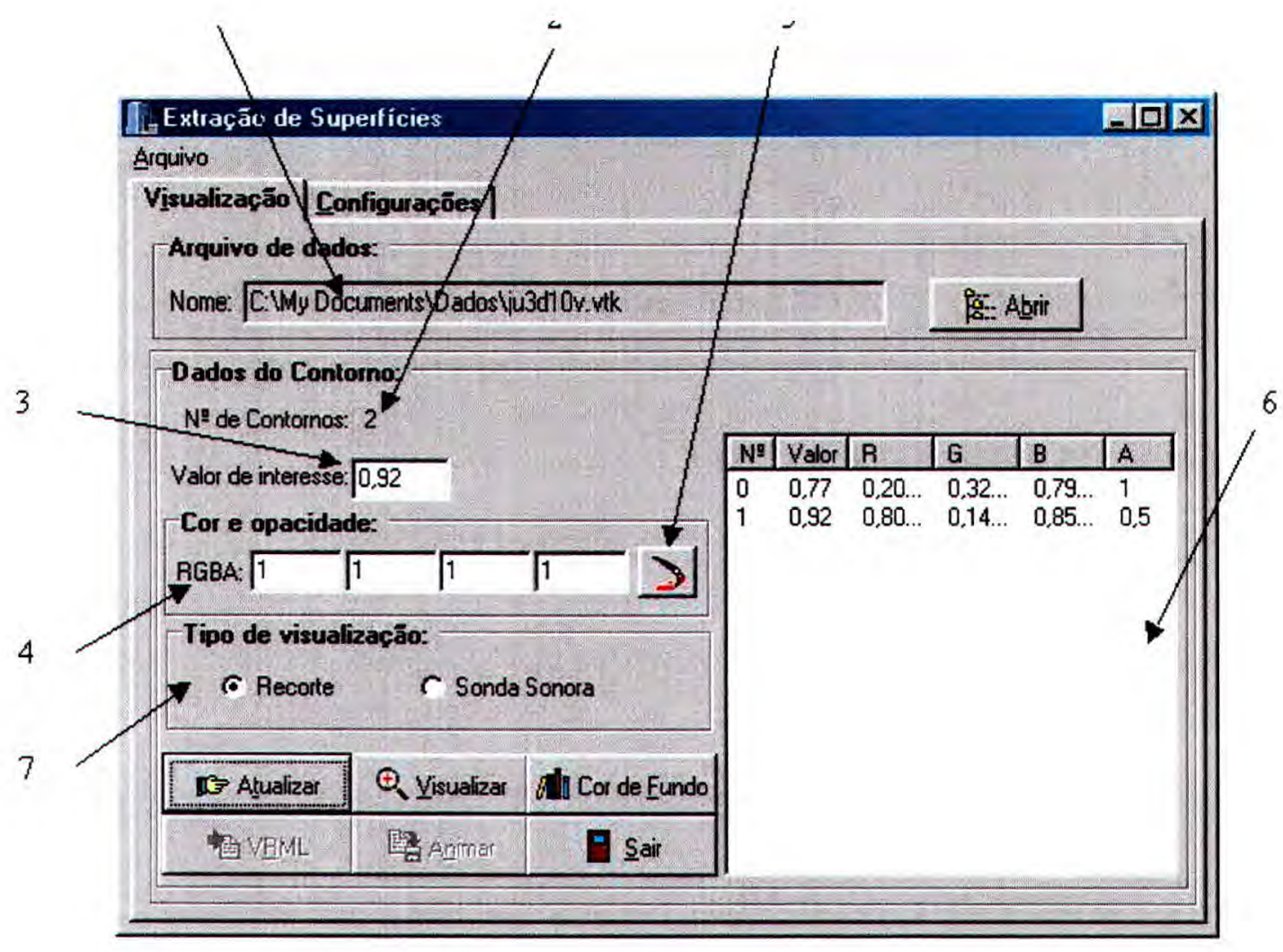

Figura 23: Interface do módulo de Extração de Superfícies

mapeamento de cores às superfícies.

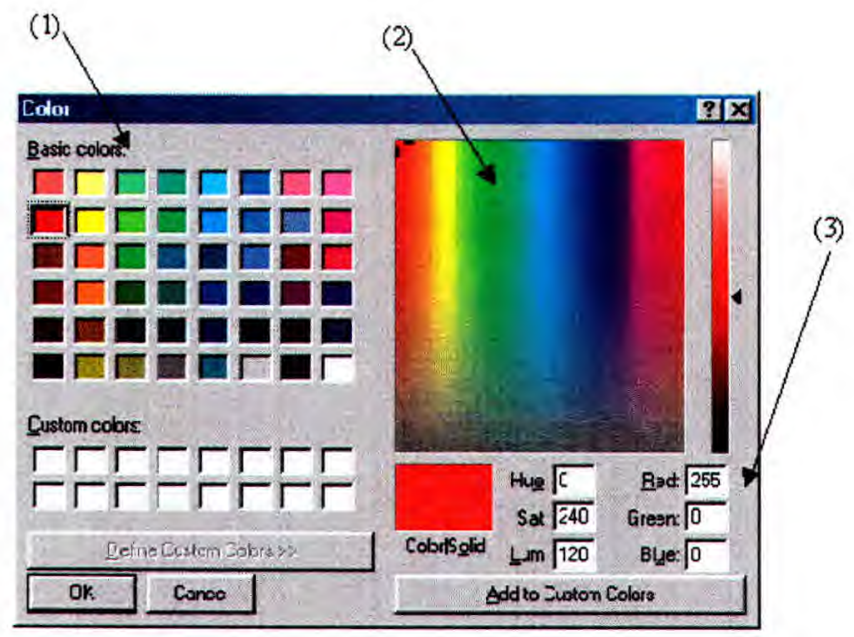

Figura 24: Palheta de cores

O usuário insere cada valor de interesse na widget rotulada "Valor de interesse" sucessivamente (Figura 23 (3)), e especifica a cor (valores R, G, B, A) na widget correspondente (Figura 23(4)). Os valores fornecidos vão sendo exibidos na caixa a direita (Figura 23 
(6)). O usuário pode, se desejar, remover a entrada correspondente a uma isosuperfície dessa caixa clicando sobre o identificador da mesma e pressionando a tecla Delete.

Os parâmetros RGBA são valores reais compreendidos no intervalo de 0 a 1 , e podem ser especificados diretamente nas caixas de texto associadas, ou pode-se escolher a cor do modelo acionando o botão posicionado ao lado das caixas de texto(Figura 23 (5)). Se esse botão é acionado, é exibida a janela mostrada na Figura 24. Nesta janela o usuário pode escolher a cor desejada clicando em uma das cores básicas (Figura 24 (1)), selecionando uma cor na palheta gradativa de cores (Figura 24(2)) ou especificando diretamente os parâmetros RGB (Figura 24 (3)).

O usuário pode escolher gerar a visualização no modo Normal, que habilita a opção de realizar cortes sobre os modelos de superfície, ou no modo Sonoro, que permite a visualização dos dados com sonorização. Ambos os modos são discutidos mais adiante nessa Seção.

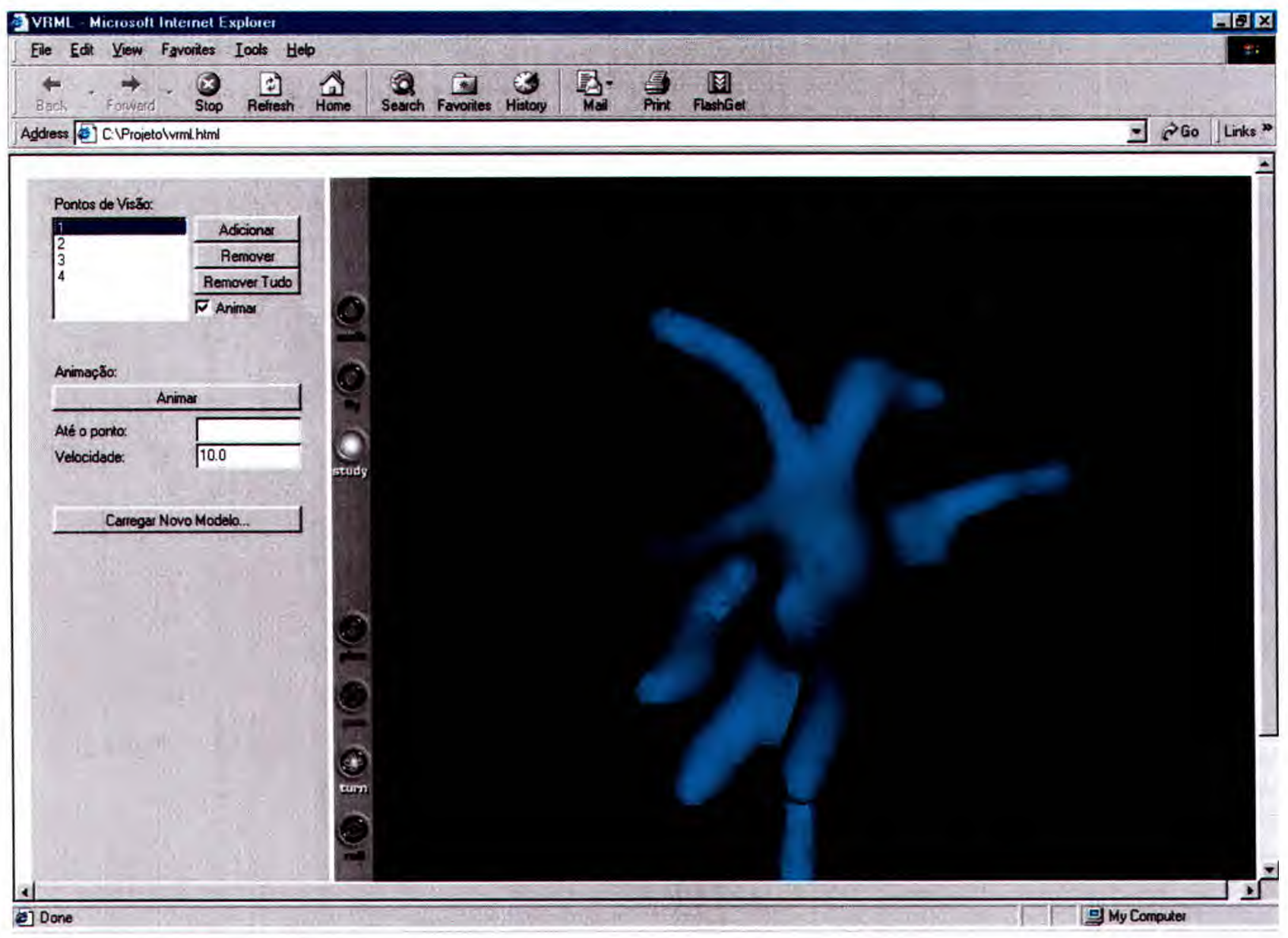

Figura 25: Interface da animação em VRML

O módulo permite gerar um arquivo VRML dos modelos resultantes. A criação do 
arquivo VRML é implementada pela classe vtkVRMLExporter e a visualização se dá pelo browser default. Assim que o arquivo é criado e salvo, o browser é acionado e abre o arquivo ".wrl" para exploração ou navegação pelo usuário (Figura 25). Existe também a opção "Animar", que permite gerar animações do modelo VRML (Opção implementada a partir do processo de iniciação científica "Interação em Odontologia utilizando técnicas 3D - Proc. FAPESP 99/03873-6). O arquivo utilizado para gerar a animação é uma modificação do arquivo original criado pelo VTK. Ao escolher a opção " Animar", o arquivo original é criado e passa por um procedimento que inclui informações adicionais, como sensores VRML e orientação de interpolação. Após as modificações uma caixa de diálogo aparecerá para que o usuário salve o arquivo final. Após a criação do arquivo do arquivo de leitura, a interface da animação, implementada em Java, é acionada e é necessário que o usuário abra o arquivo que foi posteriormente criado para que possa interagir com o mundo virtual definindo interativamente uma seqüência de pontos de observação. $O$ usuário pode posicionar o modelo de interesse como desejado, e adicionar cada posicionamento na lista de "Pontos de visão". Em seguida, pode navegar pelos diferentes posicionamentos definidos clicando nos diferentes "Pontos de visão", ou alternativamente, pode visualizar uma trajetória do posicionamento atual até um ponto de observação especificado na caixa de texto "Até o ponto" (ver Figura 25). A animação é exibida após o acionamento do botão "Animar", e mostra um percurso do observador pela cena VRML, ao longo da trajetória definida (i.e., a seqüência de "Pontos de visão"). O usuário também pode fixar a velocidade com que a animação será exibida. No caso, é exibido inicialmente o valor 10.0, o qual é aumentado ou reduzido conforme a conveniência do usuário (qualquer valor maior ou igual a 1.0 é válido).

No modo de visualização Normal (sem sonorização) foi incluída uma função que permite ao usuário interagir diretamente com o modelo de uma isosuperfície para extrair regiões de interesse da mesma.

Para a extração de regiões de interesse o usuário deve, primeiramente, escolher uma isosuperfície entre as múltiplas superfícies sendo exibidas. Um identificador numérico para cada superfície, assim como o seu valor, ficam disponíveis no formulário de entrada (Figura 23 (6)) para que o usuário possa consultá-los quando necessário. O usuário seleciona a isosuperfície de interesse no grid clicando sobre o seu identificador, e a mesma será destacada em relação às demais, que passam a ser mostradas como "nuvens de pontos".

Após a seleção da isosuperfície o usuário pode eliminar as demais (com um clique duplo sobre o número da isosuperfície selecionada) e trabalhar somente com a superfície escolhida. O processo de demarcação de regiões de interesse é realizado percorrendo a superfície com o mouse a procura dos pontos que definem essa região. Este processo 
pode ser realizado tanto no modo Wireframe como no modo Tonalizado (Shaded), sendo que o usuário pode alternar entre estes dois modos utilizando as teclas "w"e "s", respectivamente. Para facilitar o processo de identificação de um ponto, o ponto que está correntemente sob o ponteiro do mouse, bem como todas as arestas do modelo que incidem nesse ponto, são destacados com uma cor diferente. A cor a ser utilizada deve ser espeficada no formulário "Configurações", exibido na Figura 26. Se o ponto destacado é um dos pontos que delimitam a região de interesse, o usuário deve clicar sobre o mesmo e continuar a procura dos demais pontos que definem a região, sendo que só é permitida a escolha de pontos vizinhos ao ponto previamente escolhido (i.e., conectados ao mesmo por uma aresta em comum). Todos os pontos escolhidos, assim como o caminho formado por eles, são realçados, até que a região seja demarcada e fechada.

Os modelos de isosuperfícies extraídos do volume de dados escalares são descritos por malhas poligonais que, no VTK, são representados por objetos da classe vtkPolyData. A extração de regiões de interesse requer a identificação das faces poligonais que pertencem a região a ser extraída, e sua posterior remoção do modelo. O processo de seleção dos pontos de interesse foi implementado utilizando a classe vtkPointPicker do VTK. Essa classe permite a seleção de pontos de dados e retorna identificadores e coordenadas dos pontos. Ele opera disparando um raio da posição da câmera em direção ao ponto a ser selecionado e projeta os pontos encontrados de acordo com a tolerância aplicada ao raio. O ponto que for projetado mais próximo da posição da câmera é selecionado e seu identificador e sua posição retornadas.

O processo de demarcação da região de interesse só é considerado completo após o fechamento da região, o que ocorre após a seleção do primeiro ponto novamente. Após este processo, a região delimitada pode ser separada da superfície e, posteriormente, extraída. A separação das regiões é disparada pela tecla "q" ou "e", após a região ter sido demarcada.

O processo de separação é realizado da seguinte maneira: o usuário seleciona um ponto de interesse, o qual é um vértice de uma célula qualquer pertencente ao modelo (i.e., uma face poligonal). O algoritmo de separação verifica quais são as células vizinhas a que foi selecionada. As células vizinhas à célula corrente são identificadas (ver Figura 40 na Seção 4.2.1) verificando-se quais células compartilham alguma aresta com ela. As arestas compartilhadas são realçadas para o usuário, que pode então selecionar um novo vértice. Com isso, uma aresta pertencente à região a ser extraída é identificada, e o processo se repete recursivamente até que toda a região a ser extraída esteja demarcada. $O$ resultado é que o modelo original é separado em duas componentes conexas. Após o processo de separação o usuário pode selecionar uma das componentes conexas de interesse utilizando 
a tecla "o", que no VTK alterna o modo de interação para o modo objeto. No modo objeto os eventos do mouse afetam o ator que está sob o ponteiro do mouse. Dessa forma, o usuário pode realizar operações como translação, rotação, etc., sobre cada objeto (i.e., cada componente da superfície) independentemente. No modo câmera, que é o default, os eventos do mouse afetam a posição da câmera e do ponto focal, e portanto todos os objetos da cena. Para retornar ao modo câmera, o usuário deve digitar a tecla "c". Um exemplo do processo de recorte é apresentado no Capítulo 4.

Esse modo de visualização permite alterar parâmetros como a cor e o tamanho do cursor para o recorte, a cor e espessura do contorno que delimita a região a ser recortada e a cor da região a ser recortada, utilizando as opções a esquerda na janela de Configuração (ilustrada na Figura 26).

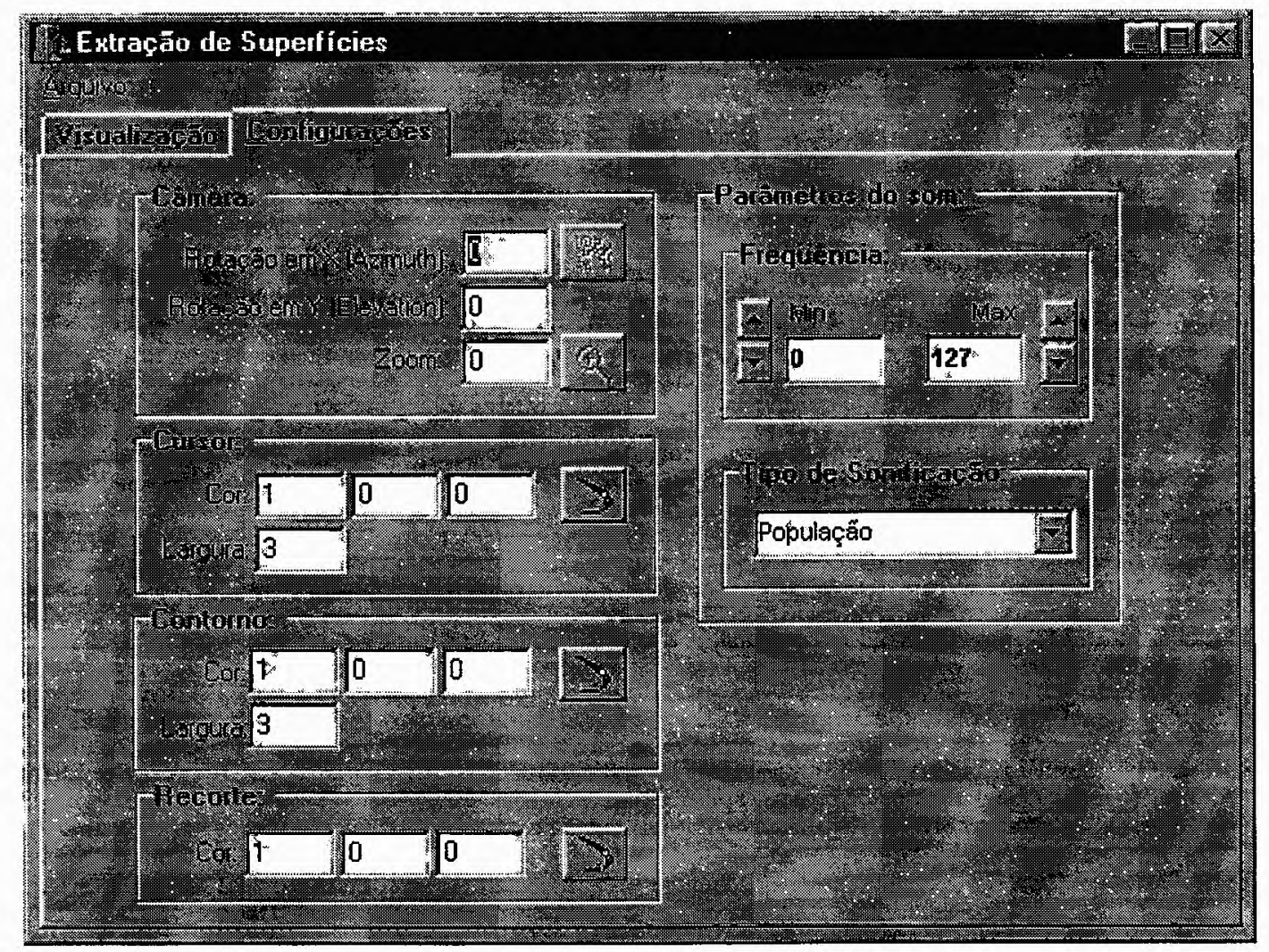

Figura 26: Interface de Configurações do módulo de Extração de Superfícies

No modo de visualização Sonoro, uma "sonda virtual" é inserida no volume que contém a superfície com o objetivo de colher informações sobre os dados e apresentá-las na forma de som. O processo de sonifiçação utiliza resultados anteriores obtidos em trabalhos de mestrado (SALVADOR, 1998; FREITAS, 2001). A principal contribuição do som em sistemas de visualização é no apoio à representação dos dados. Ele pode ser usado para prover redundância aos dados apresentados ou adicionar algumas dimensões ao processo visual. Uma das grandes vantagens do som está no fato de que a audição possui 
propriedades diferentes da visão, podendo, assim, ser útil na identificação de padrões e estruturas não observados na imagem. No processo de sonificação uma "caixa"de tamanho variável, que representa a sonda sonora, é inserida no volume de dados, e as informações coletadas pela sonda são apresentadas através de som.

As sonificações implementadas para a sonda sonora são densidade e população da sonda. A densidade local representa a ocupação da sonda sonora pela superfície, isto é, quanta informação de interesse está contida dentro da sonda. Esse valor é calculado identificando qual o conteúdo existente na sonda em relação ao conteúdo total que a sonda pode suportar. O valor obtido é, então, sonificado, por meio de um mapeamento para freqüência, sendo que o usuário define o intervalo de mapeamento. A outra função corresponde à população da sonda. Esta função está relacionada com a idéia de conteúdo dentro da sonda, ou seja, encontra-se a proporção entre o conteúdo da sonda sonora e o conteúdo do volume total sob análise e sonifica-se esse valor encontrado. Durante esse processo o usuário pode mover a sonda pelo volume de dados e mudar o tamanho da sonda.

Nesse modo de visualização é possível alterar parâmetros como o intervalo de freqüência que será mapeado na utilização da sonda sonora, o tipo de sonificação desejada (densidade local ou população), como indicado nas opções a direita na janela de Configuração (ilustrada na Figura 26).

\subsection{Módulo de Rendering Volumétrico Direto}

O processo de rendering volumétrico direto não cria estruturas geométricas intermediárias, como o de extração de superfícies. Essa solução permite ao usuário enxergar "dentro" (ou "através") do volume de dados, possibilitando a visualização de mais informações do que as técnicas de rendering de superfícies. Mas, para que isto ocorra é necessário definir funções de cor e opacidade (transparência) adequadas para os diferentes "materiais" contidos no volume de dados (como discutido na Seção 2.2.1). A desvantagem do rendering volumétrico direto tradicional é que os algoritmos, implementados em software, são computacionalmente caros e não viabilizam interação em tempo real com os modelos resultantes. Uma alternativa consiste em implementar rendering volumétrico direto por textura (SOARES, 2000). Nesse caso, os recursos para texturização por hardware, se disponível, são explorados no processo de rendering, que pode ser significativamente mais rápido do que o implementado por algoritmos tradicionais, inclusive habilitando interação em tempo real. 
No ambiente desenvolvido, o módulo de rendering volumétrico direto implementa duas abordagens: a técnica de disparo de raios (ray casting (Seção 2.2.1) - utilizando as classes vtkVolumeRayCastCompositeFunction e vtkVolumeRayCastMapper do VTK, e o rendering por mapeamento de textura 2D (classe vtkVolumeTextureMapper2D).

No rendering por mapeamento de textura o volume pode ser apresentado na forma de polígonos e projetados pelo hardware gráfico. Neste tipo de mapeamento são geradas fatias do volume em relação um dos seus eixos (XYZ), sendo que o eixo escolhido será o que estiver mais próximo da direção de observação. Quando há alteração na direção de observação, a distância da amostragem entre as fatias também serão alteradas e em algum momento ocorerá a mudança do conjunto de fatias para um novo eixo o que poderá causar artefatos temporais. Estes artefatos, geralmente, aparecem com maior frequiência em pequenos volumes. No caso do mapeamento de textura $3 \mathrm{D}$, os polígonos podem ser gerados de maneira a ficarem sempre perpendicular a direção de observação, diminuindo assim os artefatos.

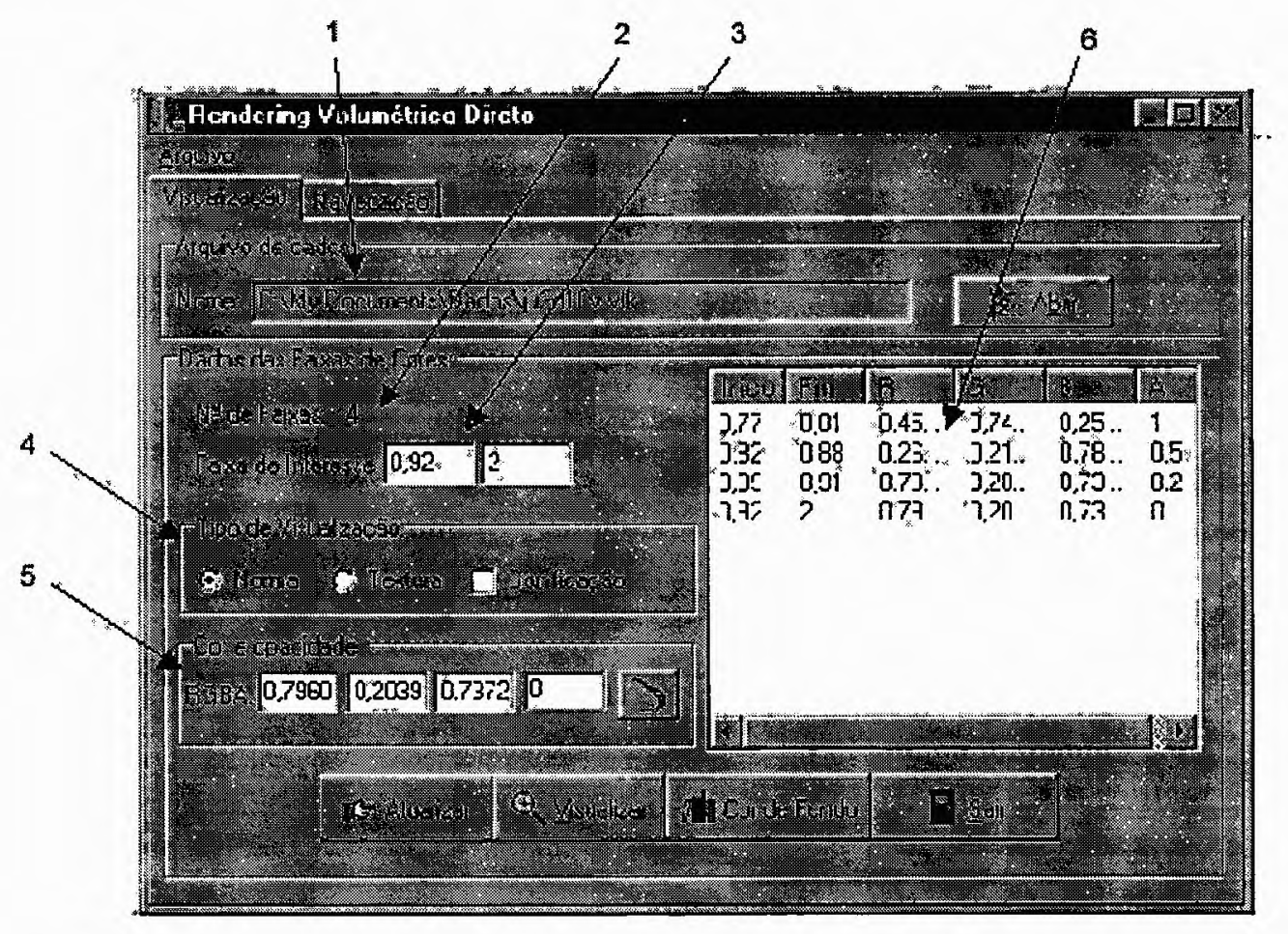

Figura 27: Interface do Módulo de rendering Volumétrico Direto

Se for utilizada uma placa gráfica que suporta texturização para acelerar o processo de rendering, o rendering volumétrico por mapeamento de textura pode ser significativamente mais rápido do que o ray casting, permitindo interação em tempo real.

A interface desse módulo permite ao usuário especificar o nome do arquivo de dados 
a ser utilizado para gerar a visualização (Figura 27(1)), as faixas de valores de interesse (Figura 27 (3)), definir funções de cor e opacidade para faixas de valores de interesse (Figura 27 (5)), a cor de fundo da visualização e o modo de visualização(Figura 27 (4)), que pode ser Normal ou Textura, com ou sem Sonificação. O modo Normal exibe a visualização por ray casting, o modo Textura exibe a visualização usando mapeamento de textura 2D e o modo Sonoro exibe a visualização por ray casting ou por textura com recursos de sonorização que funcionam de maneira análoga aos do módulo de extração de superfícies descrito nas seções 2.3 e 3.3 .

O processo de visualização é gerado pelo pressionamento do botão "Visualizar" após a inserção dos dados relativos as faixas de valores de interesse (Figura 27 (3)), cor e opacidade (Figura $27(5)$ ), seleção do tipo de visualização (Figura 27 (4)) e atualização dos dados na caixa a direita do formulário (botão "Atualizar"). A escolha das cores e opacidade para cada faixa de interesse funciona de maneira análoga ao módulo de superfícies, ou seja, o usuário pode optar por inserir os dados manualmente nas caixas de texto ou pressionar o botão a direita das mesmas (Figura 27 (5)).

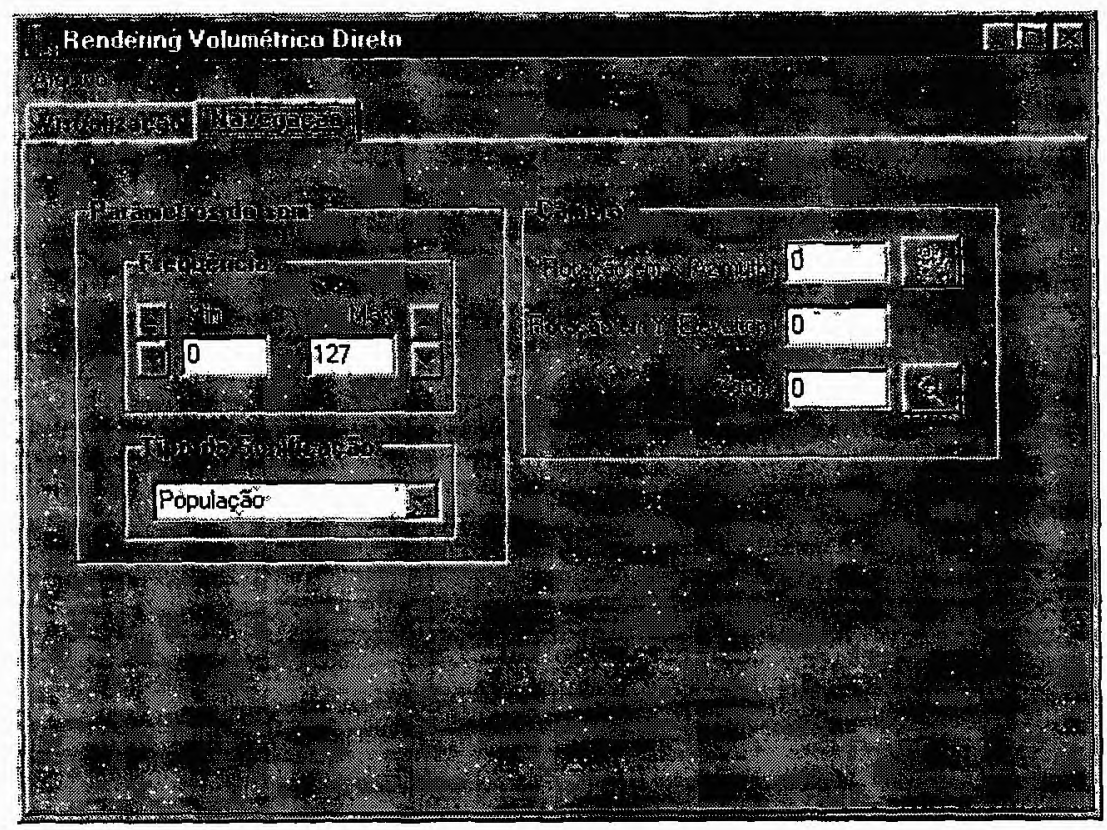

Figura 28:- Interface de Configurações do Módulo de rendering Volumétrico Direto

\subsection{Módulo de Visualização Vetorial}

Este módulo disponibiliza duas técnicas distintas para visualização de dados vetoriais. Uma delas, muito utilizada nesse contexto, consiste no uso de símbolos, ou glyphs. Esses glyphs podem ser simples ou complexos, desde simples segmentos de reta ou cones orienta- 
dos a glyphs multi-variados como as faces de Chernoff ${ }^{1}$ (CHERNOFF, 1973). O módulo permite a visualização de vetores por dois tipos de glyphs: segmentos. de reta e cones orientados. No.primeiro caso é utilizada a classe (vtkHedgeHog), que cria segméntos de reta que representam cada vetor, sendo que o segmento começa no ponto ao qual ò vetor está associado (como descrito na Seção 2.2.1), e tem direção e comprimento controlados pela direção e magnitude do vetor que representa. No segundo caso, são criados cones orientados pelo valor vetorial do dado, utilizando a classe vtkGlyph3D.

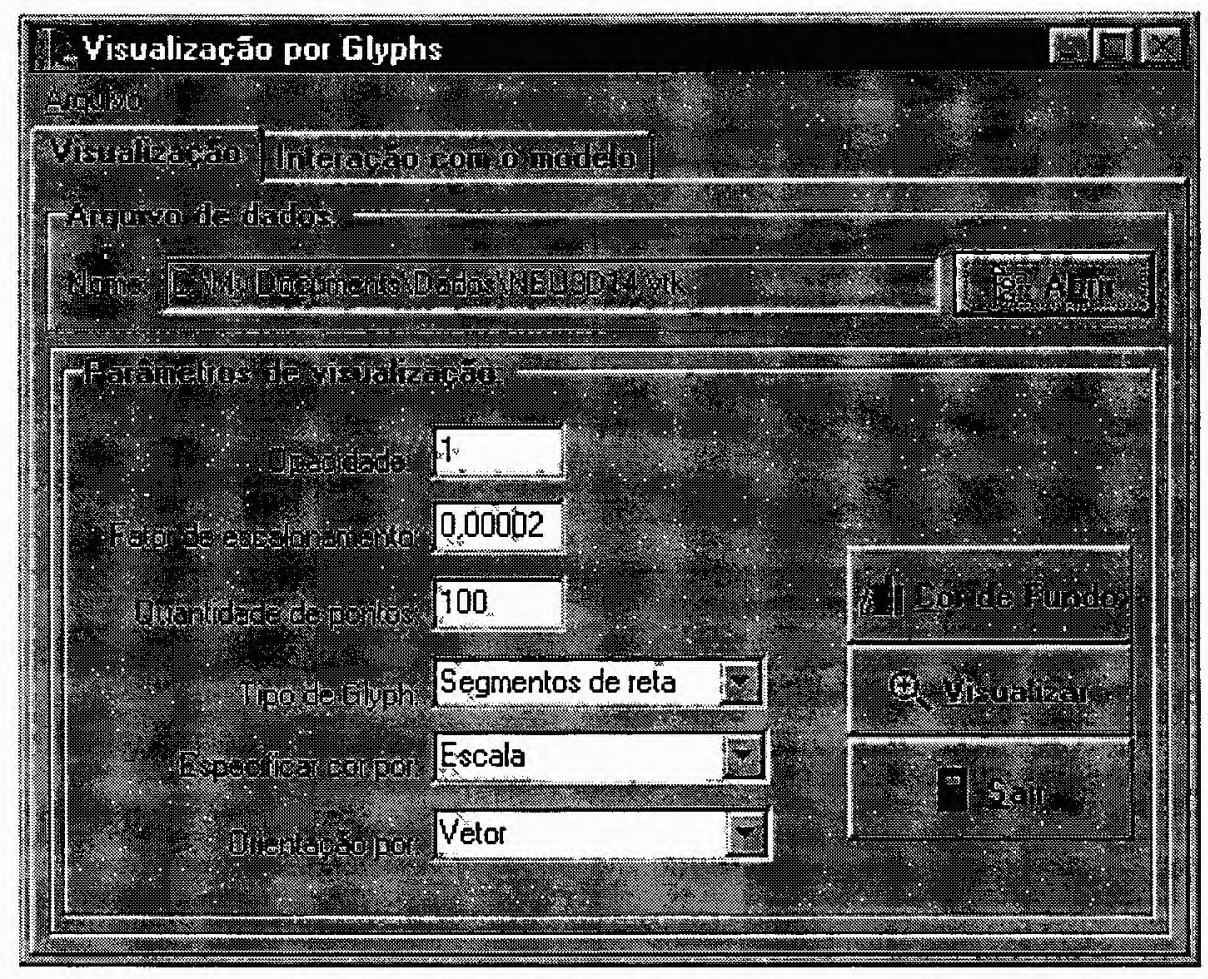

Figura 29: Interface do Módulo Vetorial por Glyphs

A interface de visualização por glyphs, exibida na Figura 29 permite ao usuário definir o arquivo de dados a ser visualizado, o grau de opacidade dos glyphs, o fator de escala para os glyphs (variável de acordo com o arquivo de dados), o número máximo de glyphs a serem exibidos na visualização (sendo que a amostragem é realizada na ordem que os dados estão dispostos no arquivo, i. e., se o número máximo de glyphs é 200, somente os primeiros 200 valores do arquivo serão visualizados (Figura 30)), o tipo de glyph (segmentos de reta ou cones), a sua direção de orientação (pelo vetor ou pela normal) e a indicação se os glyphs serão coloridos pelo fator de escalonamento ou pelo vetor. As duas últimas opções só são possíveis para a visualização por cones orientados.

A visualização por streamlines é a outra alternativa implementada para a visualização

\footnotetext{
${ }^{1}$ Representação simbólica de uma face humana na qual os atributos visuais de uma face estilizada são controladas por valores de dados
} 


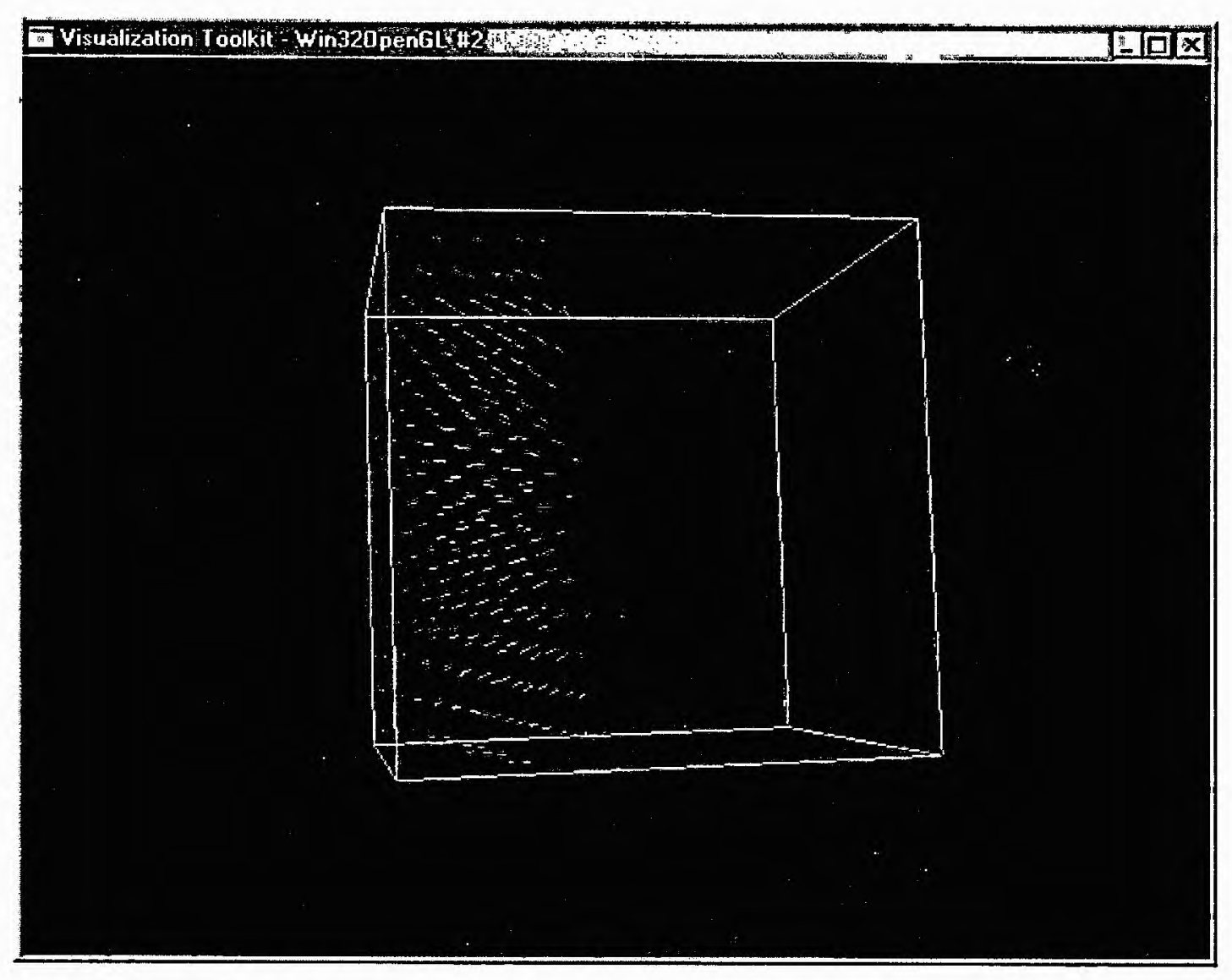

Figura 30: Visualização por Glyphs do campo vetorial de um neurônio

de dados vetoriais. Como discutido na Seção 2.2.1, uma streamline é uma curva tangente ao campo vetorial em todos os pontos, que pode ser construída a partir da integração de um ponto inicial pelo campo vetorial. A implementação utiliza a classe vtkStreamLine do VTK. A direção da integração pode ser controlada com os métodos SetIntegrationDirectionToForward (define para onde a curva vai), SetIntegrationDirectionToBackward (define de onde a curva vem) ou SetIntegrationDirectionToIntegrateBothDirection (em ambas as direções) que na interface podem ser selecionados por meio da widget "Direção de integração", onde tem-se as opções Progressiva, Regressiva e Ambas as direções. Também é possível, se necessário, mostrar vorticidades do campo vetorial acionando a opção "Sim" da Widget "Gerar Vórtices". A Figura 31 mostra a interface deste módulo.

Para interação com os modelos, além das técnicas implementadas no próprio VTK (rotação, translação, zoom utilizando o mouse) foi incluída, em ambos os modos (glyphs e streamlines)a opção de gerar um arquivo VRML do modelo resultante, de forma análoga ao módulo de extração de superfícies. A criação e a visualização do arquivo VRML são ativadas com o botão "VRML"que, ao ser pressionado, chama o browser default e abre o arquivo ".wrl" para exploração ou navegação (Figura 33). Também é possível definir 


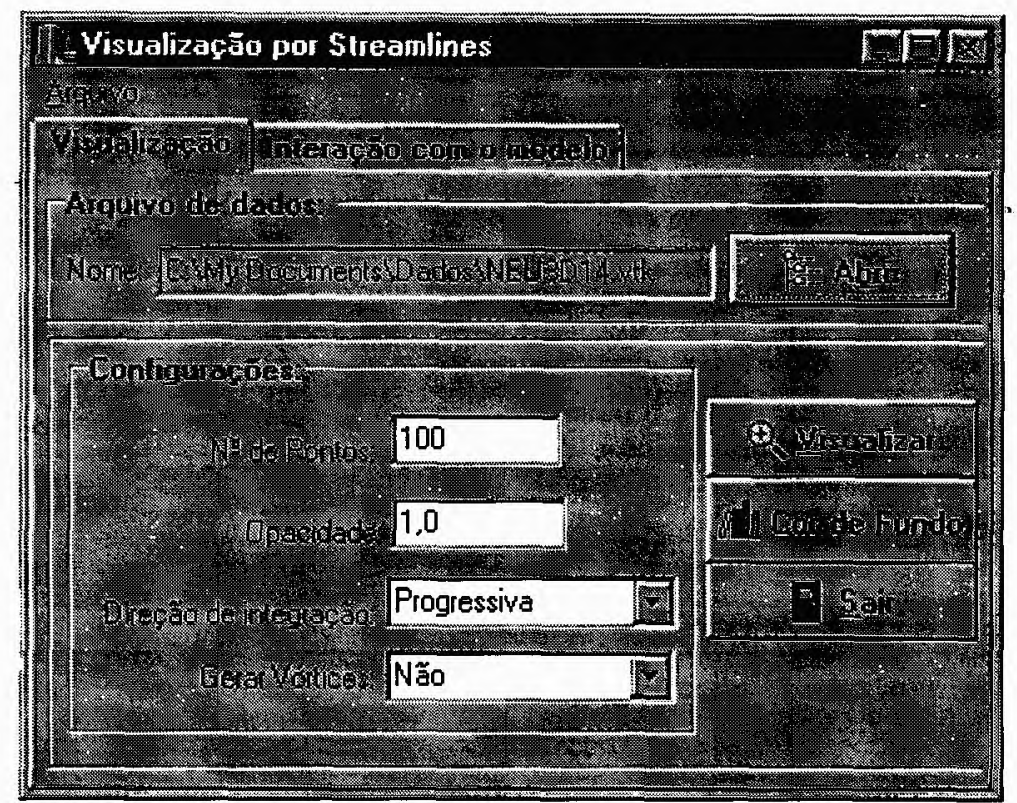

Figura 31: Interface do Módulo Vetorial por Streamlines
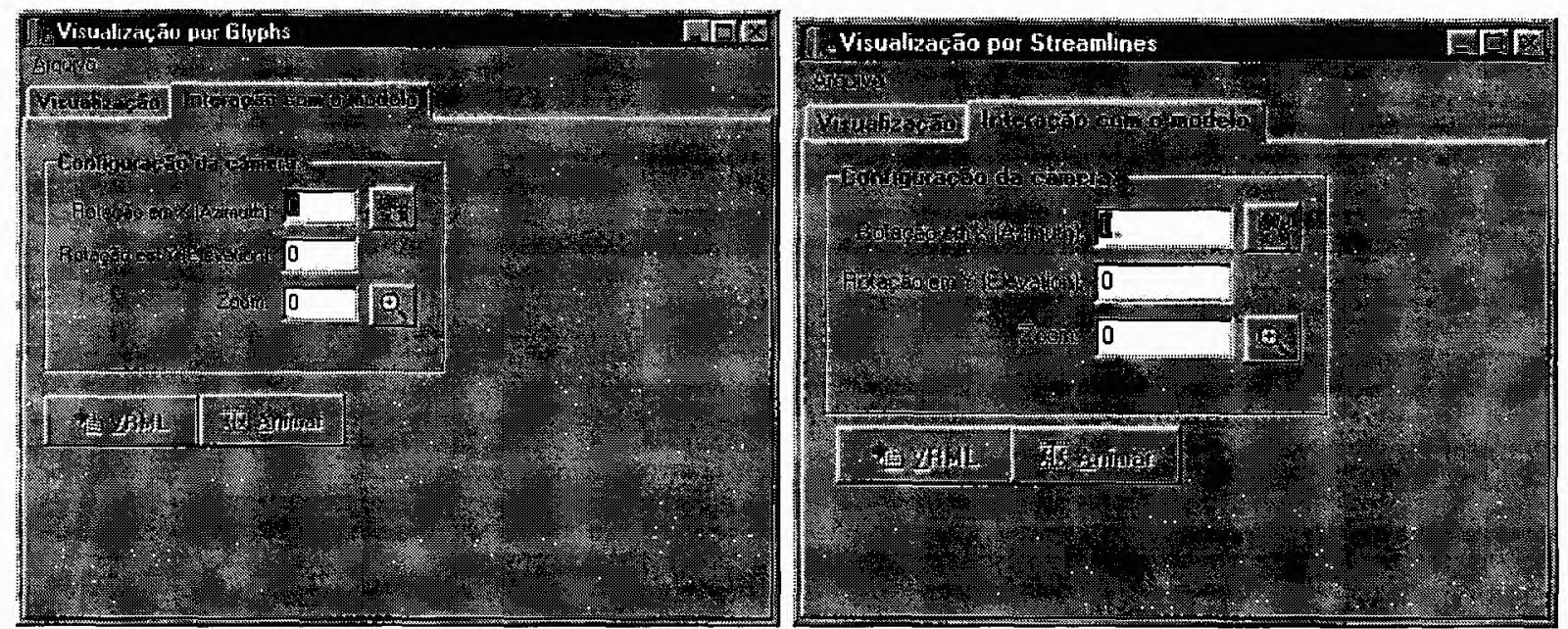

Figura 32: Interfaces de interação dos módulos de visualização vetorial

animações com o modelo VRML resultante, especificando uma seqüência de pontos de observação do modelo. Há dois modos de animação, a animação de um trajeto pelo mundo virtual de um ponto de observação para o outro, ou a animação de um trajeto ao longo de uma seqüência de pontos de observação. No primeiro caso, a opção "Animar"deve ser selecionada e os pontos de observação escolhidos. No segundo, o usuário estabelece o ponto de observação limite para a animação na caixa de texto "Até o ponto"e aciona o botão "Animar". Em ambos os casos o usuário pode fixar a velocidade de exibição da animação (Figura 34). 


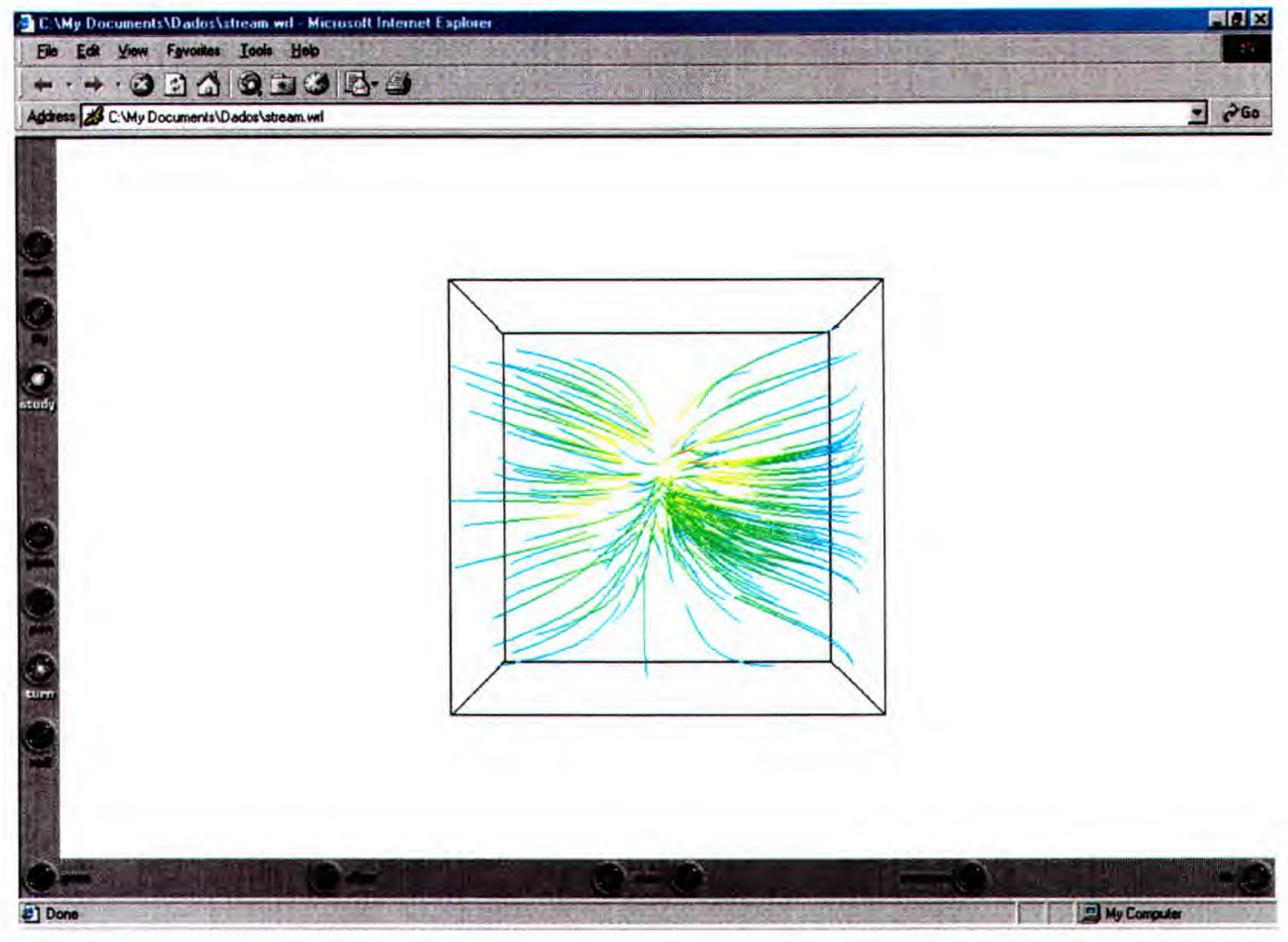

Figura 33: Visualização do arquivo VRML com streamlines

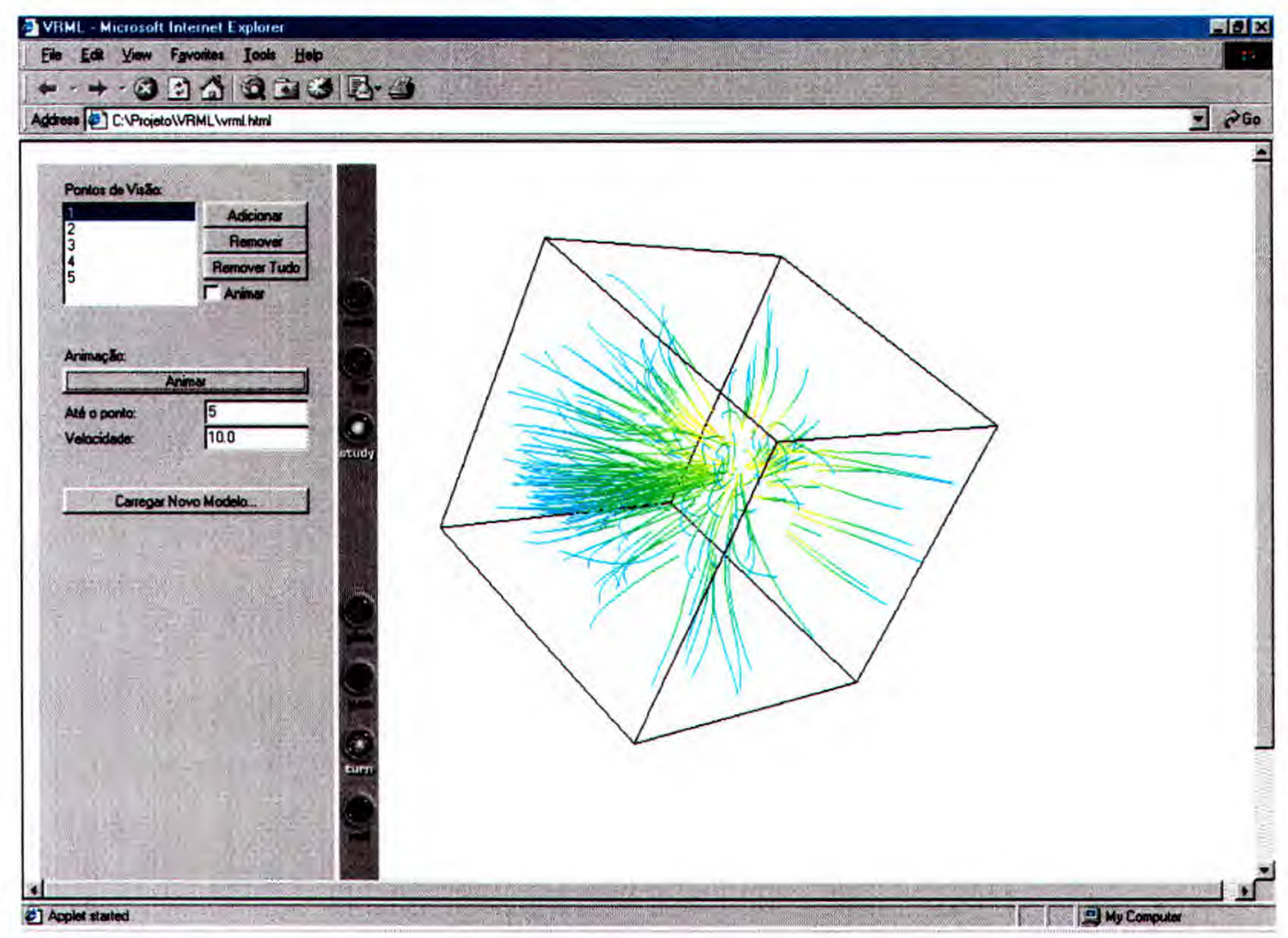

Figura 34: Interface de animação do arquivo VRML com streamlines 


\subsection{Considerações finais}

Neste capítulo foram descritas as funcionalidades dos diferentes módulos do ambiente de visualização de dados escalares e vetoriais, e os recursos oferecidos em nível de interface com o usuário. O próximo capítulo ilustra a utilização do ambiente. 


\section{Capítulo 4}

\section{Utilização do ambiente}

\subsection{Considerações Iniciais}

Este Capítulo ilustra alguns exemplos de utilização do ambiente desenvolvido. Os exemplos foram gerados utilizando dois tipos de arquivos de dados de neurônios gerados pelo Grupo de Visão Cibernética do IFSC e um arquivo de dados que descreve um modelo dentário, gerado no âmbito do projeto "Odontologia Virtual", em andamento no ICMC - USP. O primeiro arquivo de dados de neurônios é composto por dados escalares e será utilizado para ilustrar os módulos de Extração de Superfícies e no DVR; o outro consiste de dados vetoriais e será utilizado para ilustrar os módulos de visualização vetorial por glyphs e streamlines. O arquivo de dados dentários é composto por dados escalares e será utilizado para complementar os exemplos de extração de superfícies.

\subsection{Extração de Superfícies}

Para ilustrar esse módulo foram usados os arquivos de dados neu3d14.vtk e denteint.vtk. Os parâmetros exibidos na tela da Figura 35 e 36.

Para o neurônio foram especificadas duas isosuperfícies com valores 0,77 e 0,92 respectivamente, sendo a primeira totalmente opaca e a segunda semi-transparente e para o dente uma isosuperfície com valor 0 totalmente opaca. As visualizações resultantes, no modo Normal, são exibidas na Figura 37. 


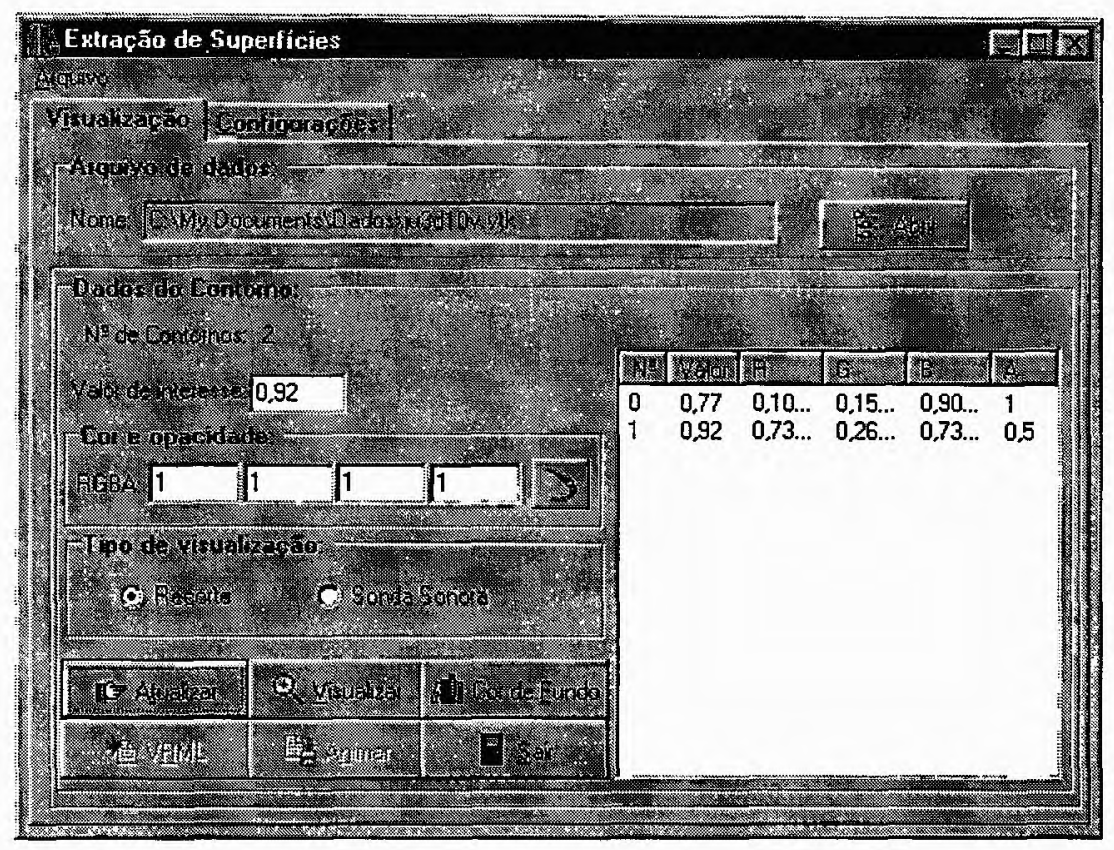

Figura 35: Parâmetros de visualização do neurônio

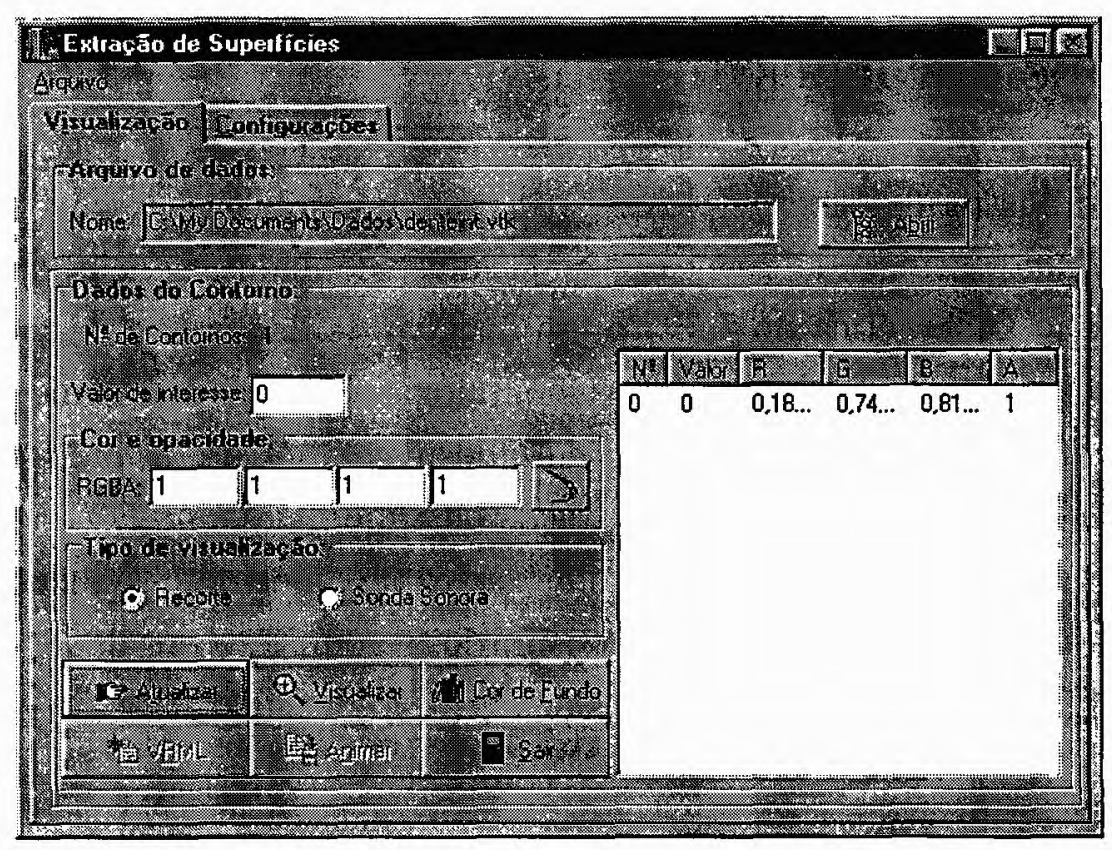

Figura 36: Parâmetros de visualização do dente

\subsubsection{Recorte de Superfícies}

A seguir, ilustramos a seqüência de passos para extrair um corte da isosuperfície número 1 do neurônio, que corresponde ao valor 0,77 e um corte do dente. Para selecionar a isosuperfície 1, o usuário deve clicar sobre o identificador da isosuperfície 1 e, consequentemente, as demais isosuperfícies são mostradas como nuvens de pontos, deixando a 


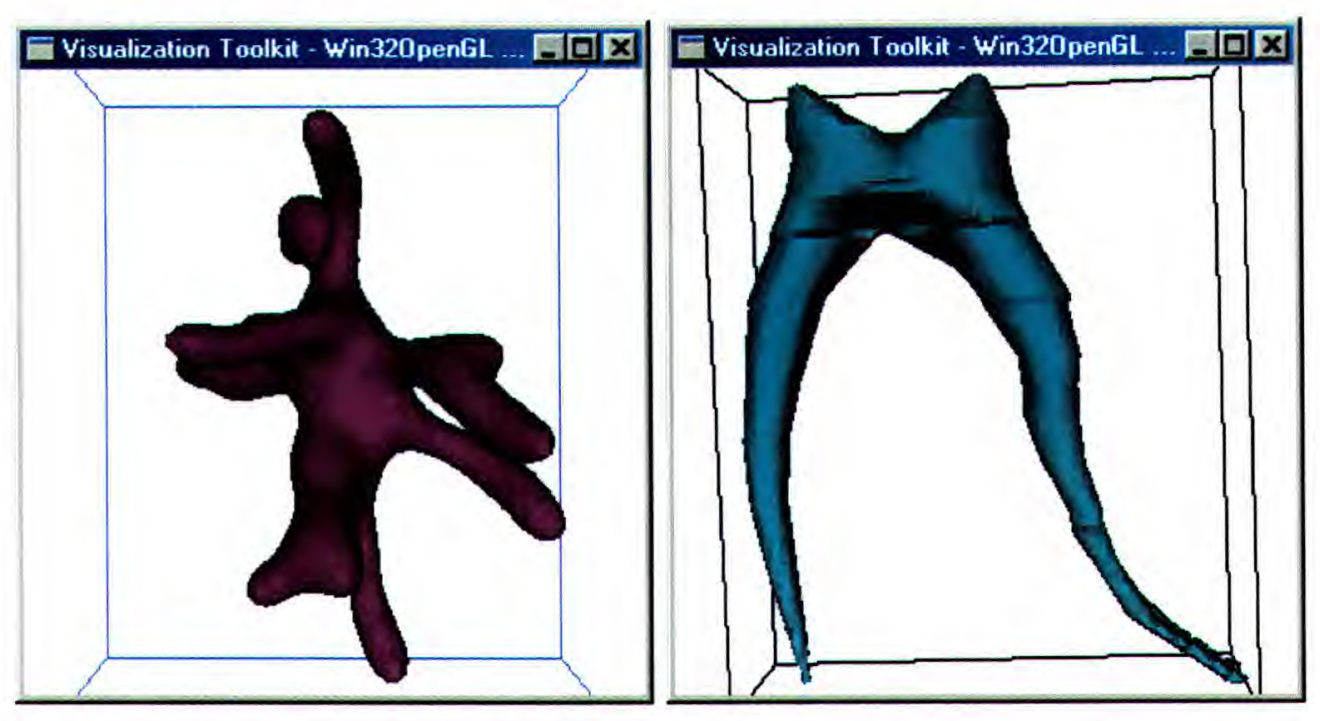

Figura 37: Neurônio e dente gerados inicialmente

isosuperfície escolhida em destaque como ilustrado na Figura 38. No exemplo do dente não é necessário realizar nenhum tipo de seleção pois o modelo só possui um contorno.

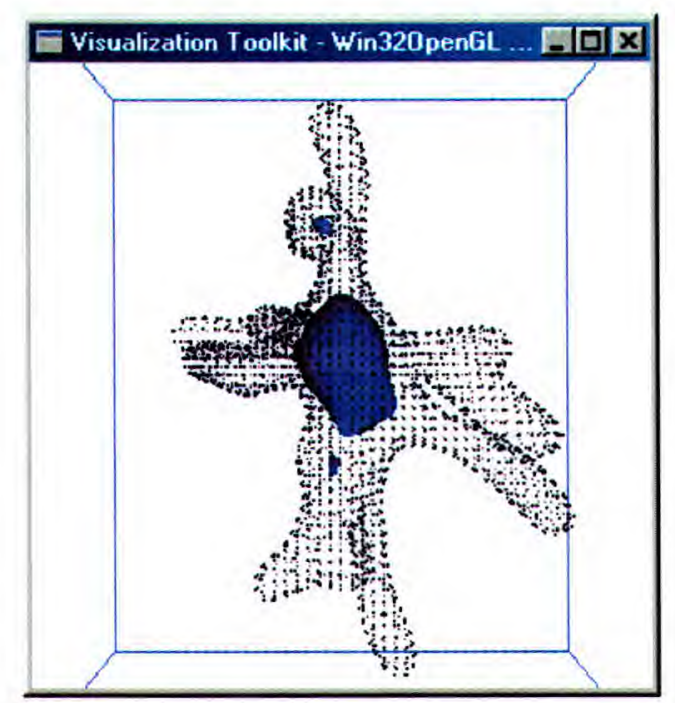

Figura 38: Isosuperfície selecionada em destaque

Após a escolha da isosuperfície final, as demais são eliminadas da visualização através de um duplo clique sobre o índice da isosuperfície escolhida, que neste caso corresponde ao índice zero (Figura 39).

Neste momento, a isosuperfície já está preparada para a realização de cortes. O próximo procedimento consiste em alterar o modo de interação do usuário pressionando a tecla "u" para que o cursor responsável pela demarcação da região de corte seja habilitado. Quando isso é feito o cursor é exibido, como ilustrado na Figura 40 (a). Com o cursor ativo é possível demarcar a região de corte, passando o cursor sobre a superfície e selecionando 


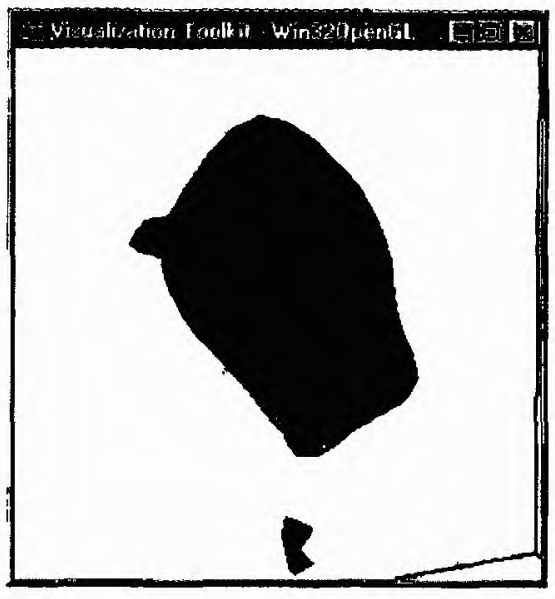

Figura 39: Isosuperfície final
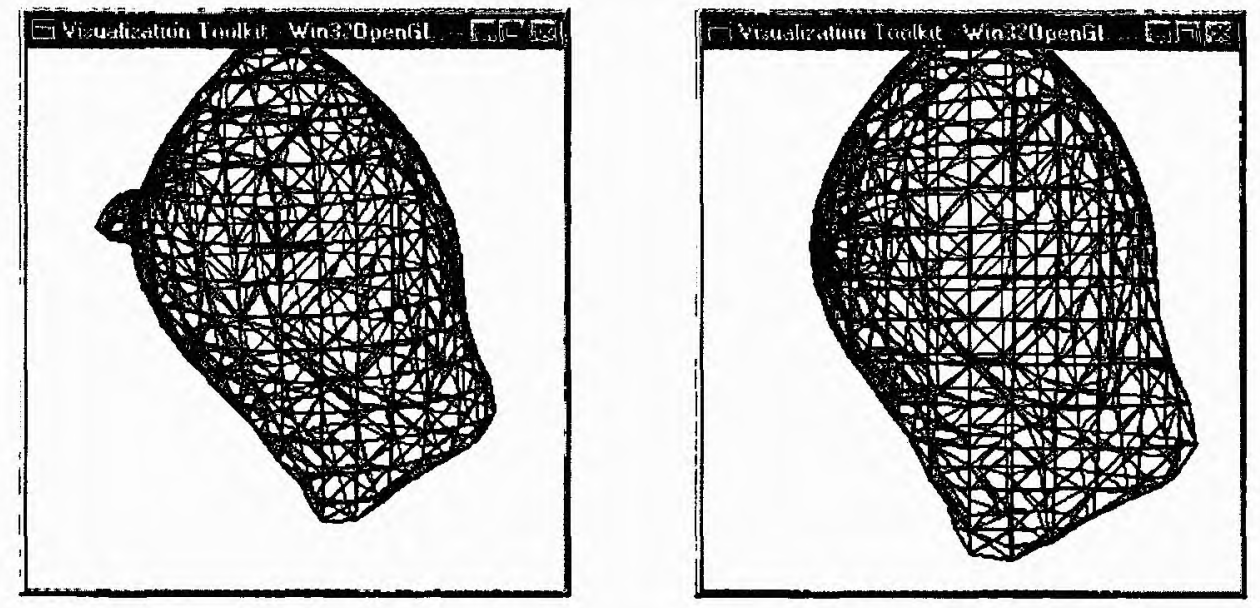

Figura 40: (a) Cursor

Figura 40: (b) Seleção de pontos

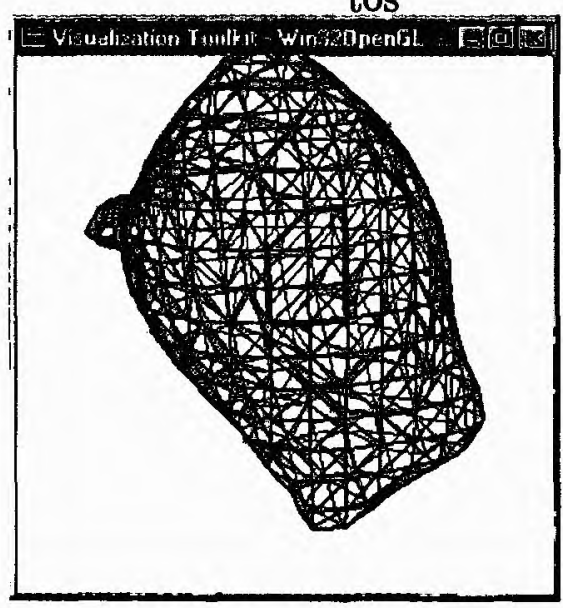

Figura 40: (c) Contorno do corte fechado 
os vértices que delimitam a região a ser extraída (Figura 40 (b), para o neurônio e Figura 41 (a) para o dente). Assim que o último ponto for escolhido, a região é fechada (Figura 40 (c), Figura 41 (b), e Figura 42). Caso o usuário queira desfazer a demarcação, basta pressionar o botão direito do mouse que todo o processo será desfeito.

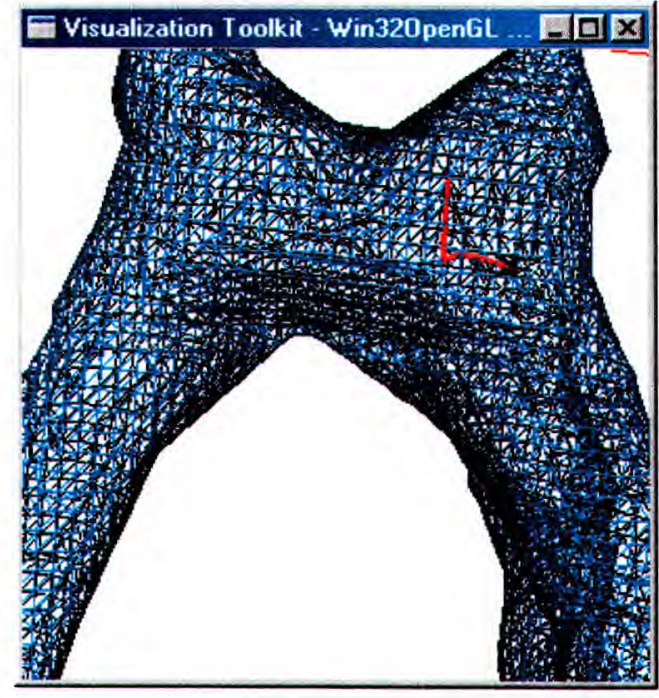

Figura 41: (a) Seleção de pontos

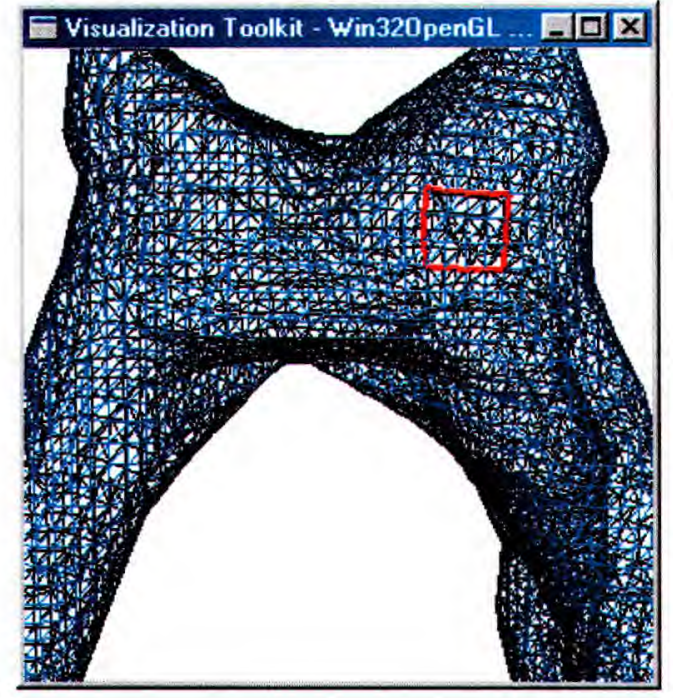

Figura 41: (b) Contorno fechado

Para finalizar o corte basta pressionar a tecla "q". Depois de cortadas, as regiões podem ser separadas retornando ao modo de interação anterior (tecla " $u$ ") e pelo pressionamento da tecla " $\mathrm{o}$ "sobre a componente desejada para que somente uma das partes seja selecionada. Para mover a componente selecionada o usuário deve pressionar "shift"e mover o mouse na direção desejada, como ilustrado na Figura 43.
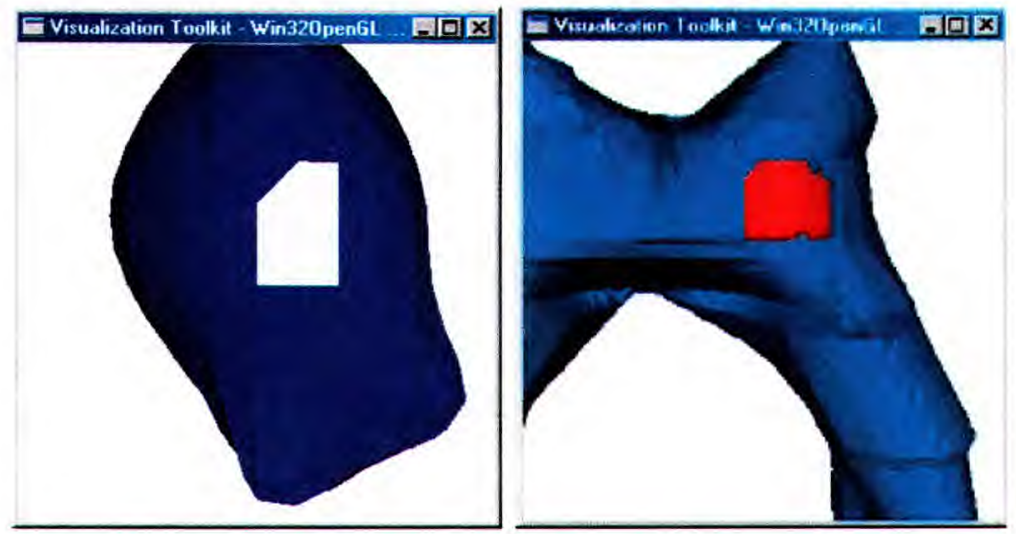

Figura 42: Região de corte selecionada 

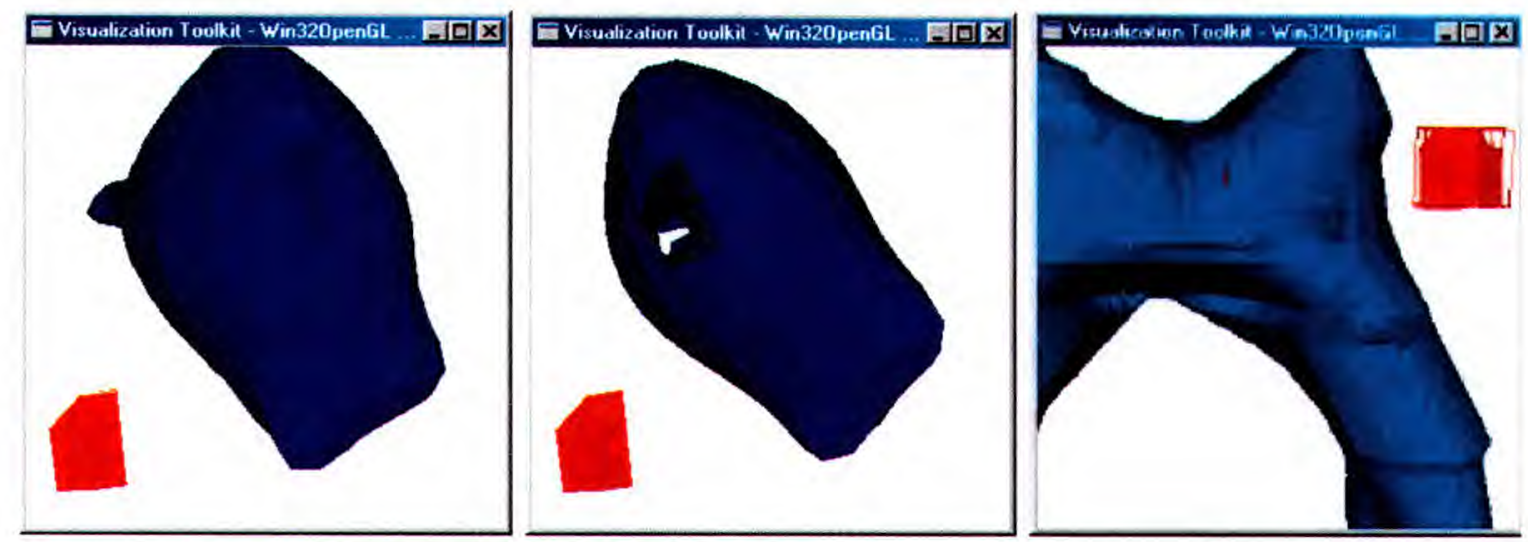

Figura 43: Translação e rotação da região recortada

\subsubsection{Sonda Sonora}

Neste segundo exemplo, uma sonda de tamanho variável é inserida no volume de dados com o intuito de captar informações e apresentá-las ao usuário na forma de som.

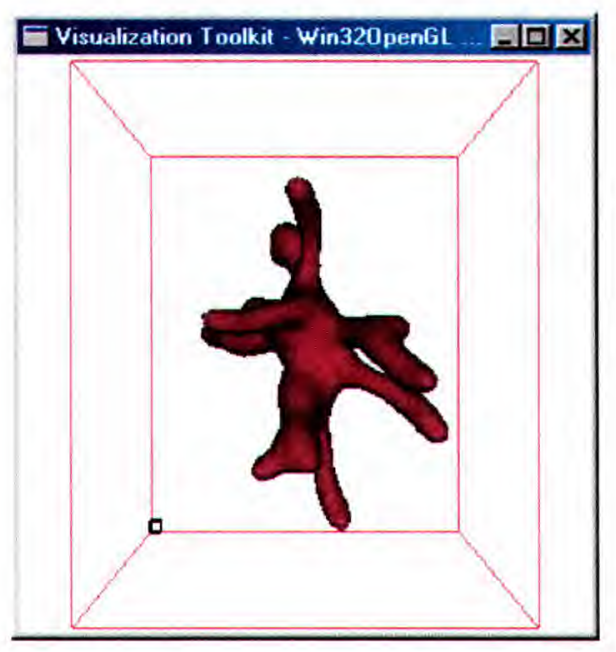

Figura 44: Sonda Sonora (canto inferior esquerdo)

Assim que a visualização é gerada, a sonda é posicionada no canto inferior esquerdo com um certo tamanho pré-definido (Figura 44). O modo de interação inicial permite que o usuário realize todos os tipos de interações pré-definidas pelo VTK (rotação, translação, etc.). Para ter acesso a sonda é necessário alternar o modo de interação (tecla "u") e por meio de algumas teclas pode-se movimentá-la no sentido desejado. Os movimentos permitidos são descritos na Figura 45.

Ao pressionar a tecla "Ctrl"em conjunto com as teclas anteriormente descritas, é acionada a função que permite a alteração do tamanho da sonda (Figura 46). A medida que a sonda é movimentada pode-se obter a sonificação dos dados contidos em seu interior 


\begin{tabular}{|l|lc|}
\hline Sentido & Tecla de acesso \\
\hline Direita & seta para direita & $\rightarrow$ \\
Esquerda & seta para esquerda & - \\
Para cima & seta para cima & + \\
Para baix & seta para baixo & $\downarrow$ \\
Para frente & tecla PageUp & PgUp \\
Para baixo & tecla PageDown & PgDn \\
\hline
\end{tabular}

Figura 45: Teclas de movimento da sonda

pressionando continuamente a tecla "s".

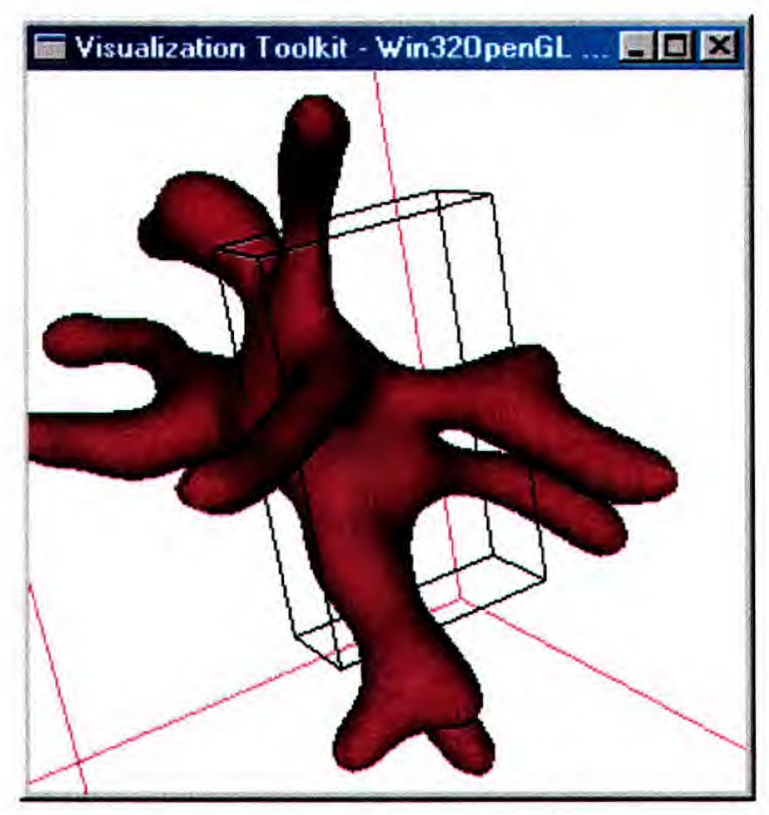

Figura 46: Sonda aumentada

\subsubsection{VRML e Animação}

A Figura 47 ilustra a criação e a visualização do arquivo VRML gerado a partir do modelo criado, usando o botão "VRML" disponível na interface principal do módulo de extração de superfícies (Figura 23) que, ao ser pressionado, chama o browser default e abre o arquivo ".wrl" para exploração ou navegação. O plugin utilizado para visualização de arquivos VRML foi o Cortona VRML Client. 


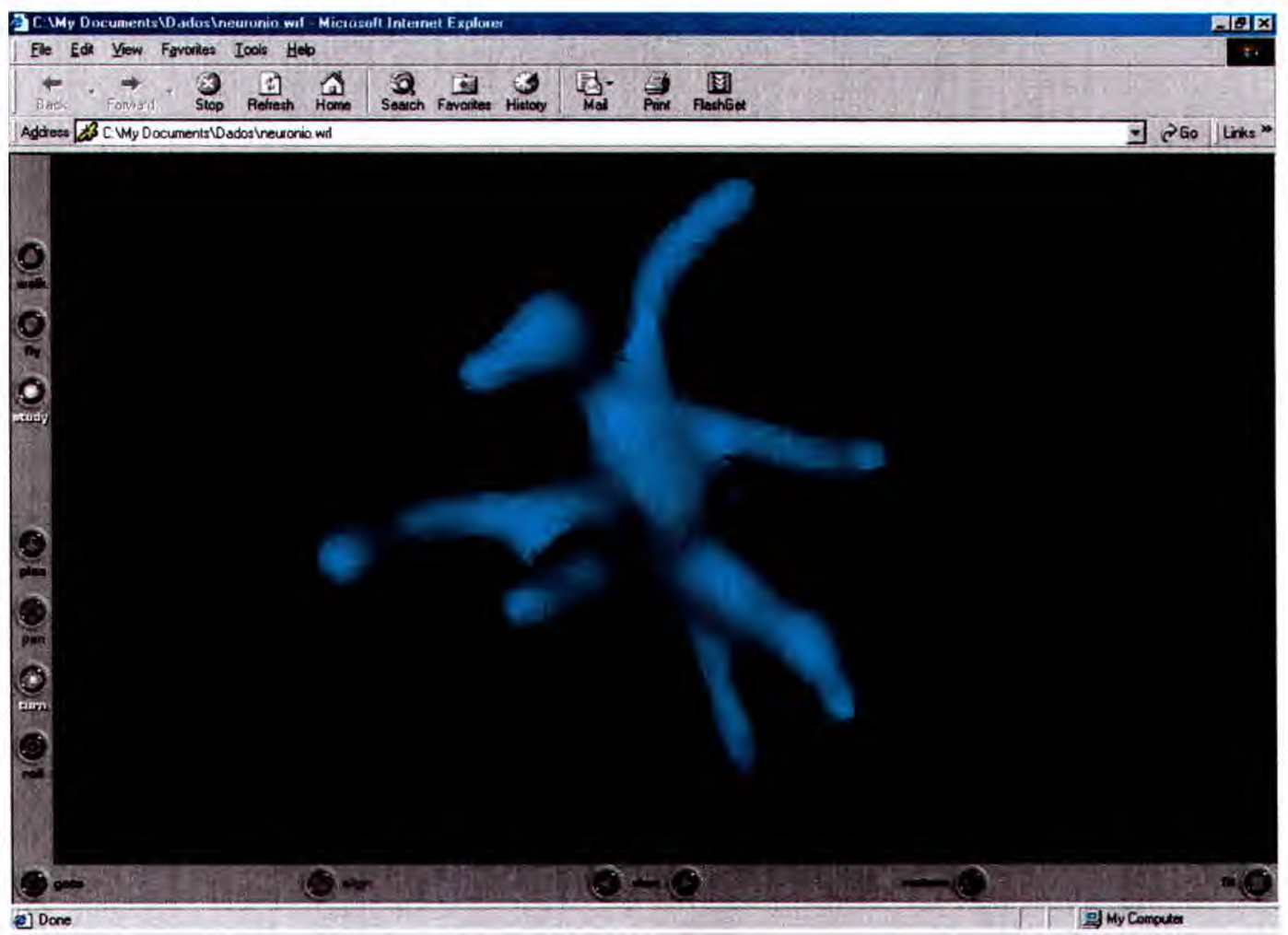

Figura 47: Visualização do arquivo VRML

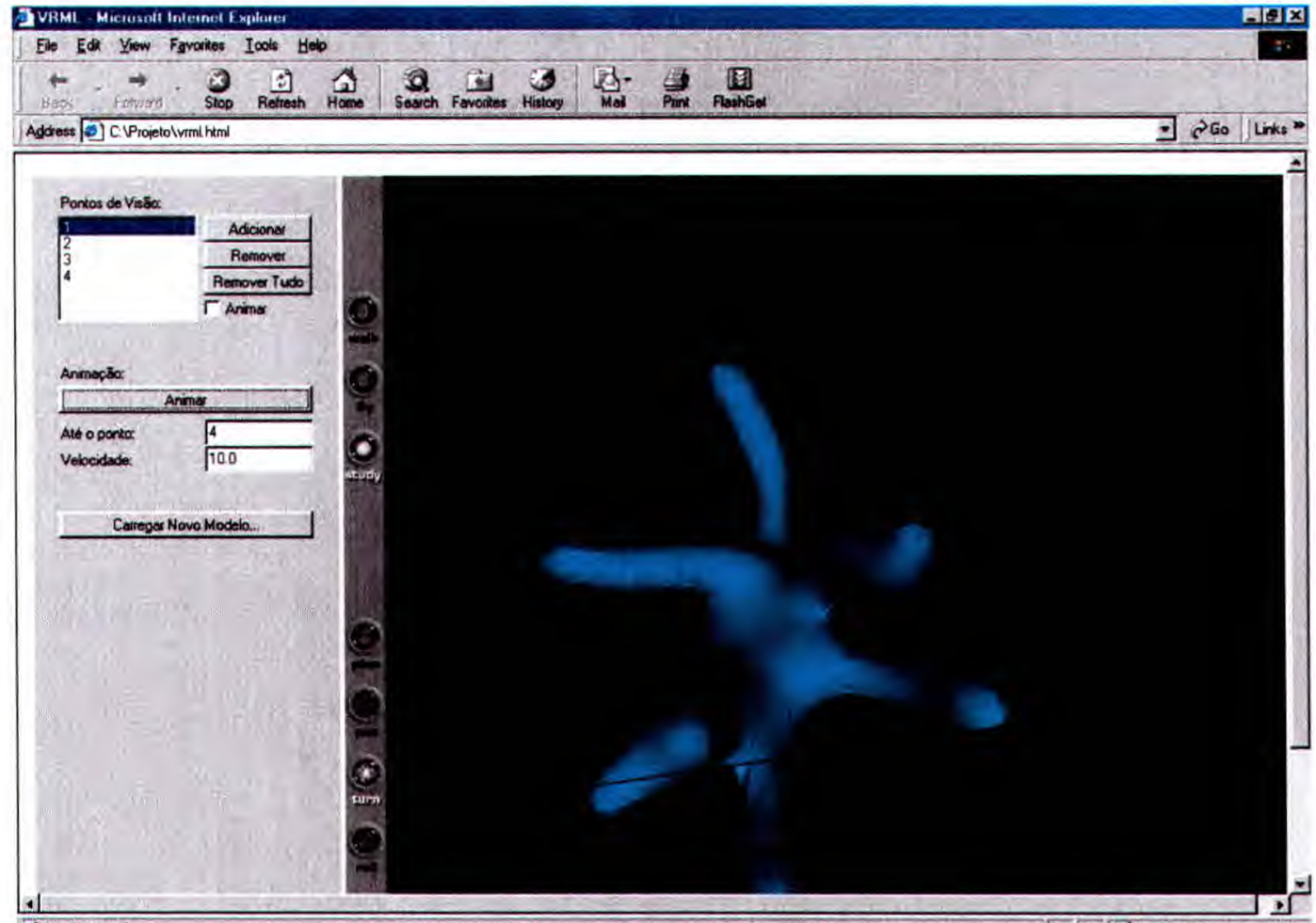

Aopolet stotod

Figura 48: Tela de configuração e exibição da animação do modelo 
A animação pode ser gerada após a criação do arquivo VRML. O arquivo de entrada deve ser um arquivo VRML gerado pelo VTK, outros arquivos não são aceitos. Para que a animação seja realizada o usuário deve especificar os pontos de observação do modelo (Figura 48) e o ponto no qual a animação deverá finalizar. Na Figura, o usuário definiu quatro pontos de observação interagindo com a cena, denominando os $1,2,3$ e 4, como indicado na janela "Pontos de visão". A Figura mostra a imagem obtida depois que a animação foi exibida até chegar ao quarto ponto de observação.

\subsection{Rendering Volumétrico Direto}

A Figura 50 ilustra dois exemplo de visualização volumétrica, um gerado no modo normal e outro no modo por textura (Seção 3.4). O volume contém valores escalares compreendidos entre 0 e 2.0, sendo que o valor 2.0 corresponde ao "fundo". Ambas as visualizações utilizaram os parâmetros apresentados na Figura 49, na qual foram definidos os intervalos $[0.77,0.81]$ como totalmente opaco, $[0.82,0.88]$ como semi-transparente, $[0.89,0.91]$ com oitenta porcento de transparência, e os dados compreendidos no intervalo $[0.92,2.0]$ totalmente transparentes.

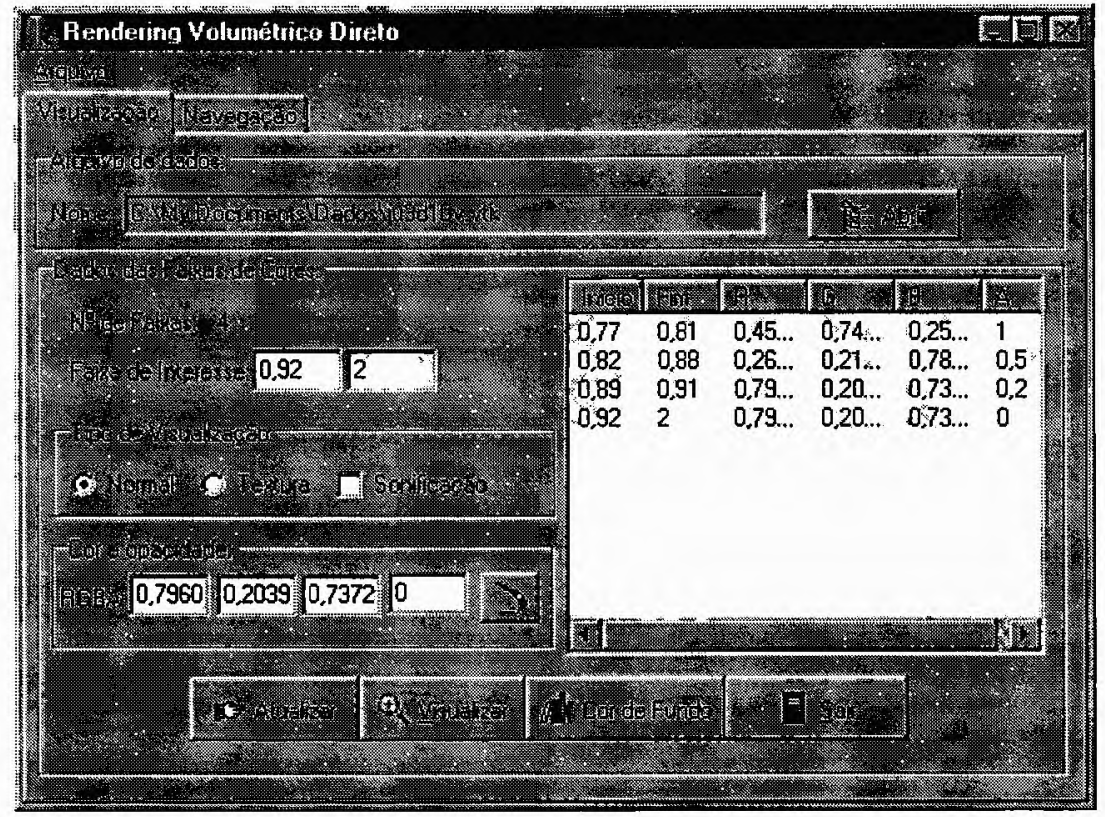

Figura 49: Parâmetros de configuração e geração da visualização volumétrica

A visualização por textura é significativamente mais rápida que no modo DVR, mas a definição da imagem no modo DVR possui uma resolução melhor, como é mostrado na Figura 50. A sonda sonora pode ser inserida em ambas as visualizações (Figura 51). A diferença entre os dois tipos está na velocidade de interação, ou seja, no modo por textura 


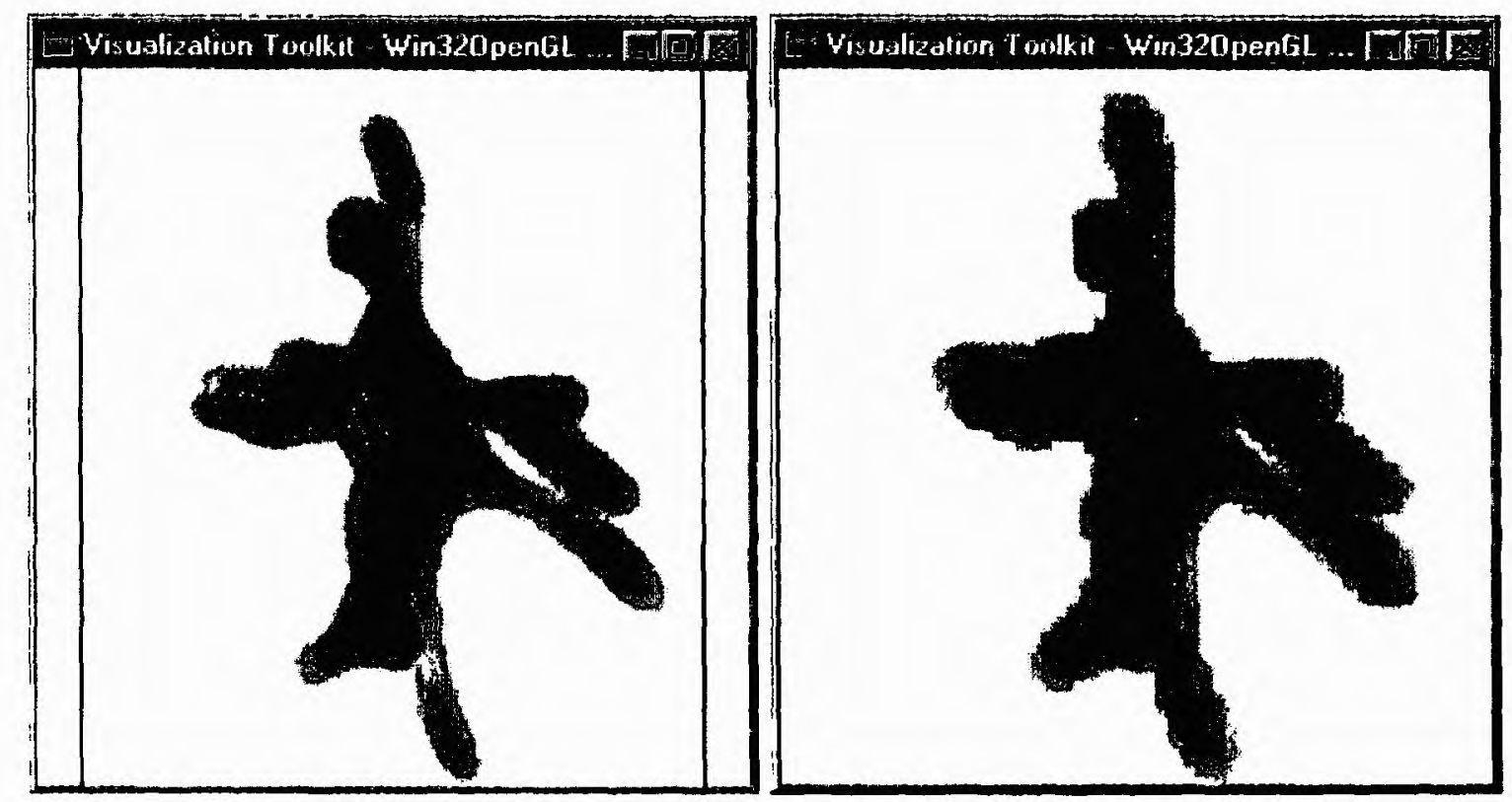

Figura 50: Rendering volumétrico direto de um neurônio no modo normal e no modo por textura

a interação é mais rápida do que no modo normal, cerca de 5 vezes mais. Como base para comparação foi utilizado um microcomputador Pentium III $550 \mathrm{MHz}$ com 128 Mbytes de RAM.
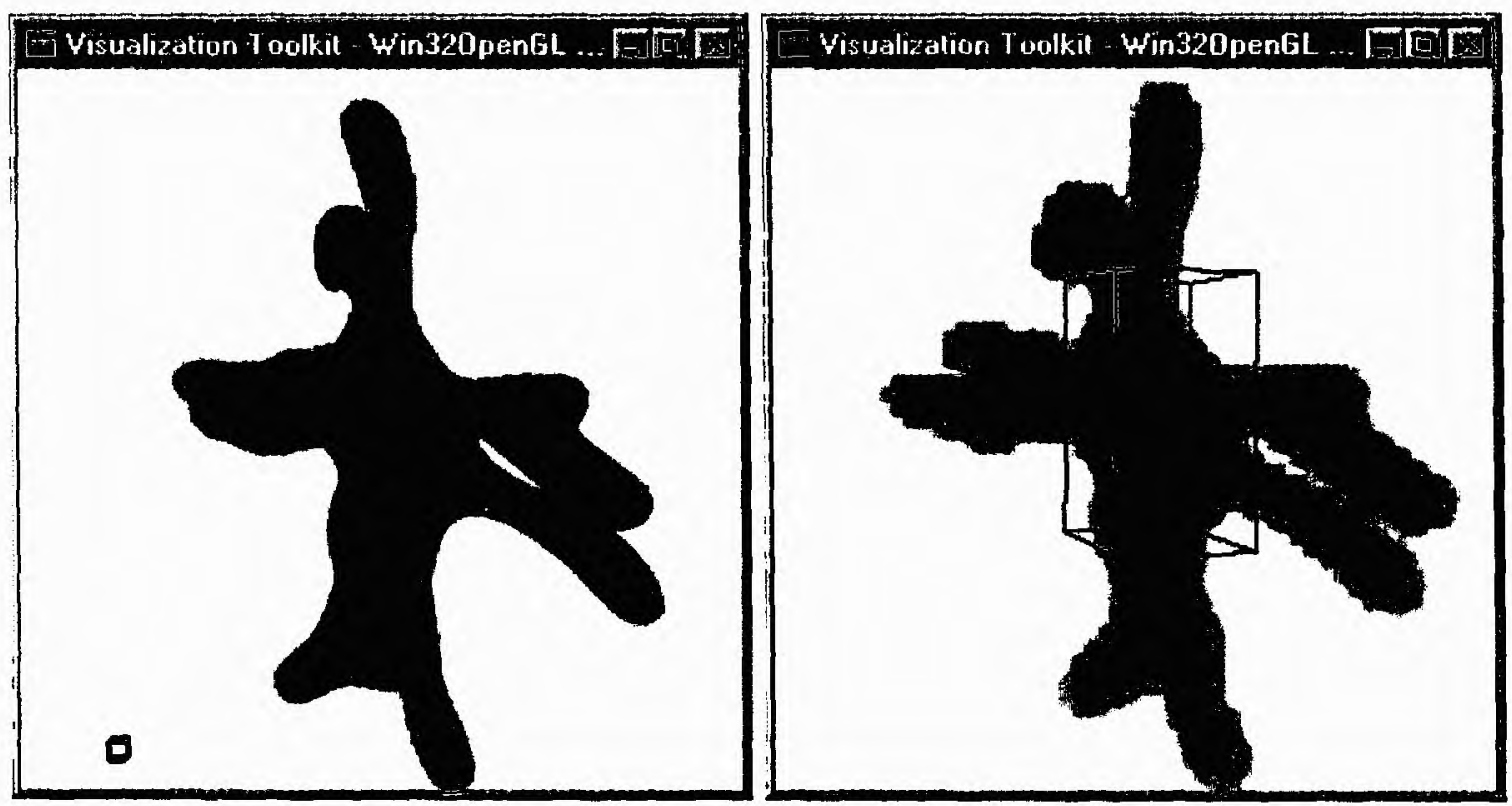

Figura 51: Rendering volumétrico direto com sonda sonora de um neurônio no modo normal e no modo por textura 


\subsection{Visualização Vetorial}

Nesta seção serão apresentados exemplos de visualização do campo vetorial de um neurônio por meio de glyphs e streamlines. $\mathrm{O}$ arquivo de dados utilizado em ambas as visualização foi o neu3d14.vtk.

\subsubsection{Glyphs}

O primeiro exemplo de visualização vetorial foi gerado utilizando os seguintes parâmetros: grau de opacidade de 1 , escala 0,00002 , quantidade máxima de 500 pontos, glyphs do tipo segmentos de reta, sendo os segmentos de reta coloridos de acordo com o valor escalar (Figura 52).
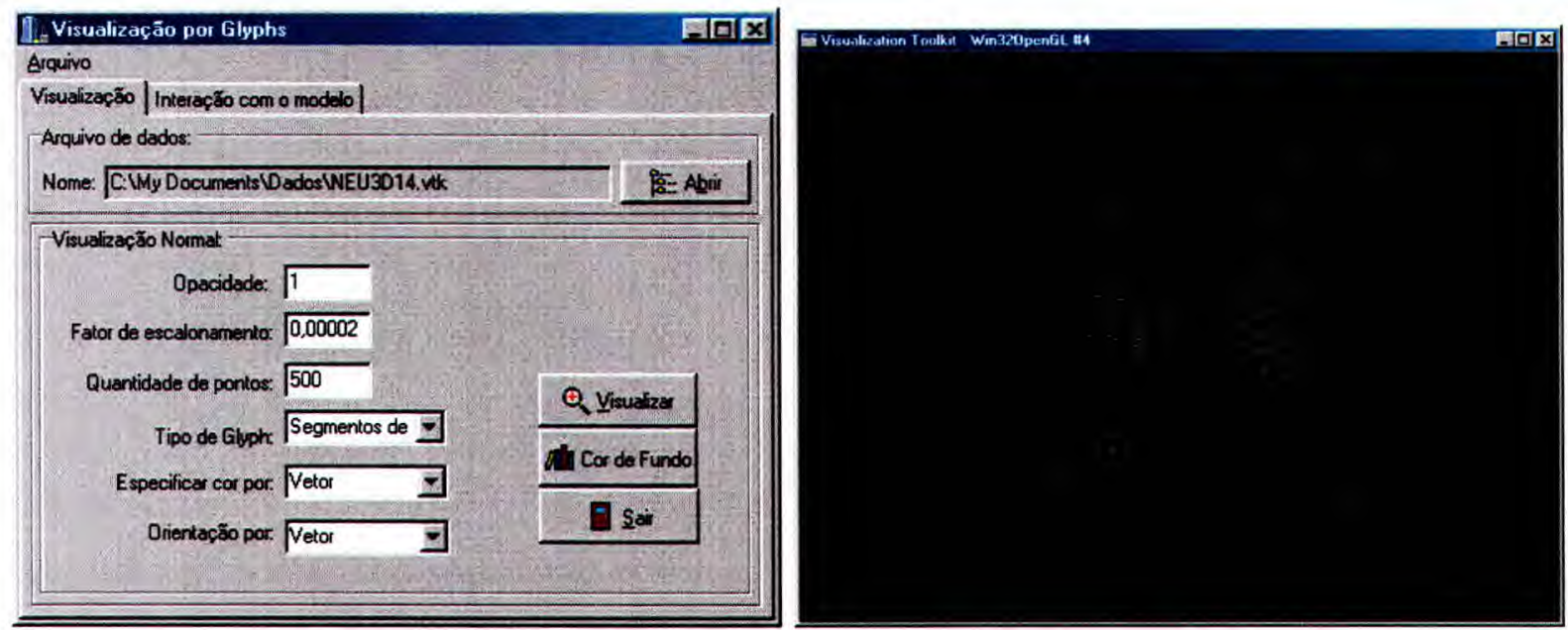

Figura 52: Interface e visualização do campo vetorial de um neurônio por meio de segmentos de reta

O segundo exemplo foi gerado utilizando os seguintes parâmetros: grau de opacidade de 1, escala 0,00009, quantidade máxima de 500 pontos, glyphs do tipo cones orientados, sendo os cones coloridos de acordo com valor escalar e orientados pela magnitude do vetor (Figura 53).

\subsubsection{Streamlines}

Um exemplo de visualização do campo vetorial de um neurônio por streamlines gerado por este módulo com resolução de 5000 pontos coloridos em relação aos valores escalares e com integração regressiva é apresentado na Figura 54. 

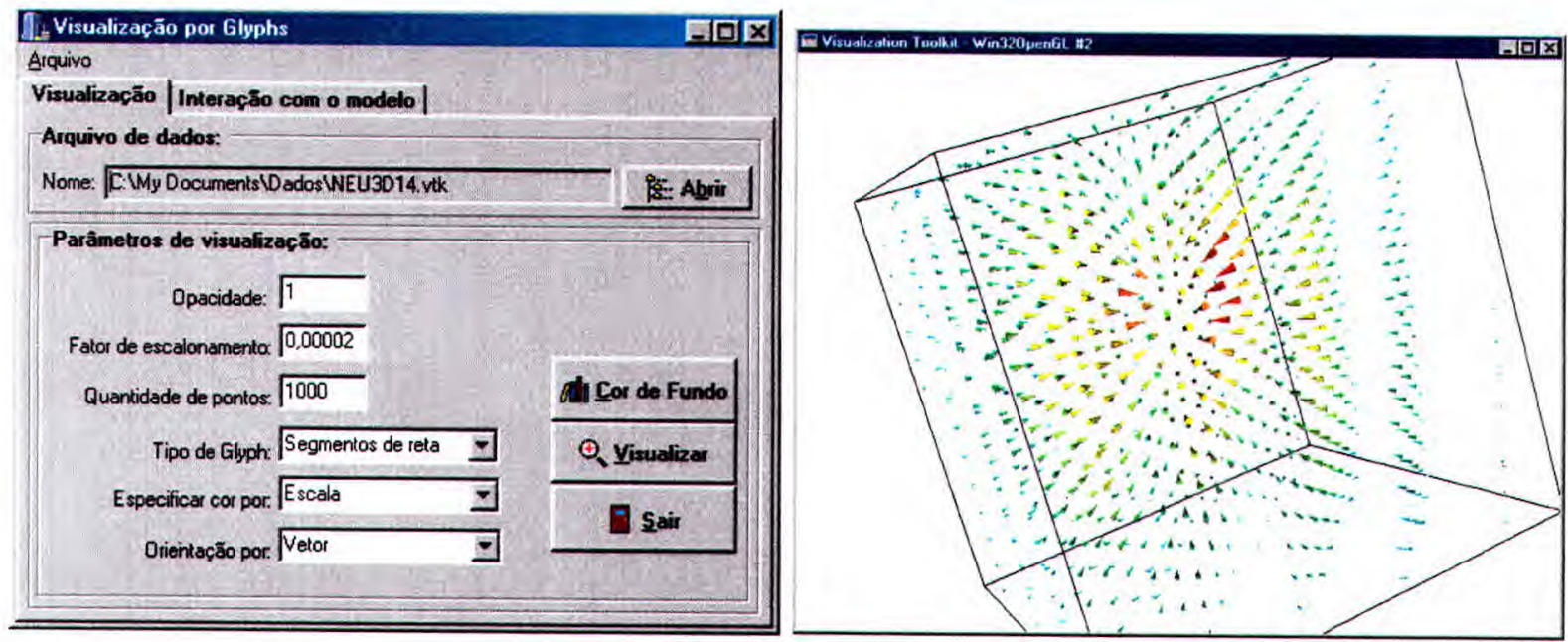

Figura 53: Interface e visualização do campo vetorial de um neurônio por meio de cones orientados
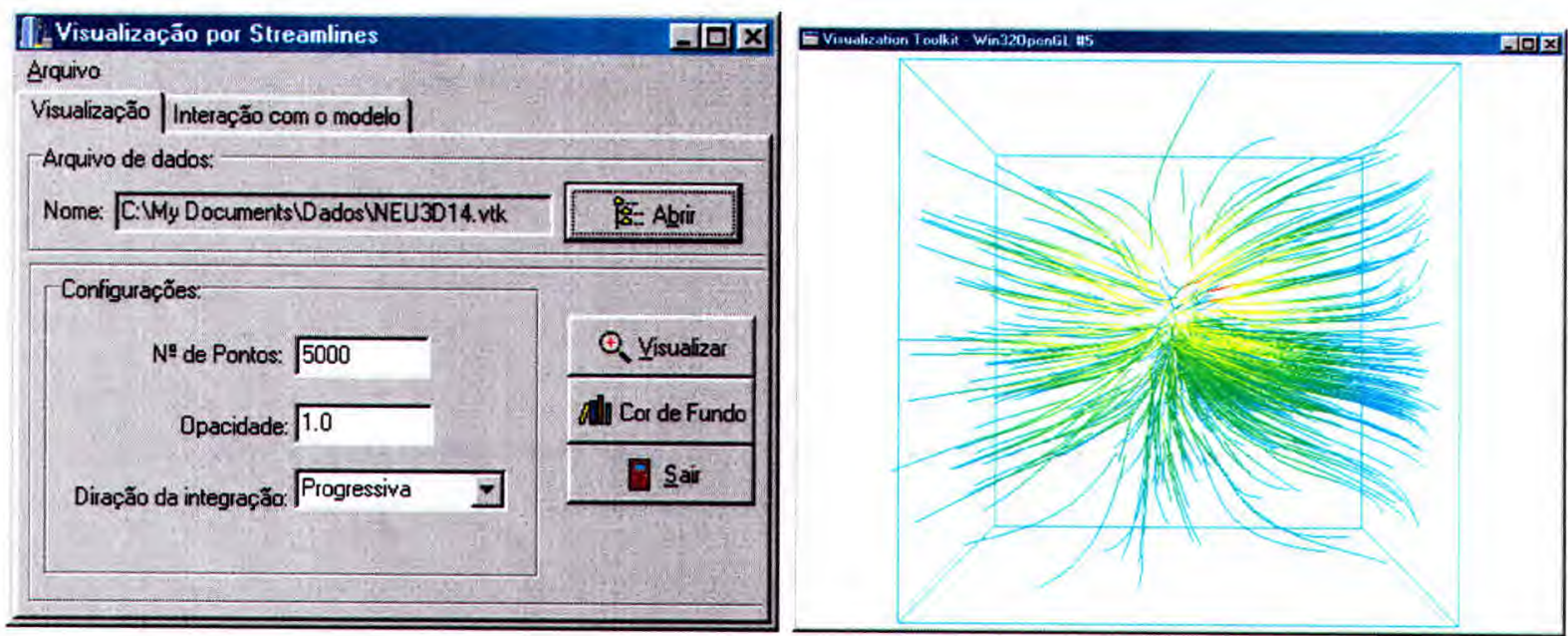

Figura 54: Interface e visualização do campo vetorial de um neurônio por meio de streamlines

\subsection{Considerações Finais}

Neste Capítulo foram apresentados alguns exemplos de utilização do programa desenvolvido neste projeto de mestrado com o objetivo de ilustrar os passos que devem ser seguidos na geração das visualizações e como interagir adequadamente com os modelos gerados. 


\section{Capítulo 5}

\section{Conclusão}

A principal contribuição deste trabalho é o desenvolvimento de um ambiente interativo voltado para usuário final que integra diversas estratégias de visualização e mecanismos de interação com as mesmas. É um ambiente genérico para dados escalares e vetoriais com armazenamento de dados em malhas estruturadas e que apresenta interações indiretas, widgets para definição de parâmetros para a criação das visualizações, e diretas, como extração de sub-regiões e a sonda sonora. Inclui também um mecanismo para interação com modelos VRML exportados diretamente do ambiente.

$\mathrm{Na}$ fase de pesquisas bibliográficas diversas técnicas de interação foram encontradas e relatadas no decorrer do trabalho mas somente algumas puderam ser implementadas e incorporadas ao projeto. Dentre as técnicas de visualização, foram implementadas as técnicas convencionais de extração de superfícies, rendering volumétrico direto e visualizações vetoriais por glyphs e streamlines. Quanto as técnicas de interação, foram incluídas as técnicas de recorte de superfícies, sonda sonora, visualização e animação em VRML, rotação e zoom via interface.

O projeto possui algumas limitações que podem servir como base para possíveis extensões, como é o caso do módulo de visualização de dados vetoriais por glyphs no qual não há a possibilidade da escolha do intervalo de dados que serão amostrados, possibilitando apenas a especificação da quantidade de dados (pontos) a serem amostrados, sendo que estes serão os primeiros $n$ pontos do arquivo de entrada.

Outra limitação está no módulo de rendering volumétrico direto, onde a princípio 
pretendia-se desenvolver a técnica de recortes, mas o tipo de visualização gerada é mais "pesada", necessitando assim de hardware de alta capacidade de processamento visto que todo processo é feito por software, e a visualização não possui uma triangularização prédefinida onde possam ser selecionados pontos ou células para o recorte. Outra tentativa foi a incorporação de visualizações e animações VRML para o DVR, mas o filtro do VTK que converte os dados da cena para um arquivo VRML não suporta tal volume de dados.

Com relação à continuidade deste projeto de pesquisa, uma possível linha de pesquisa seria a inclusão de outras das técnicas de visualização e o suporte a outras organizações de dados visando atender um número maior de usuários, possibilitar retroalimentação visual adicional, ou seja, incluir à visualização uma indicação visual do sistema de eixo de coordenadas e de projeção do modelo em planos de referência (xy, xz, yz). Uma outra possibilidade de pesquisa seria a implementação de estratégias de interação adicionais, como o uso de quering dinâmica do volume de dados, que permitiria definir sub-conjuntos de valores de interesse e poderia ser efetuado sobre os modelos gerados por rendering volumétrico direto, o suporte a técnica de brushing com multiresolução, onde subconjuntos de dados seriam identificados e realçados em relação ao conjunto de dados inicial, e implementação de estratégias adicionais para manipulação direta dos modelos VRML gerados. Um outro aspecto a ser abordado seria o estudo do uso do sistema por usuários alvo para avaliação. 


\section{Referências Bibliográficas}

ALEGRE, D. P. P. (1997). Técnicas básicas para interações $3 D$ através do mouse, Dissertação (Mestrado), Universidade Estadual de Campinas, Campinas. 94 p.

BAKER, M. P. \& WICKENS, C. D. (1995). Human factors in virtual environments for the visual analysis of scientific data, Relatório Técnico NCSA-TR032, Pacific Northwest Laboratory, Richland, Washington. Web: file://ftp.ncsa.uiuc.edu/ncsapubs/preprints/TR032.os (Abril de 2001).

BALAKRISHNAN, R., BAUDEL, T., KURTENBACH, G. \& FITZMAURICE, G. (1997). The Rockin' Mouse: integral 3D manipulation on a plane, CHI Electronic Publications. Web: http://www.acm.org/sigchi/chi97/proceedings/paper/rb1.htm (Abril de 2001).

BIER, E. A. (1990). Snap-dragging in three dimensions, Computer Graphics - Proceedings of the 1990 Symposium on Interactive 3D Graphics, Vol. 24, Palo Alto, CA, pp. 193204.

BRYSON, S. (1994). Real-time exploratory scientific visualization and virtual reality, Academic Press, San Diego, CA. In: Rosenblum, L. et al.; Scientific Visualization Advances and Chanllenges.

BRYSON, S. \& LEVIT, C. (1991). The virtual windtunnel: an environment for the exploration of three-dimensional unsteady flows, Proceedings of Visualization'91, pp. 1724.

BURDEA, G. \& COIFFET, P. (1994). Virtual reality technology, John Wiley \& Sons, New York, USA.

CESAR, R. M. J. \& COSTA, L. F. (1997). Semi-automated dendogram generation for neural shape analysis, Proceedings SIBGRAPI'97, Campos do Jordão, pp. 147-154. 
CESAR, R. M. J., COELHO, R. C. \& COSTA, L. F. (1997). Automatic classification of retinal ganglion cells, Proceedings II Workshop on Cybernetic Vision, São Carlos, pp. 51-56.

CHEN, M. \& MOUNTFORD, J. (1988). A study in interactive 3D rotation using 2D control devices, Computer Graphics - Proceedings of the ACM SIGGRAPH'88, Vol. 22, pp. 121-129.

CHERNOFF, H. (1973). The use of faces to represent points in k-dimensional space graphically, $J$. of the American Statistical Assoc 68: 361-368.

COELHO, R. C. \& COSTA, L. F. (1994). Gramáticas para síntese de estruturas neurais, Anais do Workshop sobre Visão Cibernética, São Carlos,SP. IFSC - USP, pp. 74-79.

COSTA, L. F., OLIVEIRA, M. C. F. D. \& MINGHIM, R. (2000). De olho nos neurônios, as 'formas'' virtuais do pensamento, Ciência Hoje 28(167): 44-51.

EICK, S. G. \& WILLS, G. J. (1994). High interaction graphics. Web: http://www1.belllabs.com/user/gwills/ejor/Paper.html (Abril de 2001).

ELVINS, T. T. (1992). A survey of algorithms for volume visualization, ACM SIGGRAPH Computer Graphics 26(3): 34-44.

EMMERIK, M. V. (1990). A direct manipulation technique for specifying 3D object transformations with a 2D input device, Computer Graphics Forum 9 pp. 355-361.

EVANS, K. B., TANNER, P. P. \& WEIN, M. (1981). Tablet-based valuators that provide one, two or three degrees of freedom, Computer Graphics - Proceedings of the ACM SIGGRAPH'81, Vol. 15, Ottawa, Ontario, pp. 91-97.

FAKE SPACE Lab (2000). Web: http://www.fakespace.com/ (Abril de 2001).

FERREIRA, J. D. (1995). Multimídia para programadores e analistas, IBPI Press.

FREITAS, B. S. (2001). Sonificação e síntese de sons por software, Dissertação (Mestrado), Universidade de São Paulo, São Carlos.

FURNAS, G. W. (1981). The fisheye view: a new look at structured files, Relatório técnico, Bell Lab. Web: http://www.cs.indiana.edu/hyplan/tkeahey/research/nlm/nlm.html (Abril de 2001). 
GUTWIN, C. \& GREENBERG, S. (1997). Interactive fisheye views for groupware, Relatório técnico, Department of Computer Science, University of Calgary. Web: http://www.cpsc.ucalgary.ca/grouplab/papers/index.html (Abril de 2001).

HAGEN, M. A. (1991). How to make a visually realistic 3D display, Computer Graphics 25(2): 77-81.

HAND, C. (1997). A survey of 3D interaction techniques, Computer Graphics Forum 16(5): 269-281.

HIX, D. (1995). Pre-screen projection: from concept to testing of a new interaction technique, CHI'95 Electronic papers. Web: http://www.sigchi.org/sigchi/chi95/proceedings/papers/dh_bdy.htm (Abril de 2001).

JACOBSON, L. (1991). Virtual reality: a status report, AI Expert pp. 26-33.

KIRNER, C. (n.d.). Sistemas de realidade virtual. Web: http://www.dc.ufscar.br/g̃rv/tutrv/tutrv.htm (Abril de 2001).

KRUEGER, M. W. (1991). Artificial Reality II, 2 edn, Addison-Wesley, Reading, MA.

LANE, D. A. (1996). Visualizing time-varying phenomena in numerical simulations of unsteady flows, Relatório Técnico NAS-96-001, NASA Ames Research Center. Web: http://www.nas.nasa.gov/Research/Reports/TechReports/1996/nas_96_001.html(Abril de 2001).

LORENSEN, W. E. (1987). Marching Cubes: A high resolution 3D surface construction algorithm, ACM SIGGRAPH Computer Graphics 21: 163-169.

MICHIGAN (2000). Selected projects. Web: http://www-vrl.umich.edu/projects.html (Abril de 2001).

MINGHIM, R. \& OLIVEIRA, M. C. F. D. (1997). Uma introdução à Visualização Computacional, XVI JAI'97, Jornadas de Atualização em Informática, XVII Congresso da $S B C$, Brasilia, pp. 85-131.

MINGHIM, R. \& OLIVEIRA, M. C. F. D. (1998). Visualization experiences in the light of visualization effectiveness, Proceedings Int. Symposium on Advances on Signal, Image Processing, Computer Vision and Graphics of the World Multiconference on Systemics, Cybernetics and Informatics (SCI-98), Orlando - USA, pp. 529-536. 
NADEAU, D., MORELAND, J. \& HECK, M. (1998). Introduction to VRML 97. Web: http://www.sdsc.edu/ nadeau/Courses/Siggraph98vrml/ (Abril de 2001).

NIELSON, G. M. \& OLSEN, D. R. J. (1986). Direct manipulation techniques of 3D objects using 2D locator devices, Proceedings 1986 Workshop on Interactive 3D Graphics, Chapel Hill - North Carolina, pp. 175-182.

OBEYSEKARE, U., WILLIAMS, C., DURBIN, J., ROSENBLUM, L., ROSENBERG, R., GRINSTEIN, F., RAMAMURTI; R., LANDSBERG, A. \& SANDBERG, W. (1996). Virtual Workbench - A non-immersive virtual environment for visualizing and interacting with 3D objects for scientific visualization, Proceedings'96 Visualization. IEEE Computer Society Press, São Francisco - CA.

OLIVEIRA, M. C. F. D., MINGHIM, R., TUTIDA, S. M. \& SALVADOR, S. M. (1998). Towards perception driven visualization, Anais do 1998 International Symposium on Computer Graphics, Image Processing and Vision (SIBGRAPI'98), Rio de Janeiro, RJ, pp. 127-134.

OSBORN, J. R. \& AGOGINO, A. M. (1992). An interface for interactive spatial reasoning and visualization, Proceedings of ACM CHI'92 Conference in Human Factors in Computer Systems, pp. 75-82.

PHILLIPS, C. B., BADLER, N. I. \& GRANIERI, J. (1992). Automatic viewing control for 3D direct manipulation, Computer Graphics pp. 71-74.

PINHO, M. \& KIRNER, C. (1999). Uma introdução a realidade virtual. Web: http://www.dcc.ufba.br/mat056/rvirtual/tutrv.htm (Abril de 2001).

ROBERTSON, G. G., MACKINLAY, J. D. \& CARD, S. K. (1991). Cone trees: animated 3D visualization of hierarchical information, Proceedings of ACM Human Factors in Computing Systems, pp. 83-91.

SALVADOR, V. C. L. (1998). Sonificação para apoio a tarefas de visualização, Dissertação (Mestrado), Universidade de São Paulo, São Carlos. 113 p.

SARKAR, M. \& BROWN, M. H. (1992). Graphical fisheye views of graphs, Relatório Técnico Technical Report 84, Systems Research Center. Web: http://www.cs.indiana.edu/hyplan/tkeahey/research/nlm/nlm.html (Abril de 2001).

SCHAFFER, D. \& GREEBERG, S. (1993). Sifting through hierarchical information, Proceedings of ACM INTERCHI Conference in Human Factors in Computer Systems Adjunct Proceedings, Amsterdam, The Netherlands, pp. 173-174. 
SCHAFFER, D., ZUO, Z., BARTRAM, L., DILL, J., DUBS, S., GREENBERG, S. \& ROSEMAN, M. (1993). Comparing fisheye and full-zoom techniques for navigation of hierarchically clustered networks, Relatório Técnico Report 92/491/29, Department of Computer Science, University of Calgary. Web: http://www.cpsc.ucalgary.ca/grouplab/papers/index.html (Abril de 2001).

SCHROEDER, W., MARTIN, K. \& LORENSEN, B. (1998). The Visualization Toolkit: an object-oriented approach to 3D graphics, 2 edn, Prentice-Hall, New Jersey.

SHNEIDERMAN, B. (1992). Tree visualization with Tree-Maps: 2D space-filling approach, ACM Transactions on Graphics 11(1): 92-99.

SHNEIDERMAN, B. (1994). Dynamic queries for visual information seeking, IEEE Software 11(6): 70-77.

SMITH, J. (2001). Floppy's VRML guide. Web: http://www.vapourtech.com/vrmlguide/ (Abril de 2001).

SOARES, I. P. (2000). Visualização volumétrica em odontologia, Dissertação (Mestrado), Universidade de São Paulo, São Carlos. 132 p.

STAPLES, L. (1993). Representation on virtual space: Visual convention in the graphical user interface, Proceedings of ACM CHI'93 Conference in Human Factors in Computer Systems, Amsterdam, The Netherlands, pp. 348-355.

VENOLIA, D. (1993). Facile 3D direct manipulation, Proceedings of ACM INTERCHI'93 Conference in Human Factors in Computer Systems, Amsterdam, The Netherlands, pp. 31-36.

WARE, C. (1999). Information visualization - perception for design, Academic Press, São Francisco.

WARE, C. \& JESSOME, D. R. (1988). Using the bat: A six-dimensional mouse for object placement, IEEE Computer Graphics \& Applications 8(6): 65-70.

WARE, C. \& OSBORN, S. (1990). Exploration and virtual camera control in virtual three dimensional environments, Computer Graphics 24(4): 175-183.

WONG, P. C. \& BERGERON, R. D. (1996). Multiresolution multidimensional wavelet brushing, Proceedings of Visualization'96, San Francisco, Ca USA, pp. 171-178. Web:

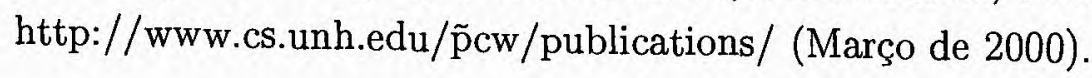


WOAG,P. P. "BERGERON, R. D. (1997). Brushing techniques for exploring volume datasets, Proceedings of

ZUFFO, J. A., SOARES, L. P., ZUFFO, M. K. \& LOPES, R. D. (2001). Caverna Digital Sistema de multiprojeção estereoscópico baseado em aglomerados de PCs para aplicações imersivas em realidade virtual, Proceedings of Symposium on virtual reality, Florianópolis, SC. 